\title{
Mechanistic Insight Into High-Spin Iron(I)-Catalyzed Butadiene Dimerization
}

Heejun Lee ${ }^{\dagger, \ddagger}$, Michael G. Campbell ${ }^{\dagger}$, Raúl Hernández Sánchez ${ }^{\dagger}$, Jonas Börgel ${ }^{\ddagger}$, Jean Raynaud $^{\dagger}$, Sarah E. Parker ${ }^{\dagger}$, and Tobias Ritter ${ }^{\star,+, \neq}$

\footnotetext{
${ }^{\dagger}$ Department of Chemistry and Chemical Biology, Harvard University Cambridge, Massachusetts 02138

${ }^{\ddagger}$ Max-Planck-Institut für Kohlenforschung, Kaiser-Wilhelm-Platz 1, 45470 Mülheim an der Ruhr, Germany `E-mail: ritter@mpi-muelheim.mpg.de
} 


\section{TABLE OF CONTENTS}

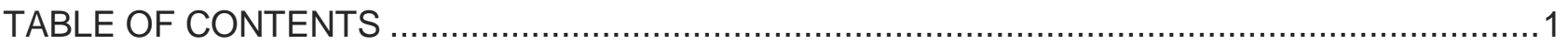

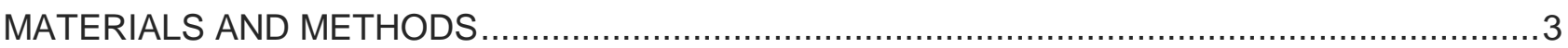

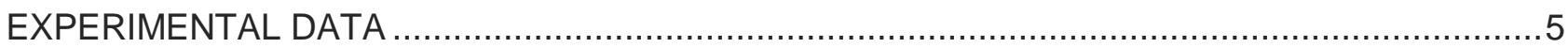

Experimental Procedures and Compound Characterization ............................................................. 5

Bis(2,6-dimethylaniline)-butane-2,3-diimine (S1) .................................................................

Bis(2,6-dimethylaniline)-butane-2,3-diimine iron(II) chloride (1) ..................................................

$\operatorname{Bis}\left(2,6\right.$-dimethylaniline)-butane-2,3-diimine iron(I) $\left(\eta^{2}: \eta^{2}-1,5-C O D\right)(2)$...................................... 6

[(Bis(2,6-dimethylaniline)-butane-2,3-diimine) $\left(\eta^{6}\right.$-toluene $\left.)\right]$ iron (3) ............................................ 7

Di[bis(2,6-dimethylaniline)-butane-2,3-diimine iron(I)] (4) .................................................... 8

Di[bis(2,6-dimethylaniline)-butane-2,3-diimine] iron (5) ..........................................................

Experimental Procedures for Butadiene Dimerization ..................................................................... 10

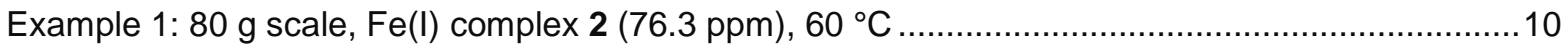

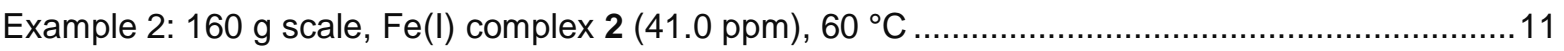

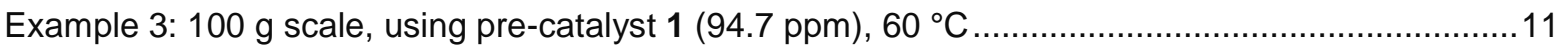

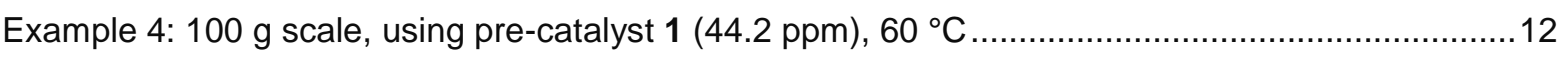

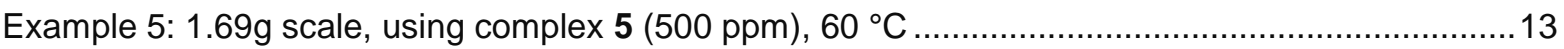

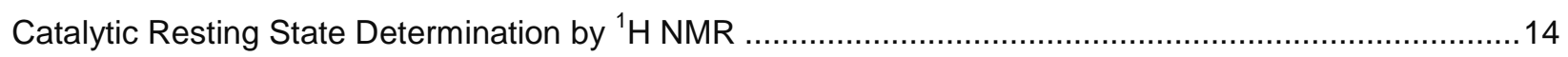

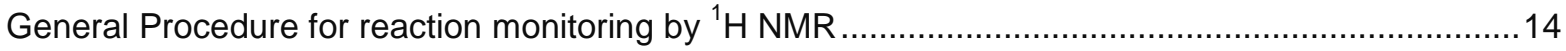

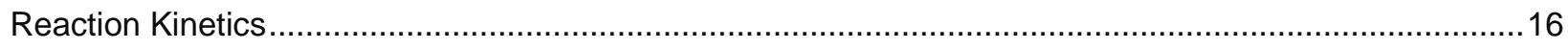

General Procedure for Kinetics Measurements and Dilatometry ............................................... 16

Kinetic Profile of Iron-Catalyzed Butadiene Dimerization Reaction ................................................17

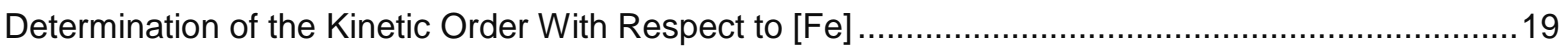

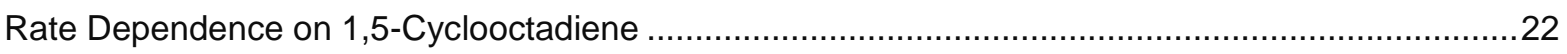

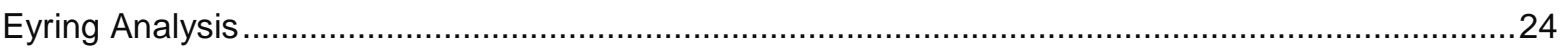

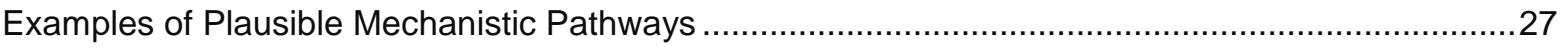

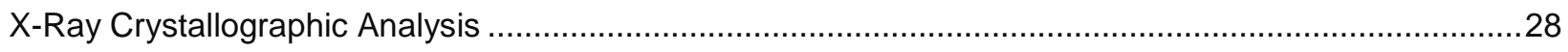

General Procedure for X-ray Data Collection and Refinement....................................................28

Bis(2,6-dimethylaniline)-butane-2,3-diimine iron(II) chloride (1) (CCDC 972790) .............................28

Bis(2,6-dimethylaniline)-butane-2,3-diimine iron(I) $\left(\eta^{2}: \eta^{2}-1,5-C O D\right)$ (2) (CCDC 1414006) ...............30

Isomer of bis(2,6-dimethylaniline)-butane-2,3-diimine iron(I) ( $\left.\eta^{2}: \eta^{2}-1,5-C O D\right)$ (2) (CCDC 1436928) 31

[(Bis(2,6-dimethylaniline)-butane-2,3-diimine) $\left(\eta^{6}\right.$-toluene)] iron (3) (CCDC 1414019) ......................33

Di[bis(2,6-dimethylaniline)-butane-2,3-diimine iron(I)] (4) (CCDC 899256) ..................................... 35 
Di[bis(2,6-dimethylaniline)-butane-2,3-diimine] iron (5) (CCDC 894093) .......................................36

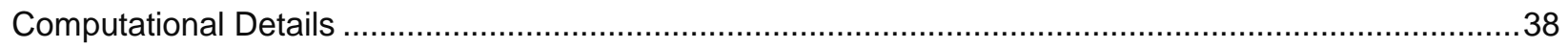

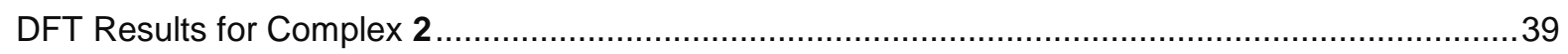

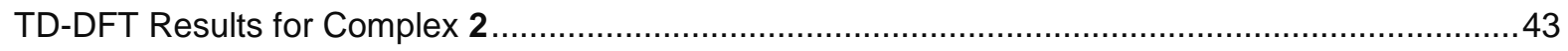

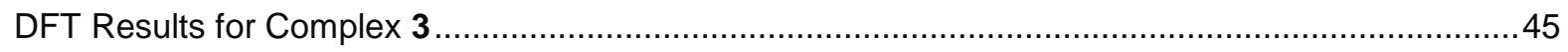

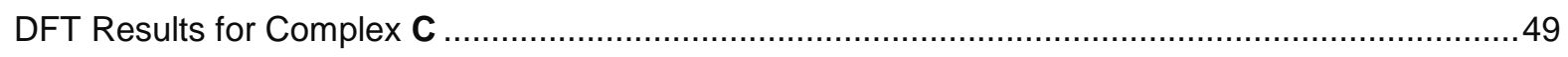

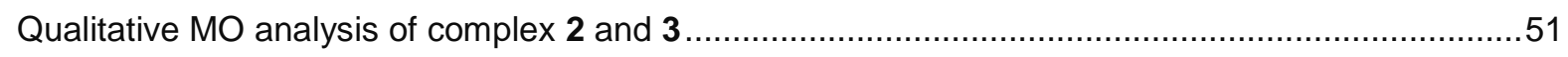

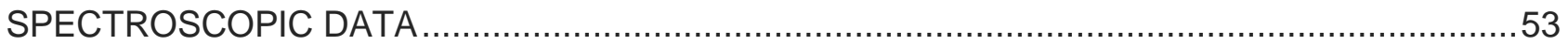

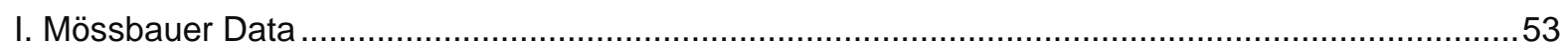

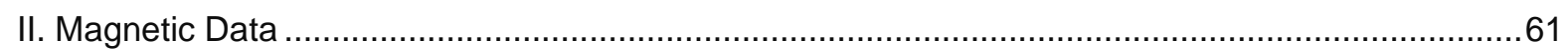

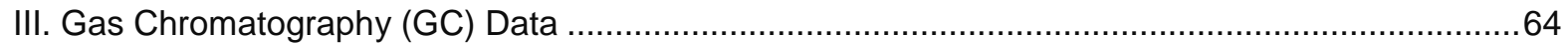

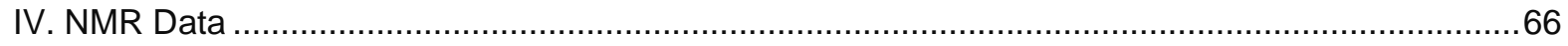




\section{MATERIALS AND METHODS}

All manipulations were carried out under an inert atmosphere using a nitrogen-filled glovebox or standard Schlenk techniques unless otherwise stated. ${ }^{1}$ All glassware was stored in an oven or was flame-dried prior to use. Anhydrous solvents were obtained either by filtration through drying columns ${ }^{2}\left(\mathrm{CH}_{2} \mathrm{Cl}_{2}\right.$, pentane) on an $\mathrm{mBraun}$ system or by distillation over sodium/benzophenone (benzene, $\mathrm{Et}_{2} \mathrm{O}$, hexane). Yields refer to isolated and spectroscopically pure compounds. Elemental analysis was performed by Mikroanalytisches Laboratorium Kolbe.

Reagents: All reagents were purchased from commercial suppliers (Aldrich, Strem, Alfa Aesar or TCI) and used as received unless otherwise noted. 2,6-dimethylaniline (Aldrich, 98\%) was distilled prior to use. Iron(II) chloride (99.99\% Aldrich) was used as received. Butadiene (99\%, Aldrich) was distilled over ( $n$ $\mathrm{Bu})_{2} \mathrm{Mg}$ and degassed by the freeze-pump-thaw method prior to use. 1,5-cyclooctadiene (COD) was purified by vacuum distillation and degassed by the freeze-pump-thaw method prior to use.

NMR Spectroscopy: ${ }^{1} \mathrm{H}$ NMR spectra were recorded on a Varian Unity/Inova 500 spectrometer operating at $500 \mathrm{MHz}$ (acquisition parameters: at=2.044, d1=1.0, pw=4.65). ${ }^{13} \mathrm{C}$ NMR spectra were recorded on a Varian Unity/Inova 500 spectrometer operating at $125 \mathrm{MHz}$ (acquisition parameters: at=1.048, d1=0.2 , $\mathrm{pw}=5.7$ ). For paramagnetic complexes, the spectral width (sw) was expanded in order to observe all signals; the full spectral window used for each complex can be seen in the NMR Data section. For the determination of selectivity in dimerization reactions, 10 seconds and 5 seconds were used as relaxation times (d1) for ${ }^{1} \mathrm{H}$ NMR and ${ }^{13} \mathrm{C}$ NMR, respectively. Prior to use, $\mathrm{CDCl}_{3}$ was passed through a plug of basic alumina and $\mathrm{CD}_{2} \mathrm{Cl}_{2}$ was degassed by the freeze-pump-thaw method ${ }^{3}$ and dried over $4 \AA$ molecular sieves. Chemical shifts are reported in ppm with the solvent resonance as the internal standard $\left({ }^{1} \mathrm{H}: \mathrm{CDCl}_{3}, \delta 7.26 ; \mathrm{CD}_{2} \mathrm{Cl}_{2}, \delta\right.$ 5.32; $\mathrm{C}_{6} \mathrm{D}_{6}, \delta 7.16 ; \mathrm{C}_{6} \mathrm{D}_{12}, \delta$ 1.38), ( ${ }^{13} \mathrm{C}: \mathrm{CDCl}_{3}, \delta 77.16 ; \mathrm{CD}_{2} \mathrm{Cl}_{2}, \delta 53.84 ; \mathrm{C}_{6} \mathrm{D}_{6}, \delta$ 128.06). ${ }^{4}$ Data are reported as follows: chemical shift, multiplicity $(s=$ singlet, $d=$ doublet, $t=$ triplet, $q=$ quartet, $m=$ multiplet and $b r=$ broad), coupling constant in $\mathrm{Hz}$, and integration. For broad signals, the ${ }^{1} \mathrm{H} N \mathrm{NR}$ and ${ }^{13} \mathrm{C}$ NMR data are reported with the chemical shift followed by the peak width at half-height in $\mathrm{Hz}$. Solution magnetic susceptibility measurements for iron complexes were obtained using the Evans method ${ }^{5}$ and are reported as

\footnotetext{
${ }^{1}$ Shriver, D. F.; Drezdon, M. A. Inert-Atmosphere Glove Boxes. The Manipulation of Air-Sensitive Compounds, 2nd ed.; John Wiley \& Sons: New York, 1986; pp. 45-67.

2 Pangborn, A. B.; Giardello, M. A.; Grubbs, R. H.; Rosen, R. K.; Timmers, F. J. Organometallics 1996, 15, $1518-1520$.

${ }^{3}$ Armarego, W. L. F.; Chai, C. L. L. Purification of Laboratory Chemicals, 5th ed.; Butterworth Henemann: Amsterdam, 2003; pp. 29-30.

${ }^{4}$ Fulmer, G. R.; Miller, A. J. M.; Sherden, N. H.; Gottlieb, H. E.; Nudelman, A.; Stoltz, B. M.; Bercaw, J. E.; Goldberg, K. I. Organometallics 2010, 29, 2176-2179.

5 (a) Evans, D. F. J. Chem. Soc. 1959, 2003-2005. (b) Sur, S. K. J. Magn. Resonance 1989, 82, 169-173.
} 
follows: (field strength, solvent, temperature): $\mu_{\text {eff }}$ (concentration in $\mathrm{mg} / \mathrm{mL}$ ).

Mass Spectrometry and Gas Chromatography: Mass spectra were obtained at the Harvard University Mass Spectrometry Facilities. High resolution mass spectra were obtained on an Agilent 6210 Time-of-Flight LC/MS or an Agilent 1100 ESI attached to a Bruker Daltonics MicrOTOF-Q II. Gas chromatography was performed on a Shimadzu GC-2014 equipped with an AOC-20i auto-injector and a set of hydrophobic columns (Restec Rtx-200MS, Crossbond trifluoropropylmethyl polysiloxane, 30 meter $0.25 \mathrm{mmID}, 1 \mu \mathrm{m} \mathrm{df}$ ), using flame ionization detection (FID). Temperature ramps between $50^{\circ} \mathrm{C}$ and $250^{\circ} \mathrm{C}$ were used.

Zero-field ${ }^{57}$ Fe Mössbauer Spectroscopy: Spectra were collected at $90 \mathrm{~K}$ on samples immobilized in paratone oil with a constant acceleration spectrometer (SEE Co., Minneapolis, MN). All samples were prepared in a dry box under $\mathrm{N}_{2}$ atmosphere. Isomer shifts are given relative to $\alpha-\mathrm{Fe}$ metal at $298 \mathrm{~K}$. Data were analyzed using an in-house package written by E. R. King in Igor Pro (Wavemetrics). y refers to the fullwidth-at-half-maximum.

Magnetic data: Data were collected using a Quantum Design MPMS-XL Evercool SQUID Magnetometer. Samples were immobilized within a gelatin capsule size \#4 by adding melted eicosane. Eicosane was used to immobilize the sample and to provide a layer against oxidation in air during the few seconds it takes to mount into the magnetometer. It was melted right above the melting point $\left(\mathrm{mp}=38^{\circ} \mathrm{C}\right)$ and added to the sample at room temperature. The gelatin capsule was then inserted into a plastic straw. Samples were prepared under a dinitrogen atmosphere. Magnetization data at $100 \mathrm{~K}$ from 0 to $7 \mathrm{~T}$ was used as a ferromagnetic-free, purity test. Direct current (dc) magnetic susceptibility measurements were collected in the temperature range 1.8$300 \mathrm{~K}$ under an applied field of $0.5 \mathrm{~T}$. Variable-field, variable-temperature magnetization data were acquired on heating at 1.8-10 $\mathrm{K}$ at increasing fields of 1, 2, 3, 4, 5, 6, and $7 \mathrm{~T}$. Magnetic susceptibility data was corrected for the diamagnetism of the sample, estimated using Pascal's constants ${ }^{6}$, in addition to the contribution from the sample holder and eicosane.

Acknowledgement: This research was supported in part by an award from the Department of Energy (DOE) Office of Science Graduate Fellowship Program (DOE SCGF). The DOE SCGF Program was made possible in part by the American Recovery and Reinvestment Act of 2009. The DOE SCGF program is administered by the Oak Ridge Institute for Science and Education for the DOE. ORISE is managed by Oak Ridge Associated Universities (ORAU) under DOE contract number DE-AC05-06OR23100.

${ }^{6}$ Bain, G. A.; Berry, J. F. J. Chem. Educ., 2008, 85, 532. 


\section{EXPERIMENTAL DATA}

\section{Experimental Procedures and Compound Characterization}

Bis(2,6-dimethylaniline)-butane-2,3-diimine (S1)

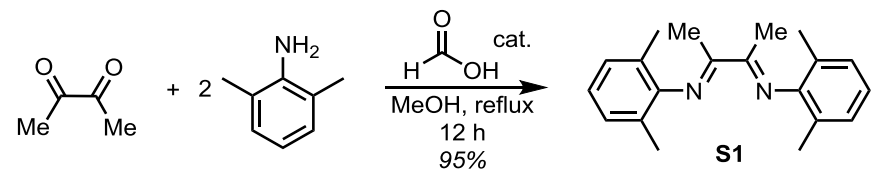

Under air, to a solution of 2,6-dimethylaniline $(10.0 \mathrm{~g}, 82.5 \mathrm{mmol}, 2.03$ equiv) in $\mathrm{MeOH}(100 \mathrm{~mL})$ was added butanedione ( $3.50 \mathrm{~g}, 40.7 \mathrm{mmol}, 1.00$ equiv). Formic acid (183 mg, $150 \mu \mathrm{L}, 4.01 \mathrm{mmol}, 0.100$ equiv) was then added as a catalyst. After heating at reflux for 12 hours, the reaction mixture was cooled to room temperature and concentrated under reduced pressure. The residue was recrystallized from $\mathrm{EtOH}(\sim 100 \mathrm{~mL})$, washed with cold $\left(0^{\circ} \mathrm{C}\right) \mathrm{MeOH}(\sim 15 \mathrm{~mL})$, and then dried in vacuo to afford the title compound as a crystalline yellow solid (11.3 $\mathrm{g}, 95 \%$ yield).

\section{NMR Spectroscopy:}

${ }^{1} \mathrm{H}$ NMR (500 MHz, $\left.\mathrm{CDCl}_{3}, 23^{\circ} \mathrm{C}, \delta\right): 7.11(\mathrm{~d}, \mathrm{~J}=7.2 \mathrm{~Hz}, 4 \mathrm{H}), 6.98(\mathrm{t}, \mathrm{J}=7.2 \mathrm{~Hz}, 2 \mathrm{H}), 2.08(\mathrm{~s}, 6 \mathrm{H}), 2.07$ $(\mathrm{s}, 12 \mathrm{H})$.

${ }^{13} \mathrm{C}$ NMR $\left(125 \mathrm{MHz}, \mathrm{CDCl}_{3}, 23^{\circ} \mathrm{C}, \delta\right): 168.2,148.4,128.0,124.8,123.4,17.9,15.9$.

HRMS-FIA(m/z) Calcd for $\mathrm{C}_{20} \mathrm{H}_{24} \mathrm{~N}_{2} \mathrm{Na}[\mathrm{M}+\mathrm{Na}]^{+}$, 315.1832. Found, 315.1839.

Bis(2,6-dimethylaniline)-butane-2,3-diimine iron(II) chloride (1) ${ }^{7}$

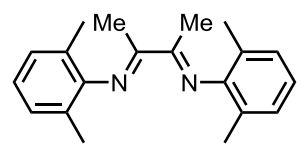

S1

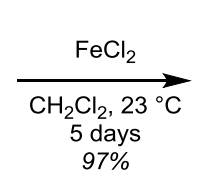

$97 \%$

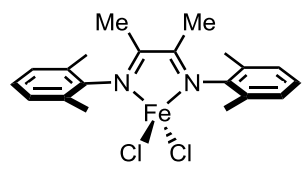

1

To a solution of bis(2,6-dimethylaniline)-butane-2,3-diimine ( $\mathbf{S 1}, 1.00 \mathrm{~g}, 3.42 \mathrm{mmol}, 1.00$ equiv) in $\mathrm{CH}_{2} \mathrm{Cl}_{2}(10$ $\mathrm{mL}$ ) was added $\mathrm{FeCl}_{2}$ (434 mg, $3.42 \mathrm{mmol}, 1.00$ equiv) in a $20 \mathrm{~mL}$ scintillation vial. The reaction mixture was stirred for 5 days at $23^{\circ} \mathrm{C}$, affording a dark red suspension that was then concentrated under reduced pressure. The residue was triturated with $\mathrm{Et}_{2} \mathrm{O}(2 \times 10 \mathrm{~mL})$ and dried in vacuo to give the title compound as a red solid ( $1.39 \mathrm{~g}, 97 \%$ yield).

$X$-ray quality single crystals of 1 were obtained as follows: $2 \mathrm{~mL}$ of a saturated solution of 1 in $\mathrm{CH}_{2} \mathrm{Cl}_{2}$ was prepared at $23^{\circ} \mathrm{C}$, and was then held at $-35^{\circ} \mathrm{C}$ for several days until crystals were observed. X-ray analysis

\footnotetext{
${ }^{7}$ Synthesis of 1 has been previously described: tom Dieck, H.; Dietrich, J. Angew. Chem. Int. Ed. Eng. 1985, $24,781$.
} 
of 1 is presented in the X-ray Data section.

Note: Complex 1 made from high-purity $\mathrm{FeCl}_{2}$ (Aldrich, anhydrous, beads, 10 mesh, 99.99\%) gives optimal results for the following reduction steps.

Solution magnetic susceptibility $\left(500 \mathrm{MHz}, \mathrm{CD}_{2} \mathrm{Cl}_{2}, 23^{\circ} \mathrm{C}\right): \mu_{\text {eff }}=5.5 \mu_{\mathrm{B}}(7.5 \mathrm{mg} / \mathrm{mL})$.

\section{NMR Spectroscopy:}

${ }^{1} \mathrm{H}$ NMR $\left(500 \mathrm{MHz}, \mathrm{CD}_{2} \mathrm{Cl}_{2}, 23^{\circ} \mathrm{C}, \delta\right): 108.42\left(\Delta \mathrm{v}_{1 / 2}=250 \mathrm{~Hz}\right), 12.98\left(\Delta \mathrm{v}_{1 / 2}=400 \mathrm{~Hz}\right), 7.31,3.74\left(\Delta \mathrm{v}_{1 / 2}=\right.$ $70 \mathrm{~Hz}), 1.25,0.86,-18.68\left(\Delta \mathrm{v}_{1 / 2}=50 \mathrm{~Hz}\right)$.

${ }^{13} \mathrm{C}$ NMR $\left(125 \mathrm{MHz}, \mathrm{CD}_{2} \mathrm{Cl}_{2}, 23 \stackrel{\circ}{\circ} \mathrm{C}, \delta\right): 186.8,78.0,21.9$.

Anal calcd for $\mathrm{C}_{14} \mathrm{H}_{22} \mathrm{Cl}_{2} \mathrm{FeN}_{2}$ : C, 57.31; $\mathrm{H}, 5.77 ; \mathrm{N}, 6.68$. Found: $\mathrm{C}, 56.96 ; \mathrm{H}, 5.77 ; \mathrm{N}: 6.68$.

Mössbauer analysis of $\mathbf{1}$ is presented in the Spectroscopic Data section.

Bis(2,6-dimethylaniline)-butane-2,3-diimine iron(I) $\left(\eta^{2}: \eta^{2}-1,5-C O D\right)(2)$

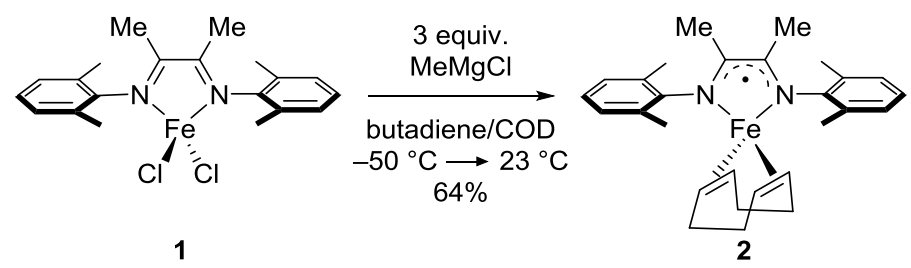

A $20 \mathrm{~mL}$ vial containing bis(2,6-dimethylaniline)-butane-2,3-diimine iron(II) chloride (1), (155. mg, $0.370 \mathrm{mmol}$, 1.00 equiv) was cooled to $-50^{\circ} \mathrm{C}$ in the cold-well of the glovebox. To the cooled vial was added COD $(1 \mathrm{~mL})$ and butadiene $(3 \mathrm{~mL})$ at $-50^{\circ} \mathrm{C}$. The mixture was stirred for 10 minutes, and to the resulting suspension was added dropwise a solution of $\mathrm{MeMgCl}$ in THF (360 $\mu \mathrm{L}, 2.90 \mathrm{M}, 2.82$ equiv) at $-50{ }^{\circ} \mathrm{C}$, and a brown solution was observed. The vial was sealed with a Teflon-lined cap, and the reaction mixture was stirred for $30 \mathrm{~min}$ at $-50^{\circ} \mathrm{C}$, slowly warmed to $23^{\circ} \mathrm{C}$ over 30 minutes then the vial was opened and butadiene evaporation was observed. The volatiles were removed under reduced pressure. To the residue was then added pentane ( 6 $\mathrm{mL}$ ), and a Teflon cap was closed. Centrifugation followed by decantation was performed to remove the magnesium salts, and then the supernatant was evaporated under reduced pressure. The residue was dissolved in pentane $(6 \mathrm{~mL})$, a vial was closed with a Teflon cap, centrifugation of a vial was performed again to remove the remaining magnesium salts, and the supernatant was again decanted and evaporated under reduced pressure. The purification cycle of dissolving a residue with pentane followed by centrifugation of a vial and evaporation of the supernatant was repeated once more. The final residue was further dried under high vacuum to afford the title compound as a dark brown crystalline solid. The solids were dissolved in pentane $(3 \mathrm{~mL})$ and allowed to recrystallize for 3 days at $-35^{\circ} \mathrm{C}$, affording the title compound as dark brown solid (169 mg, 64\% yield). Crystals grown in this manner were suitable for X-ray diffraction; X-ray analysis of 2 is presented in the X-ray Data section.

Note 1: While only 2 equiv $\mathrm{MeMgCl}$ are necessary to perform the reduction of $\mathbf{1}$, we found the use of a slight 
excess of $\mathrm{MeMgCl}$ to be optimal with respect to isolation and purification of 2 . We have observed that the presence of even trace amounts of side products resulting from incomplete reduction of $\mathbf{1}$ generally results in decomposition of $\mathbf{2}$ upon attempted purification, while $\mathbf{2}$ is stable to the presence of excess $\mathrm{MeMgCl}$.

Note 2: Recrystallization of the complex 2 result in two slightly distinct isomers in which the COD ligand bound to 2 subtly differ. See X-ray data section for the further information.

Note 3: Reduction of 1 using $\mathrm{Na}(\mathrm{Hg})$ in 1,5-COD gives significant amount of the bis( $\alpha$-diimine)iron complex 5

\section{NMR Spectroscopy:}

${ }^{1} \mathrm{H}$ NMR (500 MHz, $\left.\mathrm{C}_{6} \mathrm{D}_{6}, 23^{\circ} \mathrm{C}, \delta\right): 6.08-4.53$ (br m), 3.01-0.97 (m), 0.04 (s), -6.37 (s), -59.43 (br s, $\left.\Delta \mathrm{v}_{1 / 2}=332 \mathrm{~Hz}\right)$.

${ }^{13} \mathrm{C}$ NMR $\left(125 \mathrm{MHz}, \mathrm{C}_{6} \mathrm{D}_{6}, 23{ }^{\circ} \mathrm{C}, \delta\right): 393.9,351.6,260.7,159.6,141.7,18.1,-4.9$.

Mössbauer, and magnetic data analysis of 2 are presented in the Spectroscopic Data section.

[(Bis(2,6-dimethylaniline)-butane-2,3-diimine $)\left(\eta^{6}\right.$-toluene $\left.)\right]$ iron $(3)^{8}$

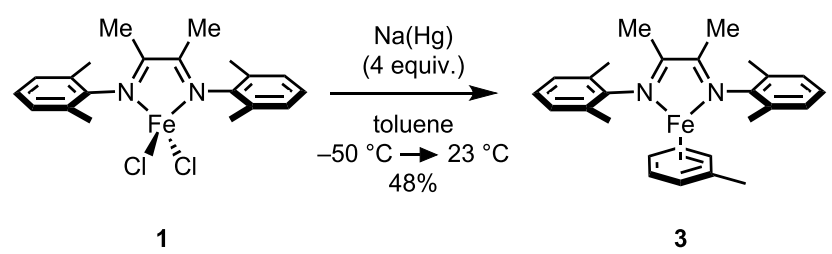

To a $20 \mathrm{~mL}$ vial containing mercury $(6.70 \mathrm{~g}, 33.4 \mathrm{mmol}, 90.0$ equiv) in $10 \mathrm{~mL}$ of toluene was added $\mathrm{Na}$ (34.1 $\mathrm{mg}, 1.48 \mathrm{mmol}, 4.00$ equiv) and the mixture stirred for $1 \mathrm{~h}$. The resulting amalgam in toluene was cooled to $50{ }^{\circ} \mathrm{C}$ in the cold-well of the glovebox and then bis(2,6-dimethylaniline)-butane-2,3-diimine iron(II) chloride (1) (155 mg, $0.370 \mathrm{mmol}, 1.00$ equiv) was added. The mixture was stirred at $-50{ }^{\circ} \mathrm{C}$ for 30 minutes, then was slowly warmed up to $23^{\circ} \mathrm{C}$ over 4 hours. The reaction mixture was stirred for 2 days at $23^{\circ} \mathrm{C}$, then it was filtered through Celite and the filtrate was evaporated under reduced pressure. The resulting solid was dissolved in pentane $(4 \mathrm{~mL})$ and allowed to recrystallize for 3 days at $-35^{\circ} \mathrm{C}$, affording the title compound as bright red solid (121 mg, 48\% yield). Crystals grown in this manner were suitable for X-ray diffraction; X-ray analysis of $\mathbf{3}$ is presented in the $\mathrm{X}$-ray Data section.

\section{NMR Spectroscopy:}

${ }^{1} \mathrm{H}$ NMR $\left(500 \mathrm{MHz}, \mathrm{C}_{6} \mathrm{D}_{12}, 23^{\circ} \mathrm{C}, \delta\right): 7.12(\mathrm{~d}, J=7.6 \mathrm{~Hz}, 4 \mathrm{H}), 7.05$ (t, $\left.J=7.6 \mathrm{~Hz}, 4 \mathrm{H}\right), 5.22(\mathrm{t}, J=5.4 \mathrm{~Hz}$, $1 \mathrm{H}), 4.42-4.38(\mathrm{~m}, 4 \mathrm{H}), 2.22(\mathrm{~s}, 12 \mathrm{H}), 2.01(\mathrm{~s}, 3 \mathrm{H}), 1.01(\mathrm{~s}, 6 \mathrm{H})$.

\footnotetext{
${ }^{8}$ Synthesis of complex 3 is based on a reported procedure for the synthesis of structurally similar Fe complex. See: Bart, S. C.; Hawrelak, E. J.; Lobkovsky, E.; Chirik, P. J. Organometallics 2005, 24, 5518.
} 
${ }^{13} \mathrm{C}$ NMR $\left(125 \mathrm{MHz}, \mathrm{C}_{6} \mathrm{D}_{6}, 23{ }^{\circ} \mathrm{C}, \delta\right): 157.2,141.6,131.0,128.6,124.6,94.5,82.0,81.4,80.8,20.2,18.3$, 15.7.

Note: When the reaction mixture was warmed up faster, formation of di[bis(2,6-dimethylaniline)-butane-2,3diimine] iron (5) was observed as a byproduct.

Mössbauer analysis of $\mathbf{3}$ is presented in the Spectroscopic Data section as a mixture with $\mathbf{5}$.

Di[bis(2,6-dimethylaniline)-butane-2,3-diimine iron(I)] (4)
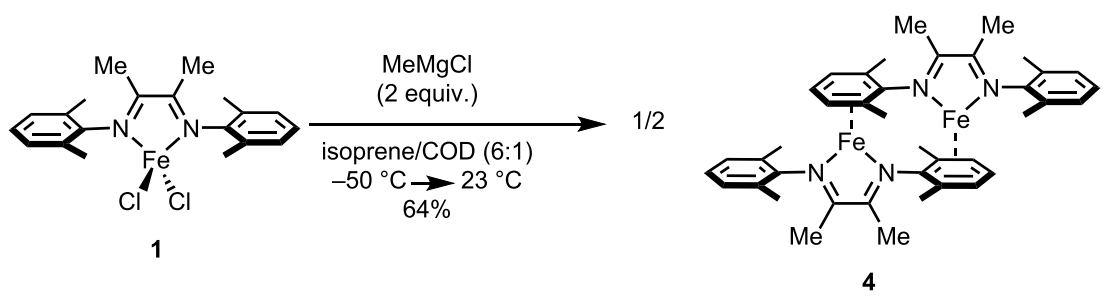

A $20 \mathrm{~mL}$ vial containing bis(2,6-dimethylaniline)-butane-2,3-diimine iron(II) chloride (1), (155 mg, $0.370 \mathrm{mmol}$, 1.00 equiv) was cooled to $-50^{\circ} \mathrm{C}$ in the cold-well of the glovebox. To the cooled vial was added $\operatorname{COD}(1 \mathrm{~mL})$ and isoprene $(6 \mathrm{~mL})$ at $-50^{\circ} \mathrm{C}$. The mixture was stirred for 10 minutes, and to the resulting suspension was added a solution of $\mathrm{MeMgCl}$ in $\operatorname{THF}\left(255 \mu \mathrm{L}, 2.90 \mathrm{M}, 2.00\right.$ equiv) at $-50^{\circ} \mathrm{C}$. The vial was sealed with a Teflon-lined cap, and the reaction mixture was stirred for $30 \mathrm{~min}$ at $-50^{\circ} \mathrm{C}$, warmed to $23^{\circ} \mathrm{C}$ over 4 hours, and stirred for 2 days. To the reaction mixture was then added hexanes $(6 \mathrm{~mL})$, and the vial was capped with a Teflon cap. Centrifugation of a vial followed by decantation of the supernatant removed magnesium salts. The supernatant was evaporated under reduced pressure. The residue was dissolved in hexanes $(6 \mathrm{~mL})$, centrifugation of a vial followed by decantation was performed again to remove the remaining magnesium salts, and the supernatant was evaporated under reduced pressure. The purification cycle of dissolving a residue with hexane followed by centrifugation of a vial and evaporation of the supernatant was repeated once more. The final residue was further dried under high vacuum to afford the title compound as a red/black crystalline solid. The solids were dissolved in hexanes $(3 \mathrm{~mL})$ and allowed to recrystallize for 7 days at $23^{\circ} \mathrm{C}$, affording the title compound as dark red/black crystals $(50.0 \mathrm{mg}, 19 \%$ yield). Crystals grown in this manner were suitable for X-ray diffraction; X-ray analysis of $\mathbf{4}$ is presented in the X-ray Data section.

\section{NMR Spectroscopy:}

${ }^{1} \mathrm{H}$ NMR $\left(500 \mathrm{MHz}, \mathrm{C}_{6} \mathrm{D}_{6}, 23^{\circ} \mathrm{C}, \delta\right): 7.29-7.22(\mathrm{~m}), 5.48(\mathrm{~d}, J=6.5 \mathrm{~Hz}, 2 \mathrm{H}), 4.10(\mathrm{t}, J=6.5 \mathrm{~Hz}), 2.41$ (s, $12 \mathrm{H}), 2.37(\mathrm{~s}, 12 \mathrm{H}), 1.04(\mathrm{~s}, 6 \mathrm{H}), 0.70(\mathrm{~s}, 6 \mathrm{H})$

${ }^{13} \mathrm{C}$ NMR $\left(125 \mathrm{MHz}, \mathrm{C}_{6} \mathrm{D}_{6}, 23{ }^{\circ} \mathrm{C}, \delta\right): 158.2,142.8,142.1,130.9,124.7,118.5,86.4,82.9,80.3,18.6$, $18.5,15.8,15.6$; One peak was not observed due to the low solubility of the complex 4.

Note: NMR sample of $\mathbf{4}$ contains a minor organic impurity that was not fully removed from the recrystallization.Small amounts of the dimer 4 was also isolated from the conditions to make the Fe complex 2. However, reduction condition with isoprene described above gives the Fe dimer 4 more cleanly. Mössbauer analysis of $\mathbf{4}$ is presented in the Spectroscopic Data section. 
Di[bis(2,6-dimethylaniline)-butane-2,3-diimine] iron (5) ${ }^{9}$

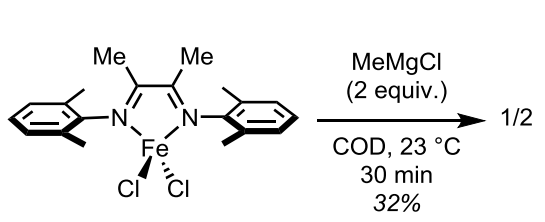

1

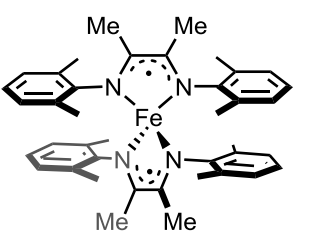

5

A dispersion of bis(2,6-dimethylaniline)-butane-2,3-diimine iron(II) chloride (1), (77.5 mg, $185 \mu \mathrm{mol}, 1.00$ equiv) in $\operatorname{COD}(3 \mathrm{~mL})$ was stirred overnight at $23^{\circ} \mathrm{C}$. To the resulting suspension was added a solution of $\mathrm{MeMgCl}$ in THF (128 $\mu \mathrm{L}, 2.89 \mathrm{M}, 2.00$ equiv) at $23^{\circ} \mathrm{C}$. The reaction mixture was stirred for $30 \mathrm{~min}$ at $23^{\circ} \mathrm{C}$, a vial was closed with a Teflon cap. Centrifugation of a vial followed by decantation of a supernatant removed the magnesium salts, and then the supernatant was decanted and evaporated under reduced pressure. The residue was dissolved in pentane $(6 \mathrm{~mL})$, a vial was closed with a Teflon cap. Centrifugation of a vial followed by decantation of a supernatant removed the remaining magnesium salts, and the supernatant was evaporated under reduced pressure. The purification cycle of dissolving a residue with pentane followed by centrifugation of a vial and evaporation of the supernatant was repeated once more. The final residue was dissolved in hexanes $(3 \mathrm{~mL})$ and allowed to recrystallize for 3 days at $-35^{\circ} \mathrm{C}$, affording the title compound as deep red crystals (38 mg, 32\% yield). Crystals grown in this manner were suitable for X-ray diffraction; X-ray analysis of $\mathbf{5}$ is presented in the X-ray Data section.

\section{NMR Spectroscopy:}

${ }^{1} \mathrm{H}$ NMR $\left(500 \mathrm{MHz}, \mathrm{C}_{6} \mathrm{D}_{6}, 23^{\circ} \mathrm{C}, \delta\right): 1.34\left(\Delta \mathrm{v}_{1 / 2}=160 \mathrm{~Hz}\right),-2.48\left(\Delta \mathrm{v}_{1 / 2}=50 \mathrm{~Hz}\right),-6.01\left(\Delta \mathrm{v}_{1 / 2}=120 \mathrm{~Hz}\right)$, $-12.04\left(\Delta \mathrm{v}_{1 / 2}=60 \mathrm{~Hz}\right)$.

${ }^{13} \mathrm{C}$ NMR $\left(125 \mathrm{MHz}, \mathrm{C}_{6} \mathrm{D}_{6}, 23{ }^{\circ} \mathrm{C}, \delta\right): 394.8,353.3,168.4,147.1,32.9,17.8,15.9$.

Mössbauer analysis of $\mathbf{5}$ is presented in the Spectroscopic Data section.

\footnotetext{
${ }^{9} \mathrm{~A}$ series of Fe complexes related to $\mathbf{5}$, and their reactivity toward butadiene dimerization, have previously been described. See: tom Dieck, H.; Bruder, H. J. Chem. Soc. Chem. Commun. 1977, 24.
} 


\section{Experimental Procedures for Butadiene Dimerization}

To demonstrate scalability of the reaction and to compare selectivities, we performed butadiene dimerization reaction on $\sim 100 \mathrm{~g}$ scale, using both precatalyst 1 and $\mathrm{Fe}(\mathrm{I})$ complex 2 at two different catalyst loadings each (Examples 1-4 ). All dimerization reactions were conducted using inert nitrogen atmosphere using a glovebox or conventional Schlenk techniques (for the $\geq 100 \mathrm{~g}$ scale reactions).CAUTION: Substantial pressure is generated upon heating butadiene (b.p. $-4^{\circ} \mathrm{C}$ at $1 \mathrm{~atm}$ ) in a sealed vessel. The use of a thick-walled, defect-free pressure Schlenk vessels or other appropriate pressure equipment is essential, and the use of protective equipment such as a blast shield is strongly recommended. Note that the complex 3 showed a lack of reactivity towards butadiene dimerization in the absence of the activating reagent which is consistent with the reported data ${ }^{10}$.

Example 1: $80 \mathrm{~g}$ scale, $\mathrm{Fe}(\mathrm{I})$ complex $2(76.3 \mathrm{ppm}), 60^{\circ} \mathrm{C}$

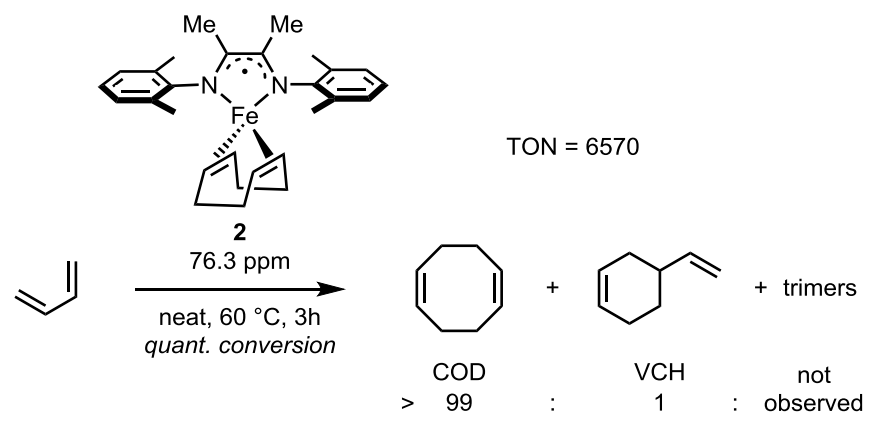

To a $350 \mathrm{~mL}$ thick-walled pressure Schlenk tube was added Fe(I) complex 2 (55.4 mg, $121 \mu \mathrm{mol}, 0.00763$ mol\%), and the vessel was then cooled to $-50^{\circ} \mathrm{C}$. To the cooled vessel was added $86.0 \mathrm{~g}$ of butadiene (134 $\mathrm{mL}, 1.59 \mathrm{~mol}, 1.00$ equiv), at $-50^{\circ} \mathrm{C}$. The Schlenk tube was sealed and was allowed to warm to ambient temperature, followed by heating in an oil bath at $60^{\circ} \mathrm{C}$.. After 3 hours (the contraction of the volume was then maximal), the reaction vessel was cooled to room temperature and then opened to air. No bubbling was observed, characteristic of a quantitative conversion of butadiene. An aliquot of the reaction mixture was removed and was analyzed by NMR spectroscopy, revealing $>99 \%$ purity for COD without purification. The reaction kinetics were followed by dilatometry by monitoring the volume of liquid in the pressure tube and discussed in the Reaction Kinetics section.

NMR Spectroscopy:

${ }^{1} \mathrm{H}$ NMR $\left(500 \mathrm{MHz}, \mathrm{CDCl}_{3}, 23{ }^{\circ} \mathrm{C}, \delta\right)$ : olefinic $\mathrm{H}$ atoms: 5.59 (s (br), 4H); aliphatic $\mathrm{H}$ atoms: $2.03(t, J=$ $2.4 \mathrm{~Hz}, 8 \mathrm{H})$.

${ }^{10}$ Floch, P. L.; Knoch, F.; Kremer, F.; Mathey, F;, Joachim Scholz, J.; Scholz, W;; Thiele, K-H.; Zenneck, U.; Eur. J. Inorg. Chem. 1998, 1998, 119. 
${ }^{13} \mathrm{C}$ NMR $\left(125 \mathrm{MHz}, \mathrm{CDCl}_{3}, 25{ }^{\circ} \mathrm{C}, \delta\right)$ : olefinic $128.8(\mathrm{~s})$, aliphatic $28.2(\mathrm{~s})$.

Selectivity cis, cis-1,5-cyclooctadiene / 4-vinylcyclohexene = >99:1 (no trimer was observed for this reaction). Note: The ${ }^{1} \mathrm{H}$ and ${ }^{13} \mathrm{C}$ NMR spectra obtained directly from this reaction, without additional purification, are given in the Spectroscopic Data section.

Example 2: $160 \mathrm{~g}$ scale, $\mathrm{Fe}(\mathrm{l})$ complex $2(41.0 \mathrm{ppm}), 60{ }^{\circ} \mathrm{C}$

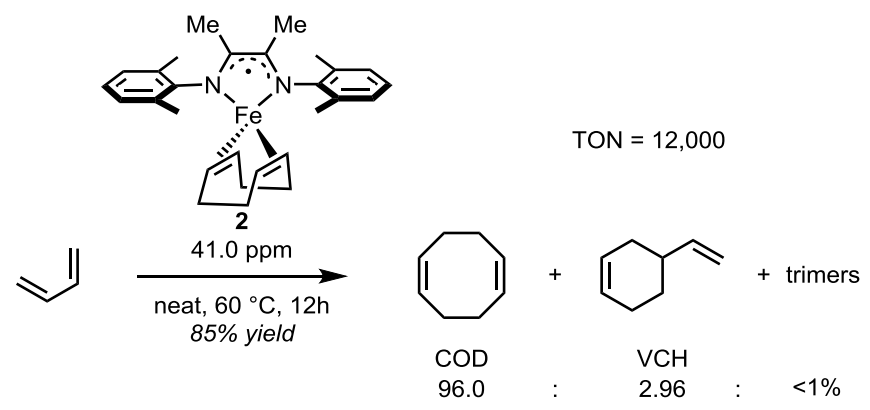

To a $500 \mathrm{~mL}$ thick-walled pressure Schlenk tube was added Fe(I) complex 2 (55.1 mg, $121 \mu \mathrm{mol}, 0.00408$ mol\%), and the vessel was then cooled to $-50^{\circ} \mathrm{C}$. To the cooled vessel was added $160 \mathrm{~g}$ of butadiene (250 $\mathrm{mL}, 2.96 \mathrm{~mol}, 1.00$ equiv), at $-50^{\circ} \mathrm{C}$. The Schlenk tube was sealed and was allowed to warm to ambient temperature, followed by heating in an oil bath at $60^{\circ} \mathrm{C}$. After 12 hours, the reaction vessel was cooled to room temperature and then opened to air. COD was then isolated by distillation under reduced pressure (b.p.: $60{ }^{\circ} \mathrm{C}, 50 \mathrm{mbar}$, yield = 85\%, $136 \mathrm{~g}$ ), and was analyzed for purity by NMR spectroscopy and GC/FID.

\section{NMR Spectroscopy:}

${ }^{1} \mathrm{H}$ NMR $\left(500 \mathrm{MHz}, \mathrm{CDCl}_{3}, 23{ }^{\circ} \mathrm{C}, \delta\right)$ : olefinic $\mathrm{H}$ atoms: 5.59 (s (br), 4H); aliphatic $\mathrm{H}$ atoms: $2.03(t, J=$ $2.4 \mathrm{~Hz}, 8 \mathrm{H})$.

${ }^{13} \mathrm{C}$ NMR $\left(125 \mathrm{MHz}, \mathrm{CDCl}_{3}, 25{ }^{\circ} \mathrm{C}, \delta\right)$ : olefinic $128.8(\mathrm{~s})$, aliphatic $28.2(\mathrm{~s})$.

Selectivity cis, cis-1,5-cyclooctadiene / 4-vinylcyclohexene = 97:3 ( $<1 \%$ trimer was observed for this reaction).

Example 3: $100 \mathrm{~g}$ scale, using pre-catalyst $1(94.7 \mathrm{ppm}), 60^{\circ} \mathrm{C}$
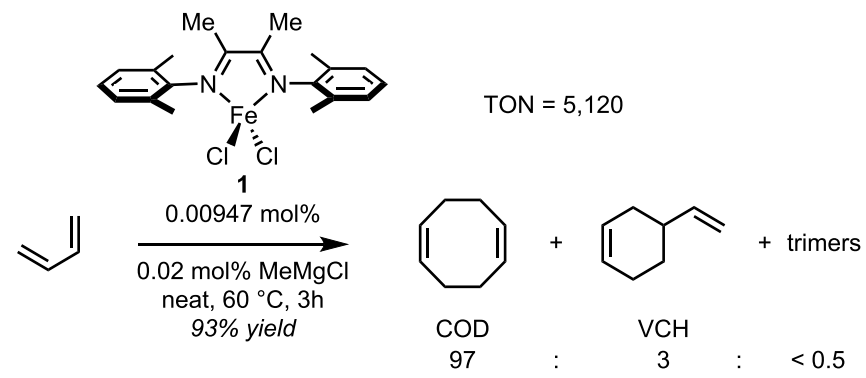

To a $20 \mathrm{~mL}$ scintillation vial was added (bis(2,6-dimethylaniline)-butane-2,3-diimine iron(II) chloride (1) (77.5 $\mathrm{mg}, 185 \mu \mathrm{mol}, 0.00947 \mathrm{~mol} \%$ ) and $1 \mathrm{~mL}$ of butadiene (640 mg, $11.8 \mathrm{mmol}, 0.605 \%$ of 1.00 equiv), at $-50^{\circ} \mathrm{C}$. 
The reaction mixture was stirred for $3 \mathrm{~min}$ and $128 \mu \mathrm{L}$ of a solution of $\mathrm{MeMgCl}(2.89 \mathrm{M}, 0.0190 \mathrm{~mol} \%)$ in THF was added at $-50{ }^{\circ} \mathrm{C}$. The scintillation vial was capped and the reaction mixture was stirred for $15 \mathrm{~min}$ at $23^{\circ} \mathrm{C}$. The reaction mixture was then added to a $350 \mathrm{~mL}$ pressure Schlenk tube containing $104 \mathrm{~g}$ of butadiene (164 mL, $1.94 \mathrm{~mol}, 99.4 \%$ of 1.00 equiv), at $-50{ }^{\circ} \mathrm{C}$. The Schlenk tube was then sealed, removed from the glovebox, and allowed to warm to ambient temperature ( $15 \mathrm{~min})$, before being placed in a thermostated oil bath at $60^{\circ} \mathrm{C}$. After 3 hours, the reaction vessel was cooled to room temperature and then opened to air. No bubbling was observed, characteristic of a quantitative conversion of butadiene. COD was then isolated by distillation under reduced pressure (b.p.: $60^{\circ} \mathrm{C}, 50 \mathrm{mbar}$, yield $=93 \%, 97.6 \mathrm{~g}$ ), and was analyzed for purity by NMR spectroscopy and GC/FID. The reaction kinetics were followed by dilatometry by monitoring the volume of liquid in the pressure tube and discussed in the Reaction Kinetics section.

\section{NMR Spectroscopy:}

${ }^{1} \mathrm{H}$ NMR $\left(500 \mathrm{MHz}, \mathrm{CDCl}_{3}, 23{ }^{\circ} \mathrm{C}, \delta\right)$ : olefinic $\mathrm{H}$ atoms: 5.59 (s (br), 4H); aliphatic $\mathrm{H}$ atoms: $2.03(t, J=$ $2.4 \mathrm{~Hz}, 8 \mathrm{H})$.

${ }^{13} \mathrm{C}$ NMR $\left(125 \mathrm{MHz}, \mathrm{CDCl}_{3}, 25{ }^{\circ} \mathrm{C}, \delta\right)$ : olefinic $128.8(\mathrm{~s})$, aliphatic $28.2(\mathrm{~s})$.

Selectivity cis,cis-1,5-cyclooctadiene / 4-vinylcyclohexene $=97: 2.7$ (0.3\% trimer was observed for this reaction).

Example 4: $100 \mathrm{~g}$ scale, using pre-catalyst $1(44.2 \mathrm{ppm}), 60^{\circ} \mathrm{C}$

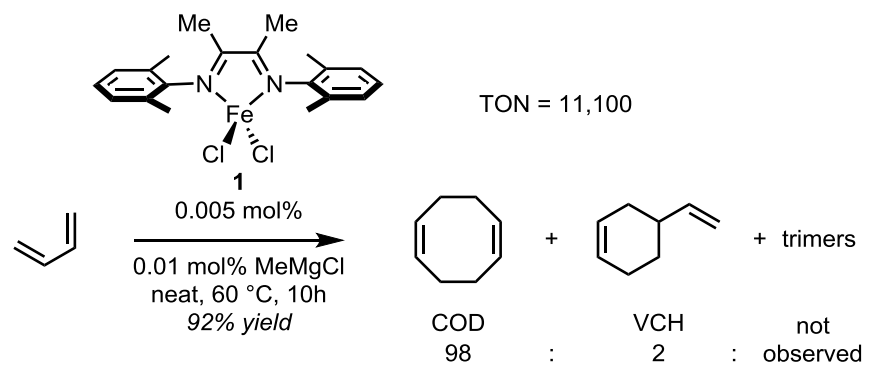

To a $20 \mathrm{~mL}$ scintillation vial was added (bis(2,6-dimethylaniline)-butane-2,3-diimine iron(II) chloride (1) (38.6 $\mathrm{mg}, 92.1 \mu \mathrm{mol}, 0.00442 \mathrm{~mol} \%$ ) and $1 \mathrm{~mL}$ of butadiene ( $640 \mathrm{mg}, 11.8 \mathrm{mmol}, 0.567 \%$ of 1.00 equiv), at $-50{ }^{\circ} \mathrm{C}$. The reaction mixture was stirred for $3 \mathrm{~min}$ and $64 \mu \mathrm{L}$ of a solution of $\mathrm{MeMgCl}(2.89 \mathrm{M}, 0.00884 \mathrm{~mol} \%)$ in THF was added at $-50{ }^{\circ} \mathrm{C}$. The scintillation vial was capped and the reaction mixture was stirred for $20 \mathrm{~min}$ at $23^{\circ} \mathrm{C}$. The reaction mixture was then added to a $350 \mathrm{~mL}$ pressure Schlenk tube containing $112 \mathrm{~g}$ of butadiene ( $175 \mathrm{~mL}, 2.07 \mathrm{~mol}, 99.4 \%$ of 1.00 equiv), at $-50{ }^{\circ} \mathrm{C}$. The Schlenk tube was then sealed, removed from the glovebox, and allowed to warm to ambient temperature ( $15 \mathrm{~min})$, before being placed in a thermostated oil bath at $60^{\circ} \mathrm{C}$. After 10 hours, the reaction vessel was cooled to room temperature and then opened to air. No bubbling was observed, characteristic of a quantitative conversion of butadiene. COD was then isolated by distillation under reduced pressure (b.p.: $60^{\circ} \mathrm{C}, 50 \mathrm{mbar}$, yield $=92 \%, 103.1 \mathrm{~g}$ ), and was analyzed for purity by NMR spectroscopy and GC/FID. The reaction kinetics were followed by dilatometry by 
monitoring the volume of liquid in the pressure tube and discussed in the Reaction Kinetics section.

\section{NMR Spectroscopy:}

${ }^{1} \mathrm{H}$ NMR $\left(500 \mathrm{MHz}, \mathrm{CDCl}_{3}, 23{ }^{\circ} \mathrm{C}, \delta\right)$ : olefinic $\mathrm{H}$ atoms: 5.59 (s (br), 4H); aliphatic $\mathrm{H}$ atoms: $2.03(t, J=$ $2.4 \mathrm{~Hz}, 8 \mathrm{H})$.

${ }^{13} \mathrm{C}$ NMR $\left(125 \mathrm{MHz}, \mathrm{CDCl}_{3}, 25{ }^{\circ} \mathrm{C}, \delta\right)$ : olefinic $128.8(\mathrm{~s})$, aliphatic $28.2(\mathrm{~s})$.

Selectivity cis, cis-1,5-cyclooctadiene / 4-vinylcyclohexene = 98:2 (no trimer was observed for this reaction).

Example 5: $1.69 \mathrm{~g}$ scale, using complex $5(500 \mathrm{ppm}), 60^{\circ} \mathrm{C}$

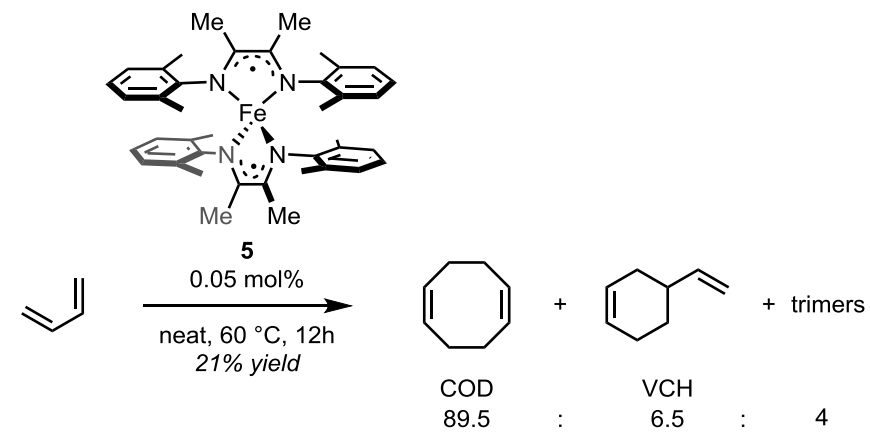

To a $20 \mathrm{~mL}$ scintillation vial was added di[bis(2,6-dimethylaniline)-butane-2,3-diimine] iron (5) (10.0 mg, 15.6 $\mu \mathrm{mol}, 0.0500 \mathrm{~mol} \%$ ) and $2.60 \mathrm{~mL}$ of butadiene (1.69 g, $31.2 \mathrm{mmol}, 1.00$ equiv), at $-50{ }^{\circ} \mathrm{C}$. The scintillation vial was capped and the reaction mixture was warmed to ambient temperature, removed from the glovebox, and then placed in a oil bath at $60^{\circ} \mathrm{C}$ for 12 hours. The reaction vessel was then cooled to ambient temperature and opened to air. Bubbling was observed, characteristic of an incomplete conversion of butadiene. The reaction mixture was filtered through a pad of silica gel, and then characterized by NMR spectroscopy and GC/FID. Following complete evaporation of unreacted butadiene, $355 \mathrm{mg}$ of a mixture of cyclooctadiene, 4-vinylcyclohexene and trimer (yield $21 \%$, see selectivity below).

This result indicates that complex $\mathbf{5}$ is not a competent catalyst for butadiene dimerization to afford COD.

\section{NMR Spectroscopy:}

${ }^{1} \mathrm{H}$ NMR $\left(500 \mathrm{MHz}, \mathrm{CDCl}_{3}, 23{ }^{\circ} \mathrm{C}, \delta\right)$ : olefinic $\mathrm{H}$ atoms: 5.59 (s (br), 4H); aliphatic $\mathrm{H}$ atoms: $2.03(t, J=$ $2.4 \mathrm{~Hz}, 8 \mathrm{H})$.

${ }^{13} \mathrm{C}$ NMR $\left(125 \mathrm{MHz}, \mathrm{CDCl}_{3}, 25{ }^{\circ} \mathrm{C}, \delta\right)$ : olefinic $128.8(\mathrm{~s})$, aliphatic $28.2(\mathrm{~s})$.

Selectivity for cis,cis-1,5-cyclooctadiene / other products = 9:1 (6.5\% 4-vinylcyclohexene and $4 \%$ trimer were observed for this reaction).

Note: An induction period of 15 minutes was observed for the reaction. 


\section{Catalytic resting state determination by ${ }^{1} \mathrm{H}$ NMR}

\section{General Procedure for reaction monitoring by ${ }^{1} \mathrm{H}$ NMR}

Fe complex 2 (8 mg, $2.5 \mathrm{~mol} \%$ ) was dissolved in $0.2 \mathrm{~mL}$ of cyclohexane-d12 in the glovebox in the J-Young NMR tube and the homogeneous solution was frozen in the cold well precooled at $-20^{\circ} \mathrm{C}$. $0.2 \mathrm{~mL}$ more of cyclohexane-d12 was then added on top of the frozen sample and the entire sample was frozen again to prevent rapid mixing of substrate butadiene and catalyst. The stock solution of 1,3-butadiene in cyclohexaned12 ( $0.7 \mathrm{~mL}$ of 1,3 butadiene in $2 \mathrm{~mL})$ was prepared and $0.2 \mathrm{~mL}$ of the stock solution $(0.83 \mathrm{mmol}$ of 1,3 butadiene) was added to the NMR tube and the sample was frozen. The frozen sample was taken out, thawed at $8{ }^{\circ} \mathrm{C}$, and the butadiene dimerization reaction was monitored by ${ }^{1} \mathrm{H}$ NMR.

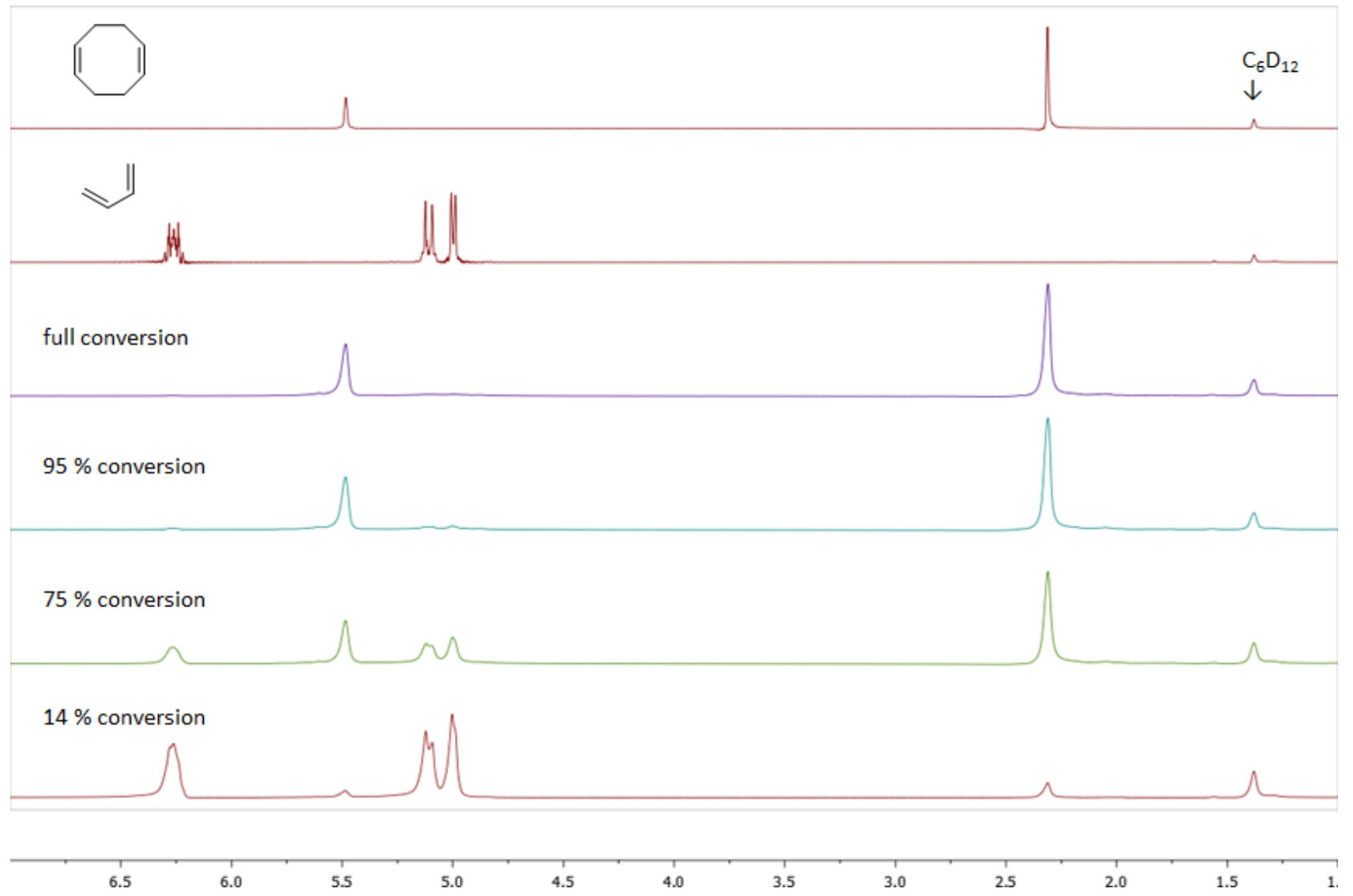

Figure S1. ${ }^{1} \mathrm{H}$ NMR spectra of 1,3-butadiene dimerization reaction at $14 \%, 75 \%, 95 \%$, full conversions, authentic sample of 1,3-butadiene and 1,5-cyclooctadiene in cyclohexane-d12. 

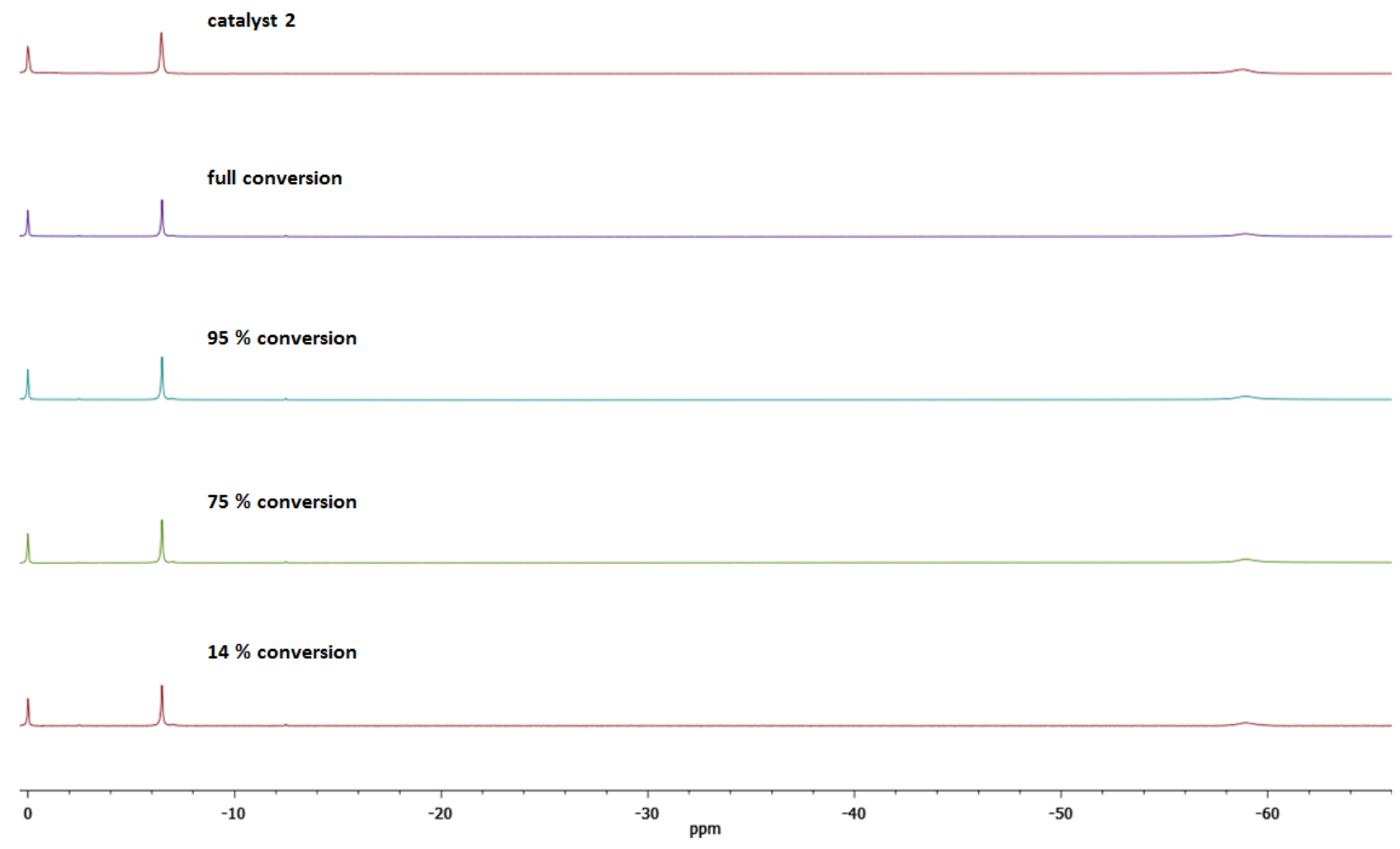

Figure S2. ${ }^{1} \mathrm{H}$ NMR spectra of the 1,3-butadiene dimerization reaction between $-66 \mathrm{ppm}$ to $0.4 \mathrm{ppm}$ at $14 \%$, $75 \%, 95 \%$, full conversions and catalyst 2 in cyclohexane-d12 showing that the catalytic resting state is 2 .

Note: For the quantification of catalyst during the dimerization reaction, we prepared an NMR sample that has the same amount of cyclohexane-d12 and Fe catalyst in the absence of 1,3-butadiene. Fe complex 2 ( $8 \mathrm{mg}$ ) was dissolved in $0.4 \mathrm{~mL}$ of cyclohexane-d12 in the glovebox in the J-Young NMR tube. The stock solution ( $0.7 \mathrm{~mL}$ of $1,5-\mathrm{COD}$ in $2 \mathrm{~mL}$ cyclohexane-d12) was prepared and $0.2 \mathrm{~mL}$ of the stock solution was added. The relative integration of the ${ }^{1} \mathrm{H}$ NMR solvent resonance indicates that catalyst 2 is likely the resting state. 


\section{Reaction Kinetics}

\section{General Procedure for Kinetics Measurements and Dilatometry}

Reaction kinetics were monitored using dilatometry, by monitoring the volume of liquid in the reaction vessel. Dilatometry utilizes the volume change that occurs upon dimerization to follow conversion versus time.

Reaction vessels with a large height/diameter ratio were used in order to most accurately observe changes in volume (for 100 gram scale reactions, a $350 \mathrm{~mL}$ pressure Schlenk tube). Accurate determination of the corresponding volumes was performed post-reaction by filling the empty marked vessel with water, and measuring the corresponding masses. For fitting of the data to a first-order regression, linear natural log plots were obtained by using an infinite time point set to $100 \%$ conversion.

Ideal solution behavior $\left(V_{\mathrm{TOT}}=V_{1,5-\mathrm{COD}}+V_{1,3 \text {-butadiene }}\right)$ of 1,5-COD/1,3-butadiene mixtures was validated by measuring total volumes at various mole fractions of 1,3-butadiene at a fixed total molar amount of 0.0163

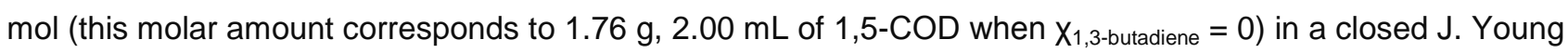
tube. The plot in Figure S3 shows that the COD/butadiene mixture follows an ideal behavior and thus enables the use of dilatometry for measuring kinetics. Partitioning of butadiene between the liquid and vapor phases in a closed system was not considered. The solution behavior of COD and VCH was not considered due to high selectivity for $\mathrm{COD}$ formation over $\mathrm{VCH}$ formation from the reaction.

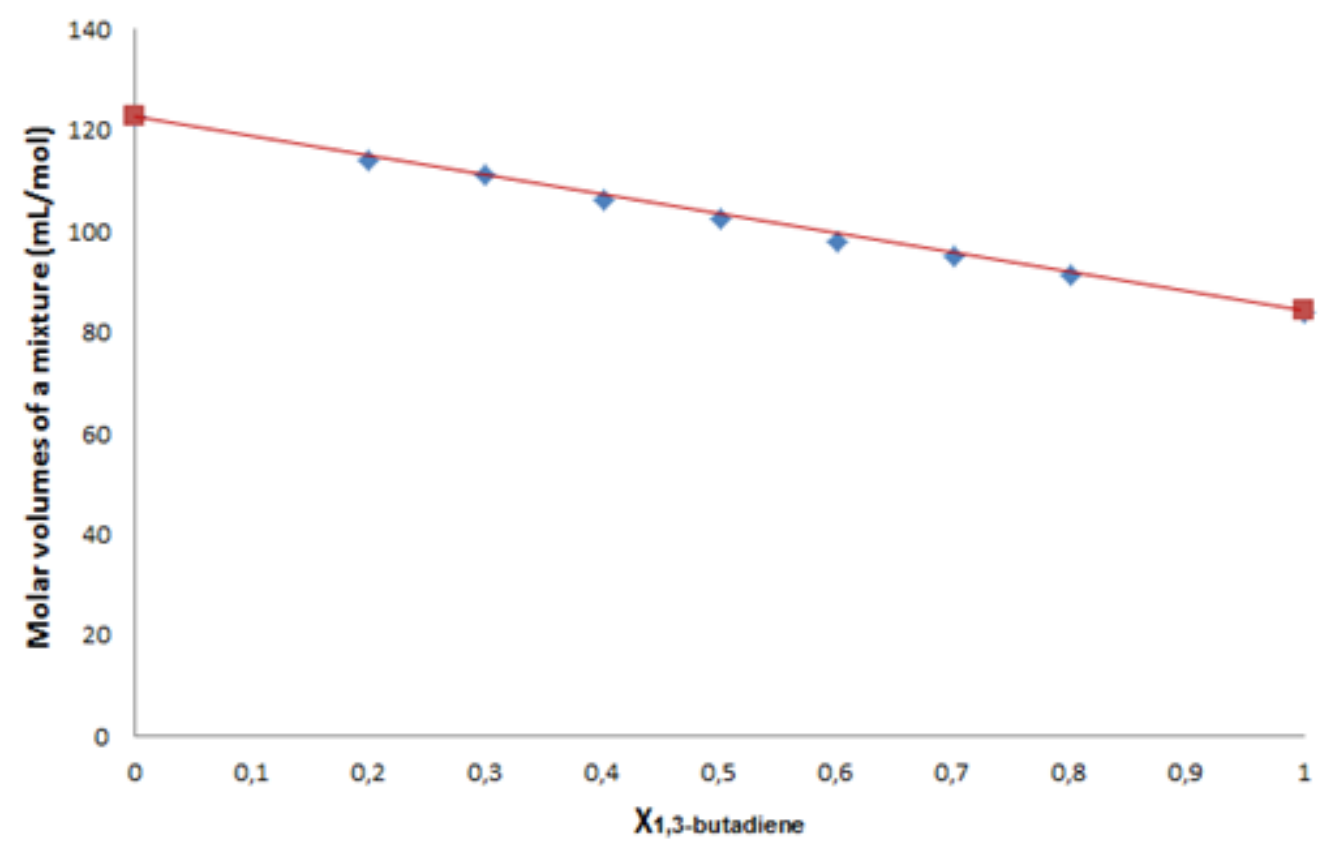

Figure S3. Plot of molar volume of a 1,5-COD/1,3-butadiene mixture versus mole fraction of 1,3-butadiene at $23^{\circ} \mathrm{C}$ in a closed vessel. The red line indicates the ideal behavior

The total fractional change in volume corresponds to conversion of a butadiene monomer of density $d_{1}$ to dimer 1,5-cyclooctadiene of density $d_{2}$. The weight of the dimer formed would also be $w_{1}$, because the reaction proceeds with no by-product. For the total fractional change in volume, this gives: 


$$
\Delta V_{\text {total fract }}=\frac{\left(\frac{w_{1}}{d_{1}}\right)-\left(\frac{w_{1}}{d_{2}}\right)}{\left(\frac{w_{1}}{d_{1}}\right)}
$$

(Equation S1)

which simplifies to:

$$
\Delta V_{\text {total fract }}=\frac{d_{2}-d_{1}}{d_{2}}
$$

The degree of monomer conversion would then be:

$$
\frac{\Delta[M]}{[M]}=\frac{\left(\frac{\Delta V}{V_{0}}\right)}{\left(\frac{d_{2}-d_{1}}{d_{2}}\right)}=\frac{\left(\frac{\Delta h}{h_{0}}\right)}{\left(\frac{d_{2}-d_{1}}{d_{2}}\right)}
$$

where $\Delta[\mathrm{M}]$ is the incremental change in monomer concentration $[\mathrm{M}]$ and $\Delta \mathrm{V}$ is the change in volume from the initial volume $V_{0}$ (or the initial height $h_{0}$ ). This is true because the term $\left(d_{2}-d_{1}\right) / d_{2}$ is the fractional volume change which would occur at $100 \%$ conversion and $\Delta \mathrm{V} / \mathrm{V}_{\mathrm{o}}$ is the fractional volume change at any time $\Delta \mathrm{t}$. The ratio of these two quantities should give the fraction of conversion. Now if both sides of equation S3 are divided by $\Delta t$, incremental time, and rearranged, then

$$
\begin{array}{cr}
\frac{\Delta[M]}{\Delta t}=\frac{\left(\frac{\Delta V}{\Delta t}\right) \times\left(\frac{[M]}{V_{0}}\right)}{\left(\frac{d_{2}-d_{1}}{d_{2}}\right)}=\frac{[M] d_{2}}{V_{0}\left(d_{2}-d_{1}\right)} \times \frac{\Delta V}{\Delta t} & \text { (Equation S4) and } \\
\lim _{\Delta t \rightarrow 0} \frac{\Delta[M]}{\Delta t}=\frac{d[M]}{d t} & \text { (Equation S5) }
\end{array}
$$

The value $-d[M] / d t$ is then defined as the overall rate of dimerization, $R_{d}$.

\section{Kinetic Profile of Iron-Catalyzed Butadiene Dimerization Reaction}

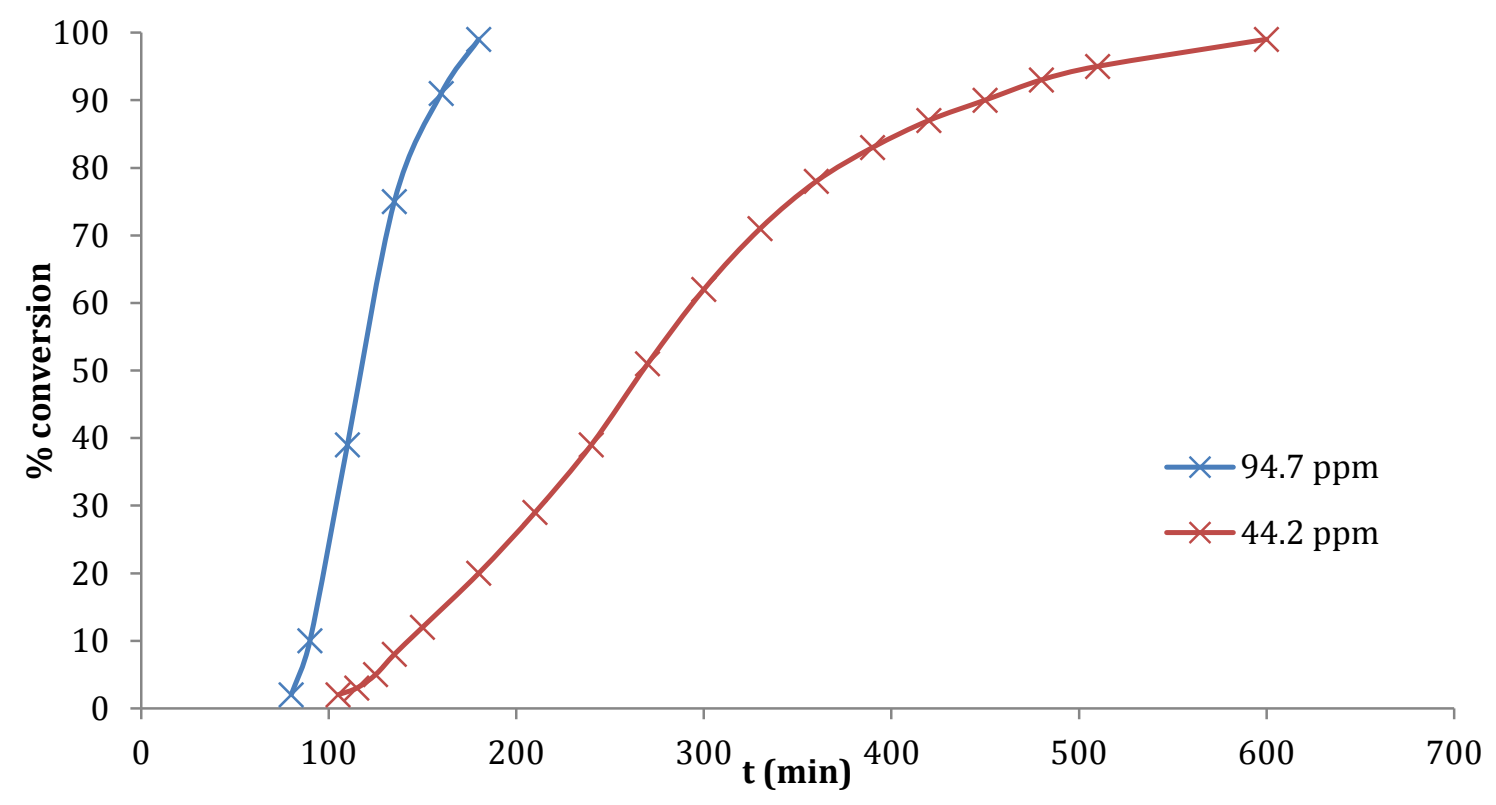

Figure S4. Kinetic profile of butadiene dimerization on $100 \mathrm{~g}$ scale using Fe(II) pre-catalyst 1 (94.7 and 44.2 
ppm catalyst loadings; examples 3 and 4, respectively).

Using pseudo-linear portions between 20 and $80 \%$ conversion, one can derive catalyst activities of 4.3 (for $44.2 \mathrm{ppm} \mathrm{1}$ ) and $8.8 \mathrm{kgCOD}^{\circ} \mathrm{gFe}^{-1} \cdot \mathrm{h}^{-1}$ (for $94.7 \mathrm{ppm} \mathrm{1).} \mathrm{Partial} \mathrm{decomposition} \mathrm{of} \mathrm{the} \mathrm{catalyst} \mathrm{could} \mathrm{potentially}$ account for the difference in activity at lower catalyst loading.

In order to calculate the catalyst activities, one should account for the amount of cyclooctadiene produced between 20 and $80 \%$ conversion of butadiene into product, normalize for the time necessary to go from 20 to $80 \%$ conversion, and normalize the obtained value for the amount of iron required (unit: $\mathrm{kg}_{\mathrm{COD}} \cdot \mathrm{g}_{\mathrm{Fe}}{ }^{-1} \cdot \mathrm{h}^{-1}$ ).

Note: The origin of the induction period results from the reduction of 1 by $\mathrm{MeMgCl}$, although we do not exactly know which step during the reduction contributes for the induction period. The complex $\mathbf{2}$ is formed in situ from the reaction starting from $\mathbf{1}$, and when 1 was pre-incubated with $\mathrm{MeMgCl}$ using a reaction condition for a synthesis of $\mathbf{2}$ then add butadiene, an induction period is not observed at room temperature.

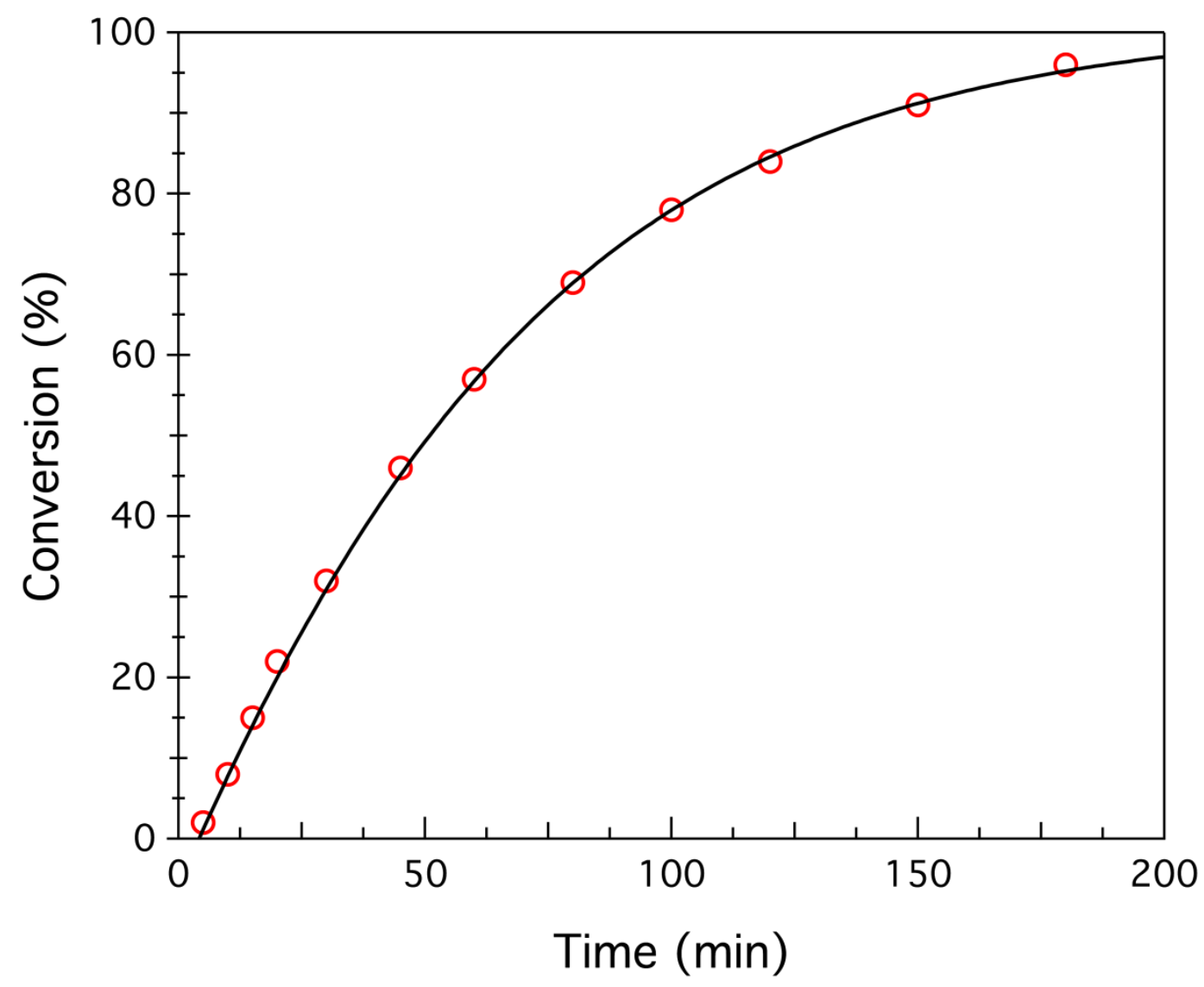

Figure S5. Kinetic profile of butadiene dimerization on $80 \mathrm{~g}$ scale using Fe(I) complex 2 (76.3 ppm 2; example 1). 


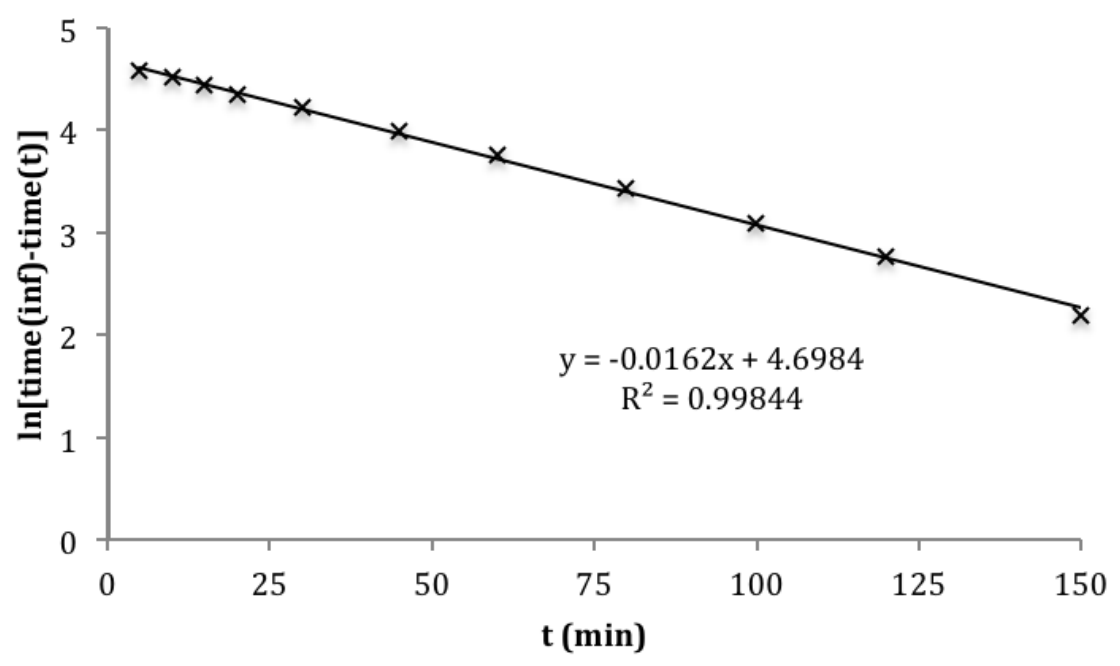

Figure S6. First-order fit for kinetics of butadiene dimerization catalyzed by 2 (based on data shown in Fig. S5; example 1).

\section{Determination of the Kinetic Order With Respect to [Fe]}

To a $6 \mathrm{~mL}$ pressure tube was added Fe(I) complex $2(0.074 \mathrm{~mol} \%-0.32 \mathrm{~mol} \%)$ as a solid. The tube was cooled to $-20^{\circ} \mathrm{C}$, followed by addition of 1,3 -butadiene $(1.9 \mathrm{~g}, 35 \mathrm{mmol})$ at $-20^{\circ} \mathrm{C}$. The tube was then sealed, held at $28^{\circ} \mathrm{C}$, and the volume of the reaction mixture was monitored to maximal contraction. At this point the reaction vessel was opened to air, and no bubbling was observed, indicative of a quantitative conversion of butadiene. The volume change vs. time was converted to \% conversion vs. time using the general procedure for kinetics measurement described above. 


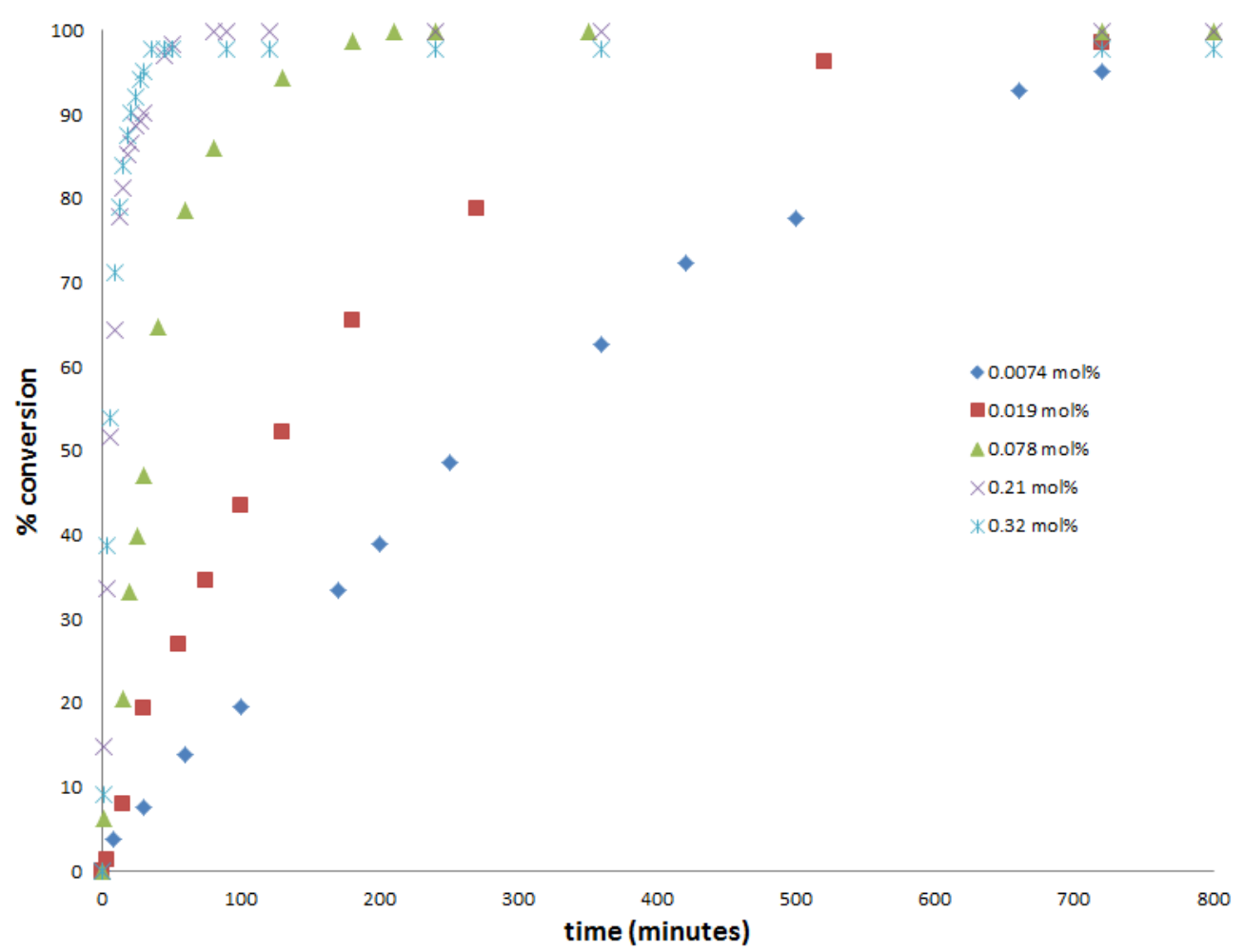

Figure S7. Conversion vs. time for butadiene dimerization for different catalyst loadings of 2 

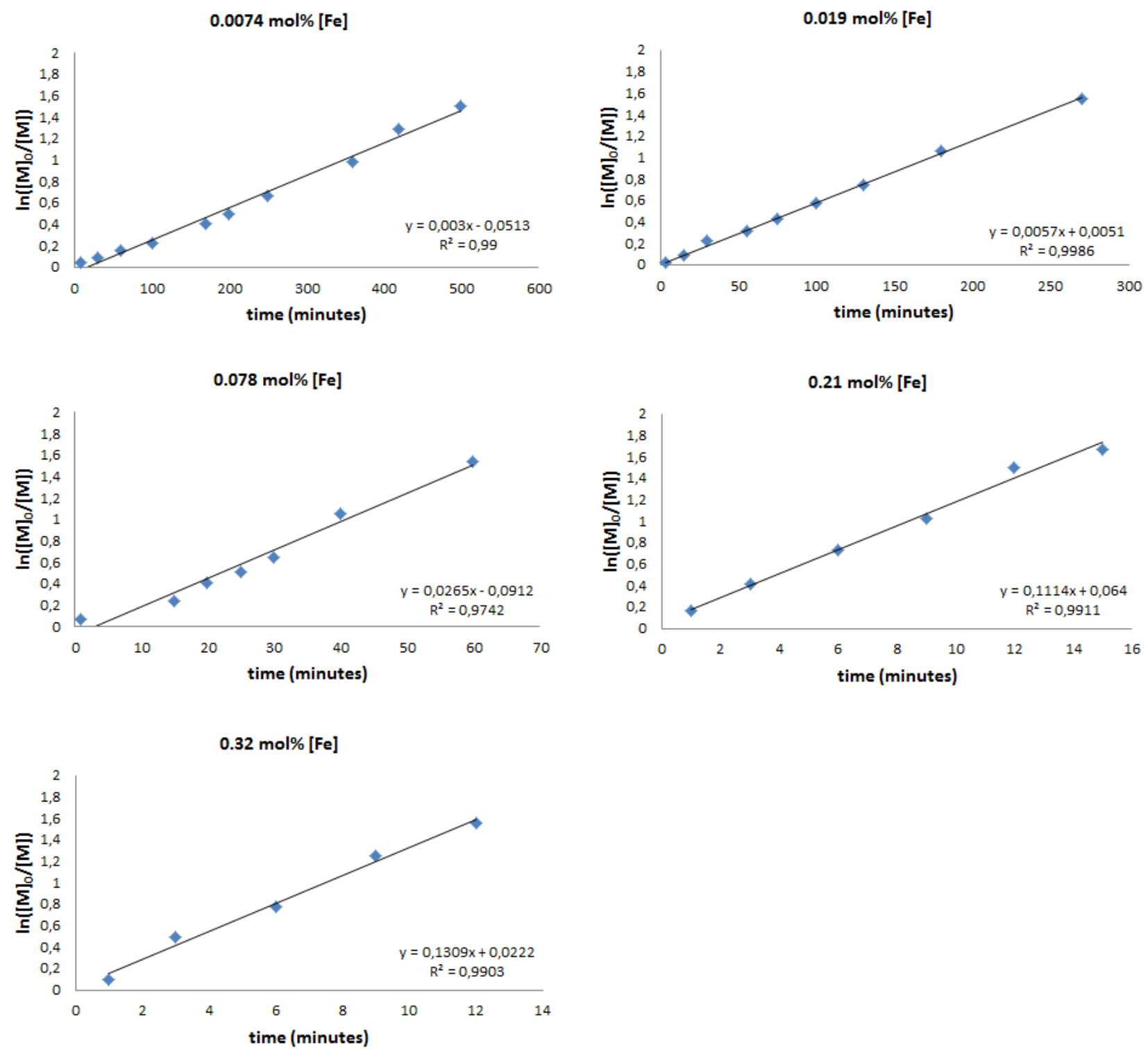

Figure S8. Extraction of pseudo-first order rate constants $\left(\mathrm{k}_{\mathrm{obs}}\right)$ by fitting of conversion up to $78 \%$ vs. time curves shown in Figure $\mathrm{S} 7$ ( $\mathrm{y}$-axis in terms of [butadiene]) 


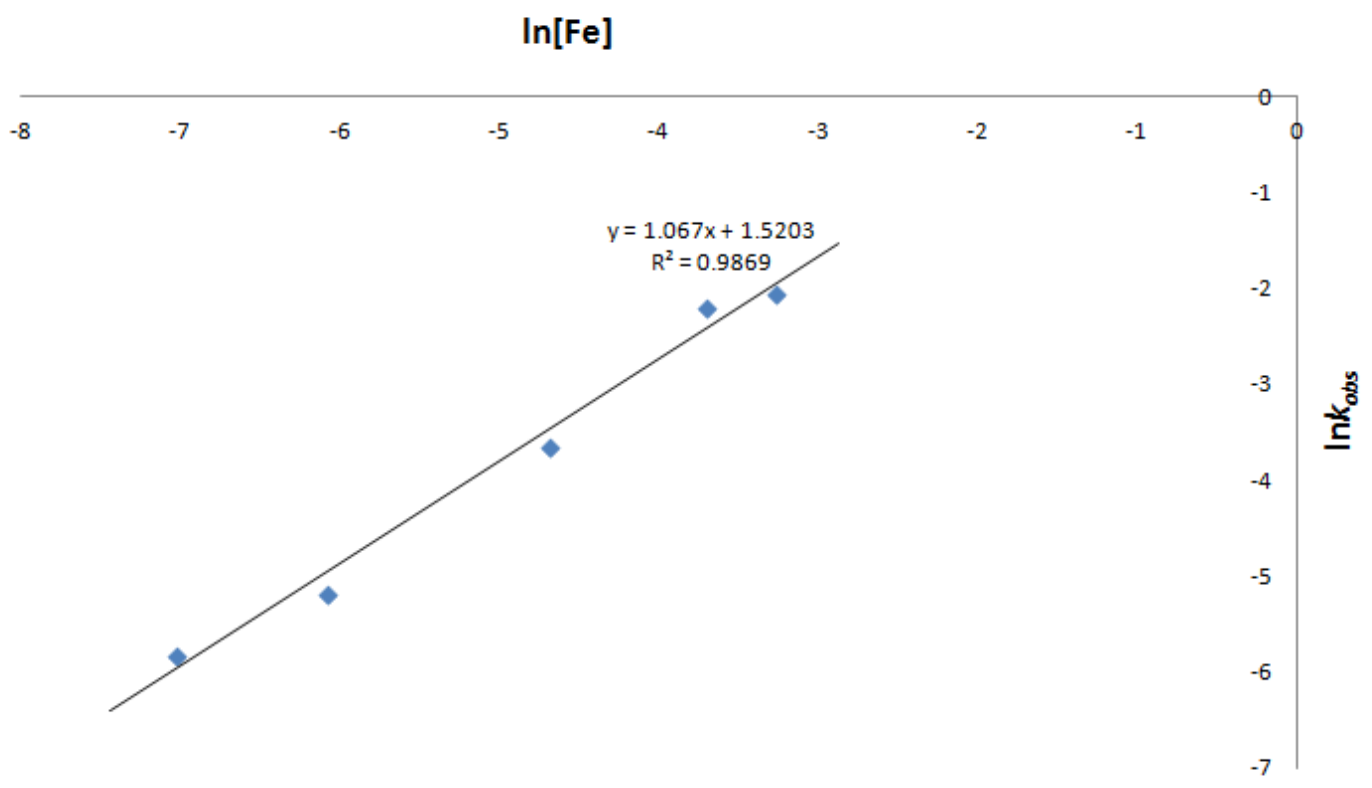

Figure S9. Determination of kinetic order of 1.07 with respect to [Fe]

We concluded that it is plausible to propose the catalytic cycle where the complex $\mathbf{2}$ is on the catalytic cycle and thus having the kinetic order of 1 . The deviation from the kinetic order of 1 presumably results from the experimental error related the precise volume contraction measurement.

\section{Rate Dependence on 1,5-Cyclooctadiene}

To monitor rate dependence of 1,5-cyclooctadiene to the reaction, two samples with same Fe catalyst and 1,3-butadiene concentration was prepared, one with 1,5-cyclooctadiene (Sample A) and one without 1,5cyclooctadiene (Sample B) and the reaction kinetics was monitored by dilatometry. Sample preparation is described below.

Sample A: To a $6 \mathrm{~mL}$ pressure tube was added Fe(l) complex 2 (30 mg, $0.066 \mathrm{~mol})$. 1,5-cyclooctadiene $(0.2$ $\mathrm{mL}, 1.63 \mathrm{mmol}$ ) was then added and the tube was cooled at $-20^{\circ} \mathrm{C}$ in the cold well. 1,3-butadiene $(1.8 \mathrm{~g}, 2.8$ $\mathrm{mL}, 33 \mathrm{mmol}$ ) was added, the pressure tube was sealed and turned upside down for 2 seconds to allow mixing of 1,5-cyclooctadiene and 1,3-butadiene.

Sample B: To a $6 \mathrm{~mL}$ pressure tube was added Fe(I) complex 2 (30 mg, $0.066 \mathrm{~mol}) .0 .2 \mathrm{~mL}$ of pentane was then added and the tube was cooled at $-20^{\circ} \mathrm{C}$ in the cold well. 1,3-butadiene (1.8 g, $\left.2.8 \mathrm{~mL}, 33 \mathrm{mmol}\right)$ was added, the pressure tube was sealed and turned upside down for 2 seconds to allow mixing of pentane and 1,3-butadiene.

Two pressure tubes were then held at $28^{\circ} \mathrm{C}$ and the volume of the reaction mixture was monitored to maximal contraction. At this point the reaction vessel was opened to air, and no bubbling was observed, indicative of a quantitative conversion of butadiene. The volume change vs. time was converted to \% conversion vs. time using the general procedure for kinetics measurement described above. 


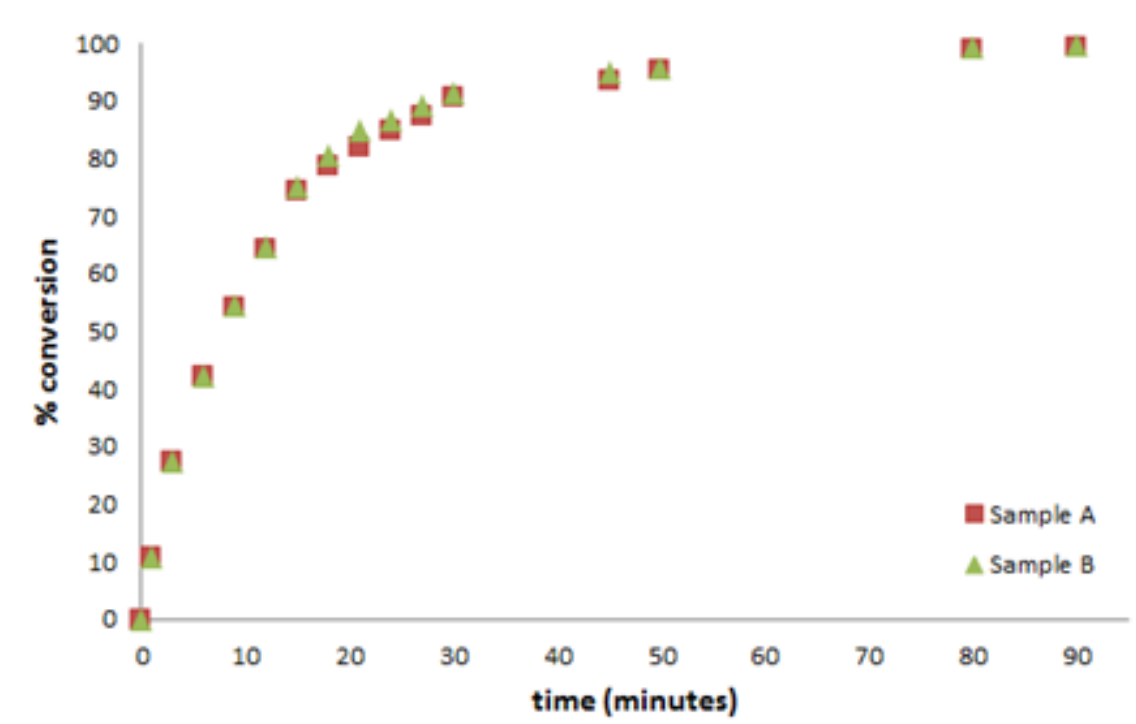

Figure S10. Conversion vs. time for butadiene dimerization for samples with and without 1,5-cyclooctadiene at $\mathrm{t}=0 \mathrm{~min}$.

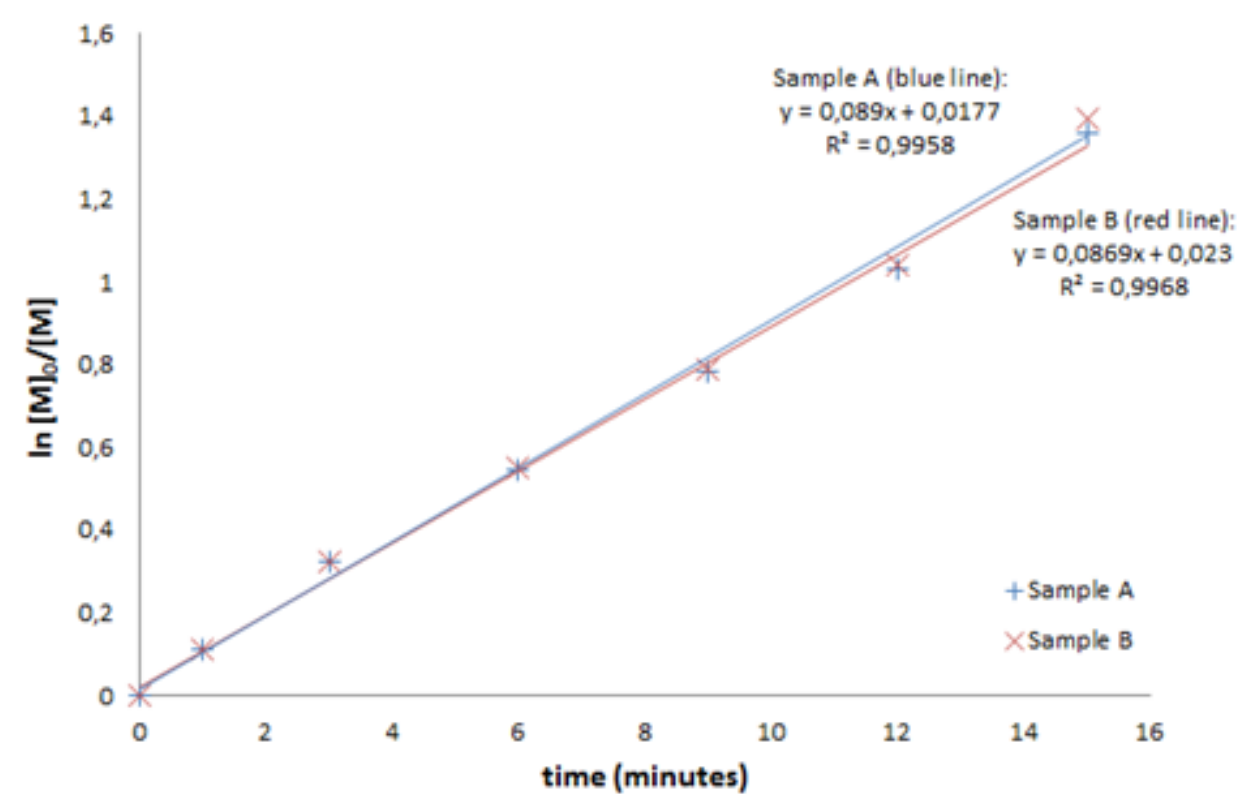

Figure S11. Extraction of pseudo-first order rate constants (kobs) by fitting of conversion up to $75 \%$ vs. time curves shown in Figure $\mathrm{S} 10$ (y-axis in terms of [butadiene])

Note: Zero-order kinetics observed for 1,5-COD is supporting that complex 2 is on the catalytic cycle. For possible mechanistic pathways that are consistent with kinetic data, see Figure S15. 


\section{Eyring Analysis}

To a $3 \mathrm{~mL}$ pressure tube was added $\mathrm{Fe}(\mathrm{I})$ complex $2(10 \mathrm{mg}, 0.022 \mathrm{mmol}, 0.18 \mathrm{~mol} \%)$ as a solid. The tube was cooled to $-50{ }^{\circ} \mathrm{C}$, followed by addition of butadiene $\left(0.64 \mathrm{~g}, 12 \mathrm{mmol}, 1.0\right.$ equiv) at $-50{ }^{\circ} \mathrm{C}$. The tube was then sealed, held at the appropriate temperature $\left(-15\right.$ to $60^{\circ} \mathrm{C}$, see data below), and the volume contraction of the reaction mixture was monitored. The volume change vs. time was converted to \% conversion vs. time using the general procedure for kinetics measurements described above. Error Analysis for Activation Parameters from Eyring Plot was performed within 95\% confidence interval, assuming that the intercept and the slope error distribution from the fitting of Eyring plot follows normal Gaussian distribution.

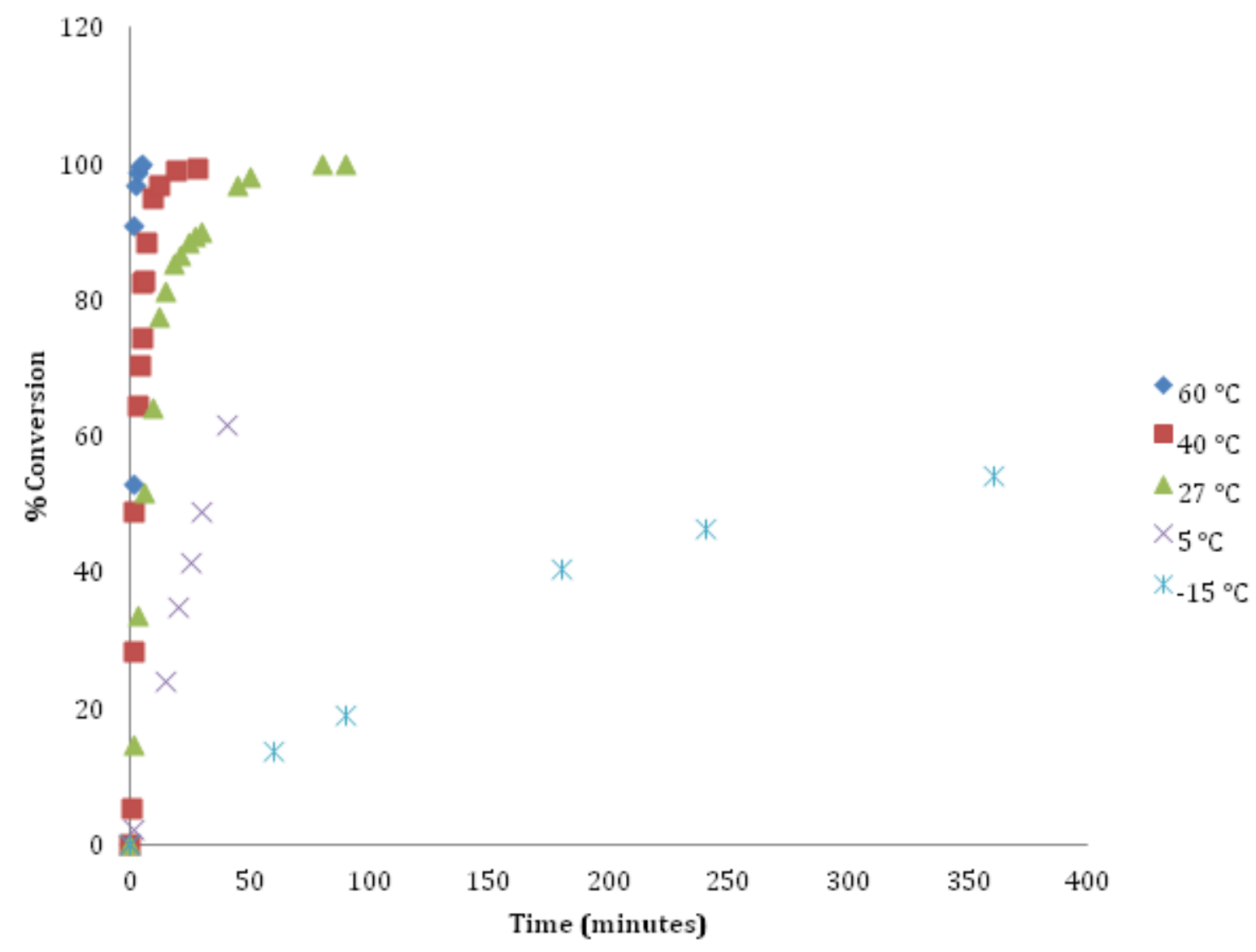

Figure S12. Conversion vs. time for butadiene dimerization catalyzed by $2(0.18 \mathrm{~mol} \%)$ at different temperatures 

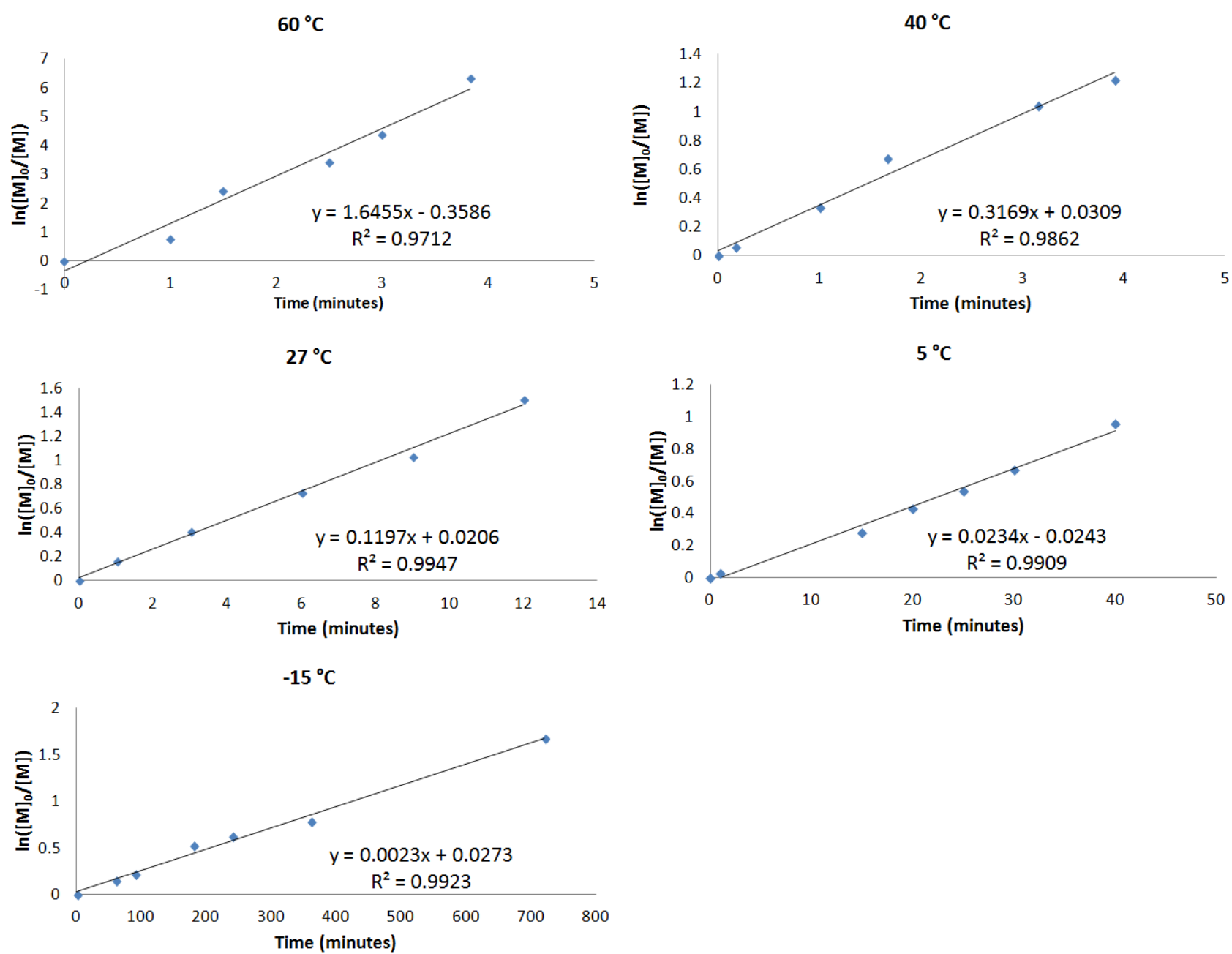

Figue S13. Extraction of pseudo-first order rate constants (kobs) by fitting of conversion vs. time curves shown in Fig. S8 (y-axis unit in terms of [butadiene]).

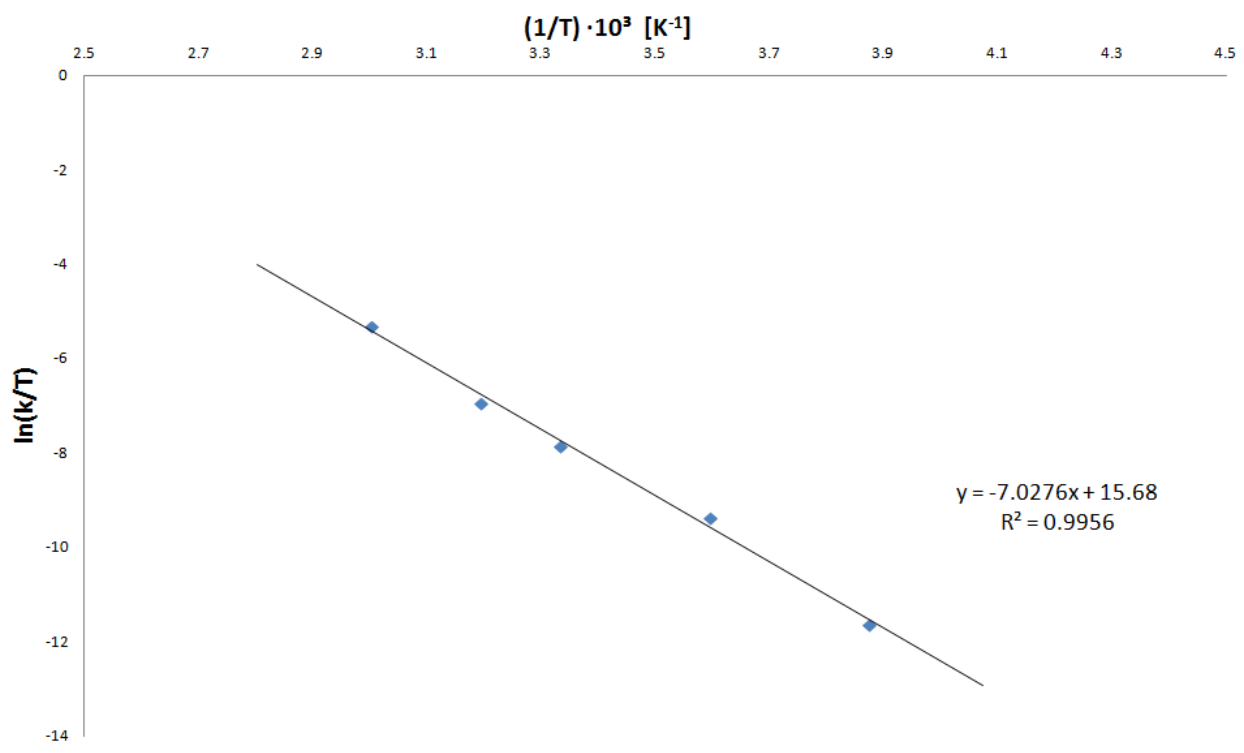

Figure S14. Eyring Plot for dimerization of butadiene catalyzed by $2(0.18 \mathrm{~mol} \%)$, based on the data shown 
in Figs. S12-S13

Activation Parameters from Eyring Plot

$\Delta H^{\ddagger}=14 \mathrm{kcal} / \mathrm{mol} \pm 2 \mathrm{kcal} / \mathrm{mol}$

$\Delta S^{\ddagger}=-16$ eu \pm 6 eu

$\Delta \mathrm{G}^{\ddagger} 298=19 \mathrm{kcal} / \mathrm{mol} \pm 1 .{ }_{5} \mathrm{kcal} / \mathrm{mol}$ 


\section{Examples of Plausible Mechanistic Pathways}

There are several closely-related pathways that are consistent with the kinetic data in addition to the proposed cycle in Figure 4 in the manuscript. Below are examples of plausible mechanistic pathways.
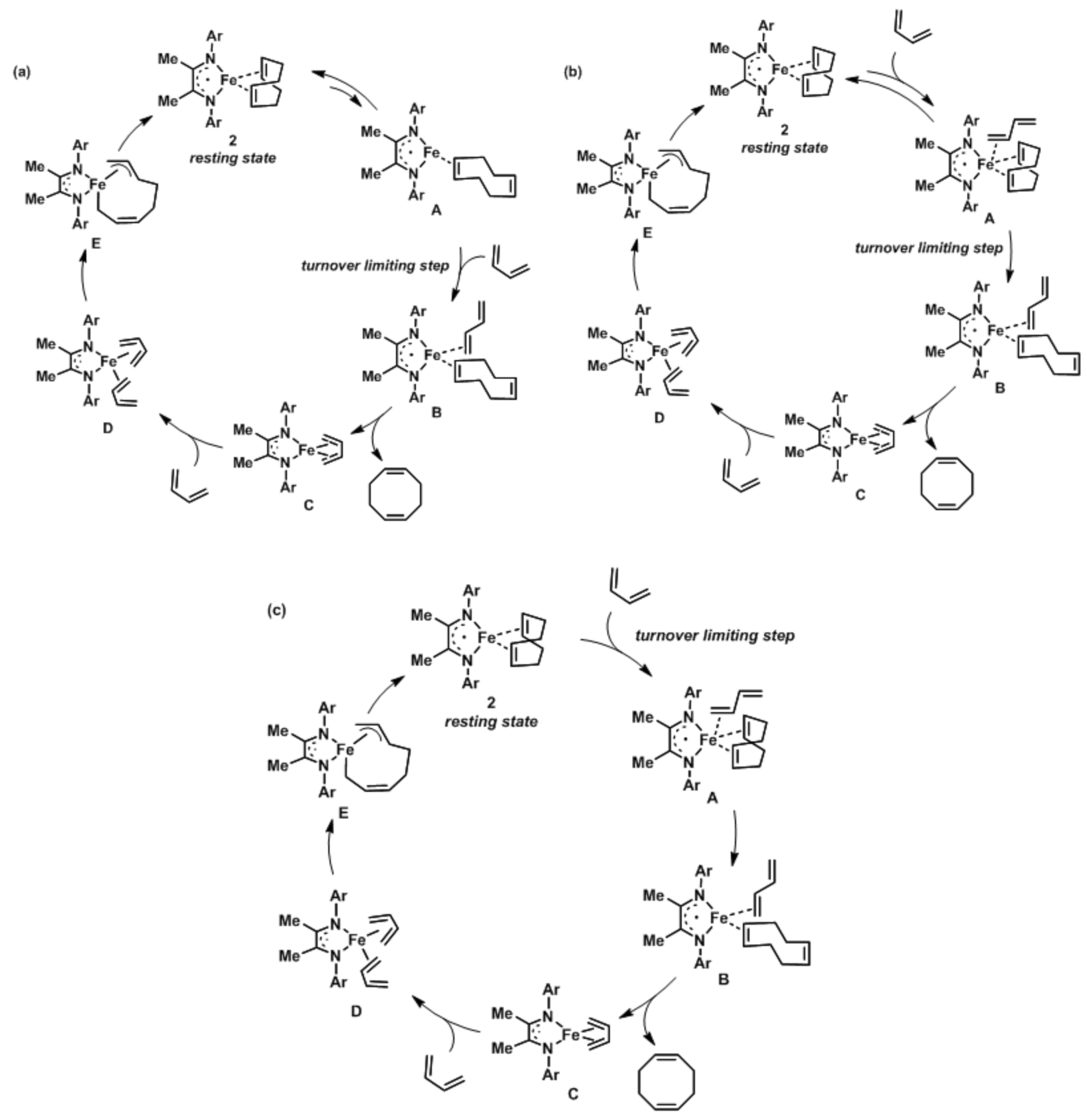

Figure S15. Examples of plausible catalytic cycle consistent with the kinetic data 


\section{X-Ray Crystallographic Analysis}

\section{General Procedure for X-ray Data Collection and Refinement}

A crystal was mounted on a nylon loop using Paratone-N oil, and transferred to a Bruker APEX II CCD diffractometer (MoK $\alpha$ radiation, $\lambda=0.71073 \AA$ ) equipped with an Oxford Cryosystems nitrogen flow apparatus. The sample was held at $100 \mathrm{~K}$ during the experiment. The collection method involved $0.5^{\circ}$ scans in $\omega$ at $28^{\circ}$ in 29. Data integration down to $0.82 \AA$ resolution was carried out using SAINT V7.46 A (Bruker diffractometer, 2009) with reflection spot size optimisation. Absorption corrections were made with the program SADABS (Bruker diffractometer, 2009). The structure was solved by the direct methods procedure and refined by least-squares methods against $F^{2}$ using SHELXS-97 and SHELXL-97 (Sheldrick, 2008). Nonhydrogen atoms were refined anisotropically, and hydrogen atoms were allowed to ride on the respective atoms. Restraints on bond lengths and constraints of the atomic displacement parameters on each pair of disorder fragments (SADI and EADP instructions of SHELXL97), as well as the restraints of the atomic displacement parameters (SIMU/DELU instructions of SHELXL97) if necessary, have been applied for the disorder refinement. Special refinement details, if applicable, are given for each compound below. Crystal data, details of data collection and refinement, and selected geometric parameters are given in the tables below. Graphics were produced using the CystalMaker 8.6 software program (@1994-2012 CrystalMaker Software Ltd.).

Computer programs: APEX2 v2009.3.0 (Bruker-AXS, 2009), SAINT 7.46A (Bruker-AXS, 2009), SHELXS97 (Sheldrick, 2008), SHELXL97 (Sheldrick, 2008), Bruker SHELXTL.

Bis(2,6-dimethylaniline)-butane-2,3-diimine iron(II) chloride (1) (CCDC 972790)

Refinement Special Details: A solvent mask was implemented in the Olex2 software program, due to the high degree of disorder in the solvent molecules.

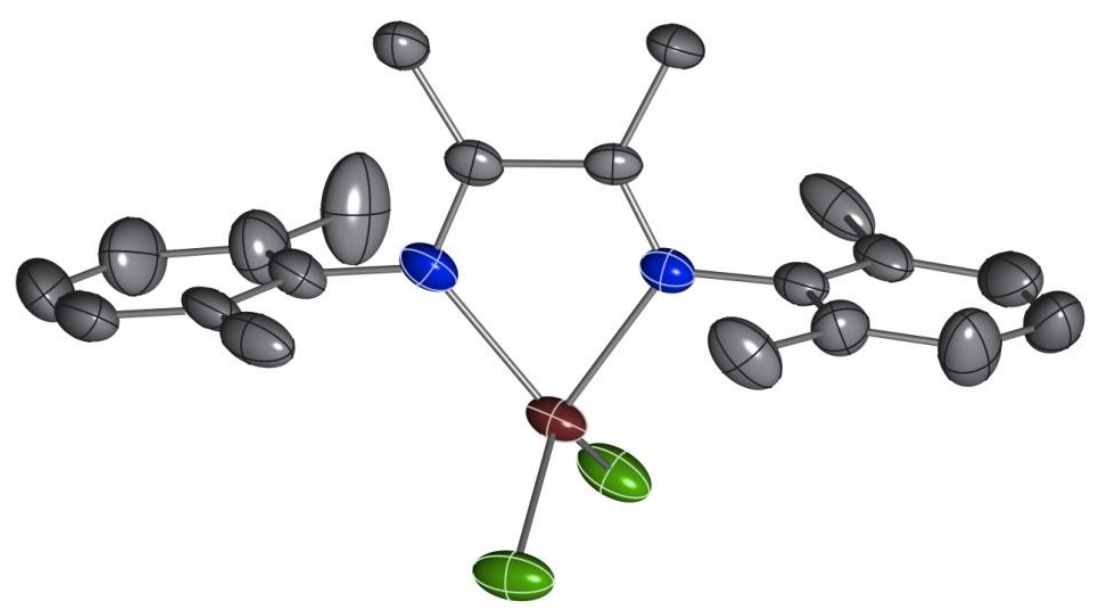

Figure S16. X-ray structure of 1 . Thermal ellipsoids are drawn at the $50 \%$ probability level, $\mathrm{H}$ atoms are omitted for clarity 
Table S1. Crystal data and structure refinement for 1 .

\begin{tabular}{|c|c|}
\hline & Complex_1 \\
\hline \multicolumn{2}{|l|}{ Crystal data } \\
\hline Chemical formula & $\mathrm{C}_{20} \mathrm{H}_{24} \mathrm{Cl}_{2} \mathrm{FeN}_{2}$ \\
\hline$M_{\mathrm{r}}$ & 419.16 \\
\hline $\begin{array}{l}\text { Crystal system, } \\
\text { space group }\end{array}$ & Monoclinic, $C 2 / c$ \\
\hline Temperature $(\mathrm{K})$ & 100 \\
\hline$a, b, c(\AA)$ & $28.675(2), 14.4213(11), 14.2903(11)$ \\
\hline$\beta\left(^{\circ}\right)$ & $109.648(1)$ \\
\hline$V\left(\AA^{3}\right)$ & $5565.4(8)$ \\
\hline$Z$ & 8 \\
\hline Radiation type & Mo $K \alpha$ \\
\hline$\mu\left(\mathrm{mm}^{-1}\right)$ & 0.74 \\
\hline Crystal size (mm) & $1.00 \times 0.31 \times 0.23$ \\
\hline \multicolumn{2}{|l|}{ Data collection } \\
\hline Diffractometer & $\begin{array}{l}\text { CCD area detector } \\
\text { diffractometer }\end{array}$ \\
\hline Absorption correction & $\begin{array}{l}\text { Numerical } \\
\text { SADABS (Sheldrick, 2009) }\end{array}$ \\
\hline$T_{\min }, T_{\max }$ & $0.526,0.846$ \\
\hline $\begin{array}{l}\text { No. of measured, } \\
\text { independent and } \\
\text { observed }[I>2 \sigma(I)] \\
\text { reflections }\end{array}$ & $5301,5301,3937$ \\
\hline$R_{\text {int }}$ & 0.0000 \\
\hline$(\sin \theta / \lambda)_{\max }\left(\AA^{-1}\right)$ & 0.611 \\
\hline \multicolumn{2}{|l|}{ Refinement } \\
\hline $\begin{array}{l}R\left[F^{2}>2 \sigma\left(F^{2}\right)\right] \\
w R\left(F^{2}\right), S\end{array}$ & $0.047,0.174,1.15$ \\
\hline No. of reflections & 5301 \\
\hline No. of parameters & 232 \\
\hline $\mathrm{H}$-atom treatment & $\mathrm{H}$-atom parameters constrained \\
\hline$\Delta \rho_{\max }, \Delta \rho_{\min }\left(\mathrm{e} \AA^{-3}\right)$ & $0.38,-0.35$ \\
\hline
\end{tabular}


Bis(2,6-dimethylaniline)-butane-2,3-diimine iron(I) $\left(\eta^{2}: \eta^{2}-1,5-C O D\right)(2)$ (CCDC 1414006)

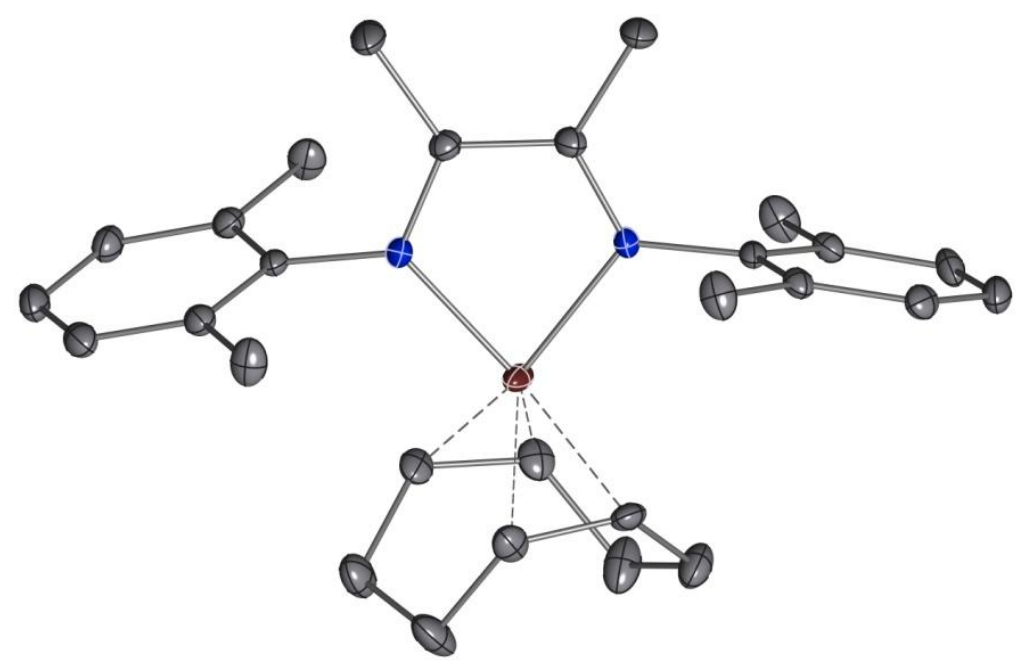

Figure S17. X-ray structure of 2. Thermal ellipsoids are drawn at the 50\% probability level, $\mathrm{H}$ atoms are omitted for clarity

Table S2. Crystal data and structure refinement for 2 .

\begin{tabular}{|c|c|}
\hline & Complex_2 \\
\hline \multicolumn{2}{|l|}{ Crystal data } \\
\hline Chemical formula & $\mathrm{C}_{28} \mathrm{H}_{36} \mathrm{FeN}_{2}$ \\
\hline$M_{\mathrm{r}}$ & 456.44 \\
\hline $\begin{array}{l}\text { Crystal system, } \\
\text { space group }\end{array}$ & Monoclinic, $P 2_{1} / c$ \\
\hline Temperature $(\mathrm{K})$ & 100 \\
\hline$a, b, c(\AA)$ & $9.8016(10), 30.318(3), 8.3018(8)$ \\
\hline$\beta\left(^{\circ}\right)$ & $104.986(2)$ \\
\hline$V\left(\AA^{3}\right)$ & $2383.1(4)$ \\
\hline$Z$ & 4 \\
\hline Radiation type & Mo Ka \\
\hline$\mu\left(\mathrm{mm}^{-1}\right)$ & 0.65 \\
\hline Crystal size (mm) & $0.44 \times 0.28 \times 0.15$ \\
\hline \multicolumn{2}{|l|}{ Data collection } \\
\hline Diffractometer & $\begin{array}{l}\text { Bruker D8 goniometer with CCD area detector } \\
\text { diffractometer }\end{array}$ \\
\hline Absorption correction & $\begin{array}{l}\text { Multi-scan } \\
\text { SADABS (Sheldrick, 2008) }\end{array}$ \\
\hline$T_{\min }, T_{\max }$ & $0.763,0.911$ \\
\hline No. of measured, & $33227,4531,3965$ \\
\hline
\end{tabular}




\begin{tabular}{|l|l|}
\hline $\begin{array}{l}\text { independent and } \\
\text { observed }[I>2 \sigma(I)] \\
\text { reflections }\end{array}$ & \\
\hline$R_{\text {int }}$ & 0.034 \\
\hline$(\sin \theta / \lambda)_{\max }\left(\AA^{-1}\right)$ & 0.610 \\
\hline \multicolumn{2}{|l}{} \\
\hline Refinement & $0.034,0.103,1.05$ \\
\hline $\begin{array}{l}R\left[F^{2}>2 \sigma\left(F^{2}\right)\right], \\
W R\left(F^{2}\right), S\end{array}$ & 4531 \\
\hline No. of reflections & 286 \\
\hline No. of parameters & $\begin{array}{l}\mathrm{H} \text { atoms treated by a mixture of independent and constrained } \\
\text { refinement }\end{array}$ \\
\hline $\mathrm{H}$-atom treatment \\
\hline$\Delta \rho_{\max }, \Delta \rho_{\min }\left(\mathrm{e} \AA^{-3}\right)$ & $0.41,-0.32$ \\
\hline
\end{tabular}

Isomer of Bis(2,6-dimethylaniline)-butane-2,3-diimine iron(I) $\left(\eta^{2}: \eta^{2}-1,5-C O D\right)$ (2) (CCDC 1436928)

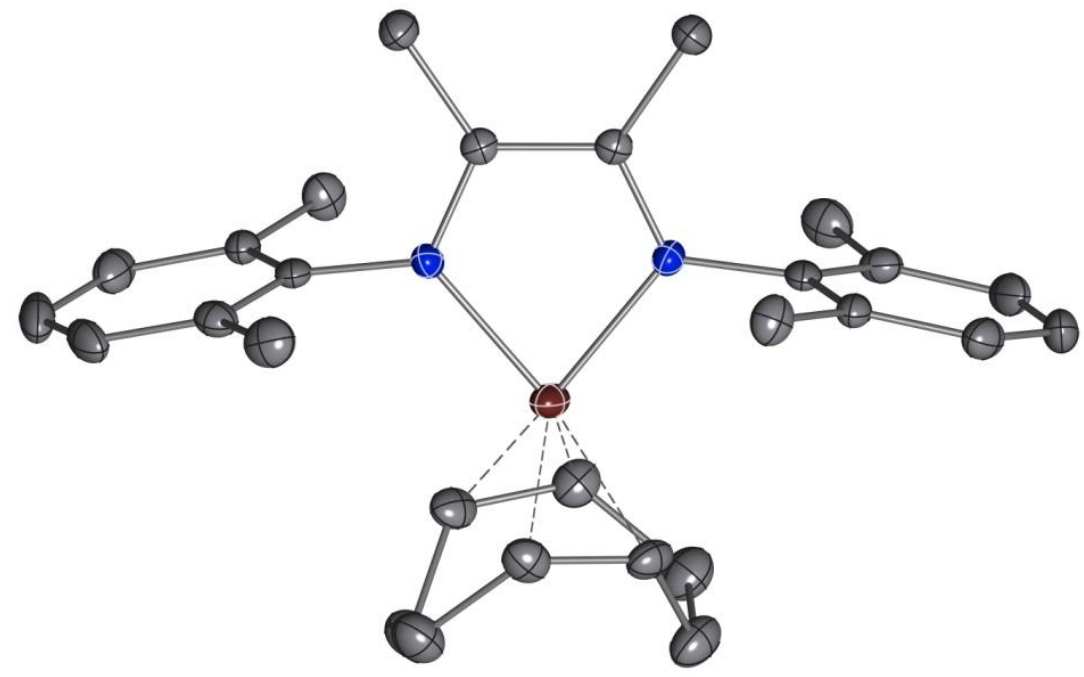

Figure S18. X-ray structure of 2. Thermal ellipsoids are drawn at the $50 \%$ probability level, $\mathrm{H}$ atoms are omitted for clarity

Table S3. Crystal data and structure refinement for 2 .

\begin{tabular}{|c|c|}
\hline & Complex_2_isomer \\
\hline \multicolumn{2}{|l|}{ Crystal data } \\
\hline Chemical formula & $\mathrm{C}_{28} \mathrm{H}_{36} \mathrm{FeN}_{2}$ \\
\hline$M_{\mathrm{r}}$ & 456.46 \\
\hline $\begin{array}{l}\text { Crystal system, } \\
\text { space group }\end{array}$ & Monoclinic, C2/c \\
\hline Temperature (K) & 100 \\
\hline
\end{tabular}




\begin{tabular}{|c|c|}
\hline$a, b, c(\AA)$ & $13.760(1), 13.7555(10), 12.8368(10)$ \\
\hline$\beta\left(^{\circ}\right)$ & $97.542(2)$ \\
\hline$V\left(\AA^{3}\right)$ & $2408.7(3)$ \\
\hline$Z$ & 4 \\
\hline Radiation type & Mo Ka \\
\hline$\mu\left(\mathrm{mm}^{-1}\right)$ & 0.64 \\
\hline Crystal size $(\mathrm{mm})$ & $0.6 \times 0.33 \times 0.22$ \\
\hline \multicolumn{2}{|l|}{ Data collection } \\
\hline Diffractometer & $\begin{array}{l}\text { Bruker APEX-II CCD } \\
\text { diffractometer }\end{array}$ \\
\hline Absorption correction & $\begin{array}{l}\text { Multi-scan } \\
\text { SADABS (Sheldrick, 2009) }\end{array}$ \\
\hline$T_{\min }, T_{\max }$ & $0.772,0.965$ \\
\hline $\begin{array}{l}\text { No. of measured, } \\
\text { independent and } \\
\text { observed }[I>2 \sigma(I)] \\
\text { reflections }\end{array}$ & $10107,2324,1601$ \\
\hline$R_{\text {int }}$ & 0.058 \\
\hline$(\sin \theta / \lambda)_{\max }\left(\AA^{-1}\right)$ & 0.613 \\
\hline \multicolumn{2}{|l|}{ Refinement } \\
\hline $\begin{array}{l}R\left[F^{2}>2 \sigma\left(F^{2}\right)\right] \\
w R\left(F^{2}\right), S\end{array}$ & $0.034,0.070,0.82$ \\
\hline No. of reflections & 2324 \\
\hline No. of parameters & 143 \\
\hline $\mathrm{H}$-atom treatment & $\begin{array}{l}\mathrm{H} \text { atoms treated by a mixture of independent and constrained } \\
\text { refinement }\end{array}$ \\
\hline$\Delta \rho_{\max }, \Delta \rho_{\min }\left(\mathrm{e} \AA^{-3}\right)$ & $0.58,-0.45$ \\
\hline
\end{tabular}


Crystal structure analysis of 2 reveals that the COD ligand to 2 rotates and produces two subtly distinct isomers with different space groups.

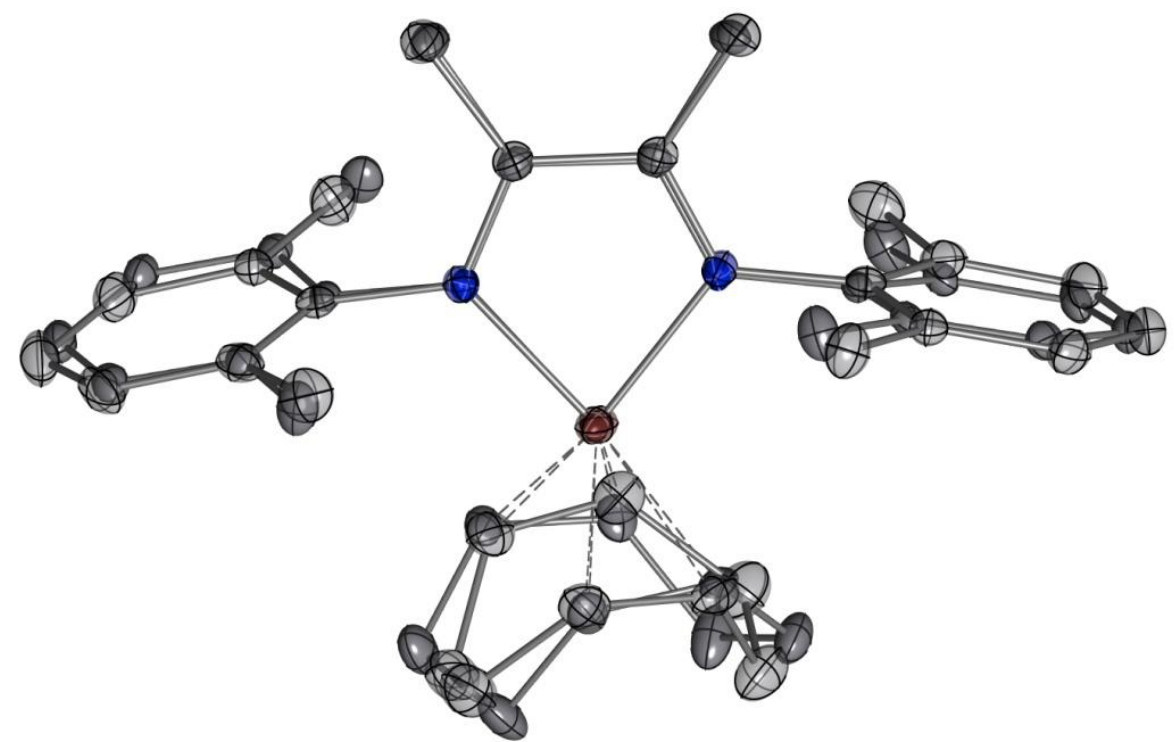

Figure S19. Overlay of two X-ray structures of 2 (Complex_2.cif and Complex_2_isomer.cif). Thermal ellipsoids are drawn at the $50 \%$ probability level.

[(Bis(2,6-dimethylaniline)-butane-2,3-diimine)( $\eta^{6}$-toluene)] iron (3) (CCDC 1414019)

Refinement Special Details: The restrains on bond lengths and constraints of the atomic displacement parameters on each pair of disorder fragments (SADI nd EADP instructions of SHELXL97), as well as the restrains of the atomic displacement parameters (SIMU/DELU instructions of SHELXL97) have been applied for the disorder refinement.

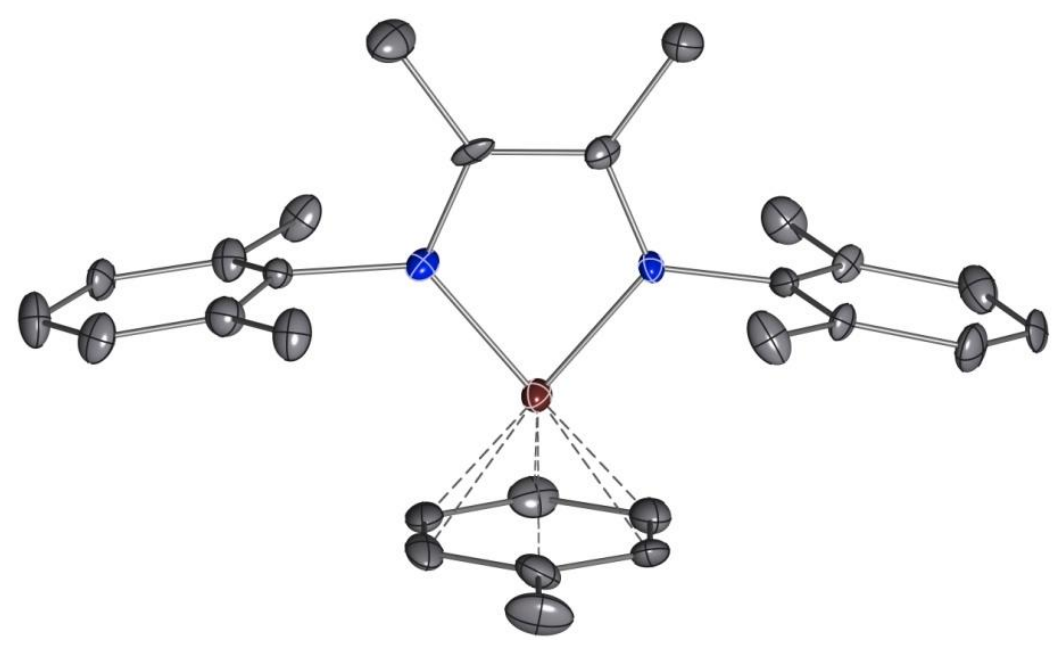

Figure S20. X-ray structure of 3. Thermal ellipsoids are drawn at the $50 \%$ probability level, $\mathrm{H}$ atoms are omitted for clarity

Table S4. Crystal data and structure refinement for 3 


\begin{tabular}{|c|c|}
\hline & Complex_3 \\
\hline \multicolumn{2}{|l|}{ Crystal data } \\
\hline Chemical formula & $\mathrm{C}_{54} \mathrm{H}_{64} \mathrm{Fe}_{2} \mathrm{~N}_{4}$ \\
\hline$M_{\mathrm{r}}$ & 880.79 \\
\hline $\begin{array}{l}\text { Crystal system, } \\
\text { space group }\end{array}$ & Triclinic, $P 1$ \\
\hline Temperature $(\mathrm{K})$ & 100 \\
\hline$a, b, c(\AA)$ & $8.191(5), 9.559(7), 15.583(12)$ \\
\hline$\beta\left(^{\circ}\right)$ & 97.767 (13), 99.295 (16), $105.53(2)$ \\
\hline$V\left(\AA^{3}\right)$ & $1139.4(14)$ \\
\hline$Z$ & 1 \\
\hline Radiation type & Mo Ka \\
\hline$\mu\left(\mathrm{mm}^{-1}\right)$ & 0.68 \\
\hline Crystal size (mm) & $0.36 \times 0.18 \times 0.05$ \\
\hline \multicolumn{2}{|l|}{ Data collection } \\
\hline Diffractometer & $\begin{array}{l}\text { Bruker D8 goniometer with CCD area detector } \\
\text { diffractometer }\end{array}$ \\
\hline Absorption correction & $\begin{array}{l}\text { Multi-scan } \\
\text { SADABS (Sheldrick, 2008) }\end{array}$ \\
\hline$T_{\min }, T_{\max }$ & $0.793,0.967$ \\
\hline $\begin{array}{l}\text { No. of measured, } \\
\text { independent and } \\
\text { observed }[I>2 \sigma(I)] \\
\text { reflections }\end{array}$ & $9802,7642,5750$ \\
\hline$R_{\text {int }}$ & 0.047 \\
\hline$(\sin \theta / \lambda)_{\max }\left(\AA^{-1}\right)$ & 0.611 \\
\hline \multicolumn{2}{|l|}{ Refinement } \\
\hline $\begin{array}{l}R\left[F^{2}>2 \sigma\left(F^{2}\right)\right] \\
w R\left(F^{2}\right), S\end{array}$ & $0.076,0.193,0.99$ \\
\hline No. of reflections & 7642 \\
\hline No. of parameters & 507 \\
\hline No. of restraints & 153 \\
\hline $\mathrm{H}$-atom treatment & $\begin{array}{l}\mathrm{H} \text { atoms treated by a mixture of independent and constrained } \\
\text { refinement }\end{array}$ \\
\hline$\Delta \rho_{\max }, \Delta \rho_{\min }\left(\mathrm{e} \AA^{-3}\right)$ & $3.04,-0.90$ \\
\hline Absolute structure & Flack H D (1983), Acta Cryst. A39, 876-881 \\
\hline $\begin{array}{l}\text { Absolute structure } \\
\text { parameter }\end{array}$ & $0.02(3)$ \\
\hline
\end{tabular}


Di[bis(2,6-dimethylaniline)-butane-2,3-diimine iron(I)] (4) (CCDC 899256)

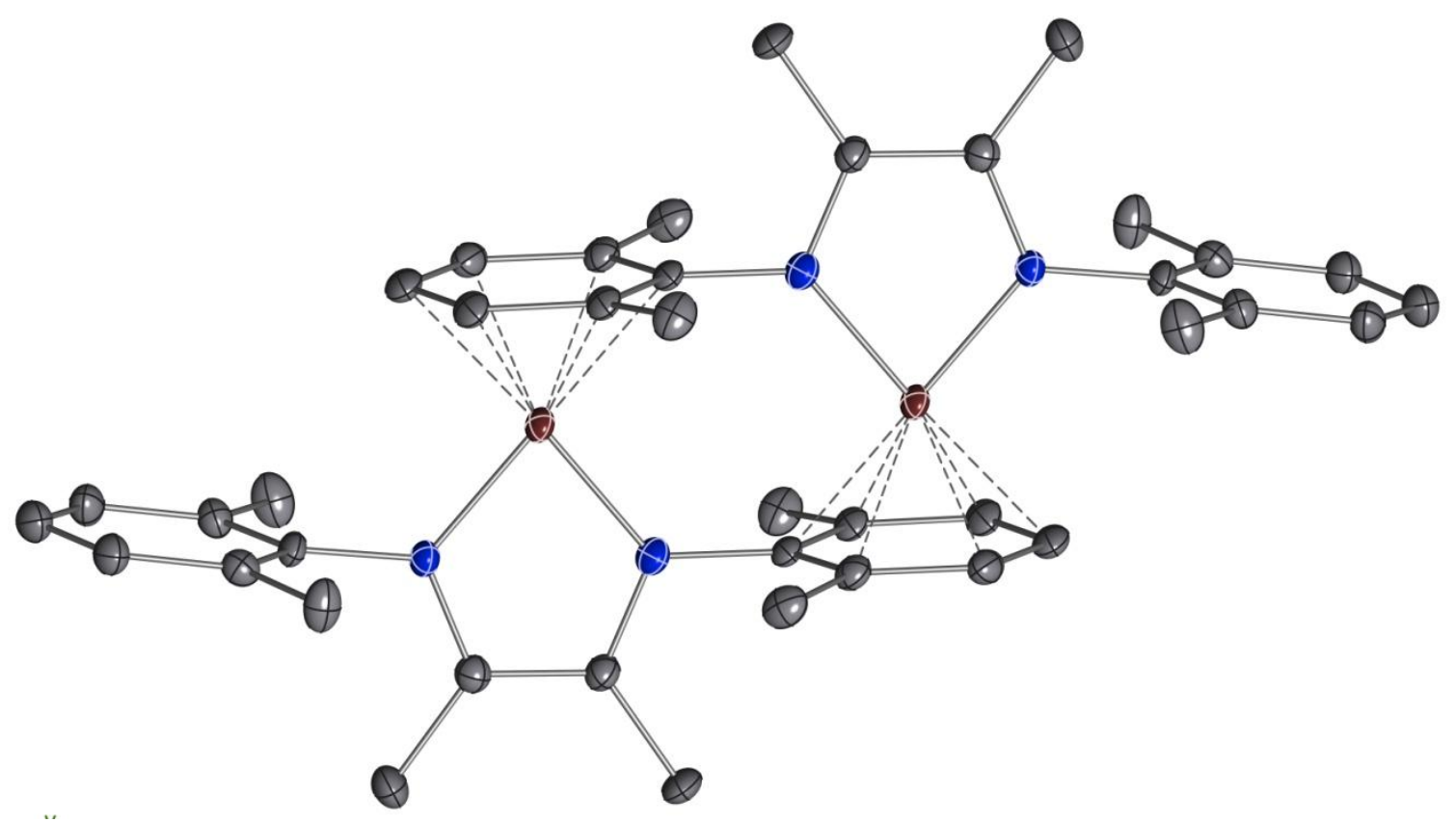

Figure S21. X-ray structure of 4 . Thermal ellipsoids are drawn at the $50 \%$ probability level, $\mathrm{H}$ atoms are omitted for clarity.

Table S5. Crystal data and structure refinement for 4.

\begin{tabular}{|c|c|}
\hline & Complex_4 \\
\hline \multicolumn{2}{|l|}{ Crystal data } \\
\hline Chemical formula & $\mathrm{C}_{20} \mathrm{H}_{24} \mathrm{FeN}_{2}$ \\
\hline$M_{\mathrm{r}}$ & 348.26 \\
\hline $\begin{array}{l}\text { Crystal system, } \\
\text { space group }\end{array}$ & Monoclinic, $P 2_{1} / c$ \\
\hline Temperature $(\mathrm{K})$ & 100 \\
\hline$a, b, c(\AA)$ & $9.6456(12), 21.538(3), 8.3416(10)$ \\
\hline$\beta\left(^{\circ}\right)$ & $106.233(2)$ \\
\hline$V\left(\AA^{3}\right)$ & $1663.8(4)$ \\
\hline$Z$ & 4 \\
\hline Radiation type & Mo $K$ \\
\hline$\mu\left(\mathrm{mm}^{-1}\right)$ & 0.91 \\
\hline Crystal size (mm) & $0.33 \times 0.21 \times 0.10$ \\
\hline \multicolumn{2}{|l|}{ Data collection } \\
\hline Diffractometer & $\begin{array}{l}\text { Bruker D8 goniometer with CCD area detector } \\
\text { diffractometer }\end{array}$ \\
\hline
\end{tabular}




\begin{tabular}{|l|l|}
\hline Absorption correction & $\begin{array}{l}\text { Multi-scan } \\
\text { SADABS (Sheldrick, 2008) }\end{array}$ \\
\hline$T_{\min }, T_{\max }$ & $0.757,0.916$ \\
\hline $\begin{array}{l}\text { No. of measured, } \\
\text { independent and } \\
\text { observed }[I>2 \sigma(I)] \\
\text { reflections }\end{array}$ & $24898,3195,2505$ \\
\hline$R_{\text {int }}$ & 0.074 \\
\hline$(\sin \theta / \lambda)_{\max }\left(\AA^{-1}\right)$ & 0.612 \\
\hline & \\
\hline Refinement & $0.036,0.089,1.03$ \\
\hline $\begin{array}{l}R\left[F^{2}>2 \sigma\left(F^{2}\right)\right], \\
w R\left(F^{2}\right), S\end{array}$ & 3195 \\
\hline No. of reflections & 214 \\
\hline No. of parameters & $\begin{array}{l}\mathrm{H} \text { atoms treated by a mixture of independent and constrained } \\
\text { refinement }\end{array}$ \\
\hline $\mathrm{H}$-atom treatment \\
\hline$\Delta \rho_{\text {max }}, \Delta \rho_{\text {min }}\left(\mathrm{e} \AA^{-3}\right)$ & $0.32,-0.40$ \\
\hline
\end{tabular}

\section{Di[bis(2,6-dimethylaniline)-butane-2,3-diimine] iron (5) (CCDC 894093)}

Refinement Special Details: The crystal was a merohedral twin, but satisfactory refinement was achieved by applying the twin law that was found by using Platon/TwinRotMat (Spek, 2003).

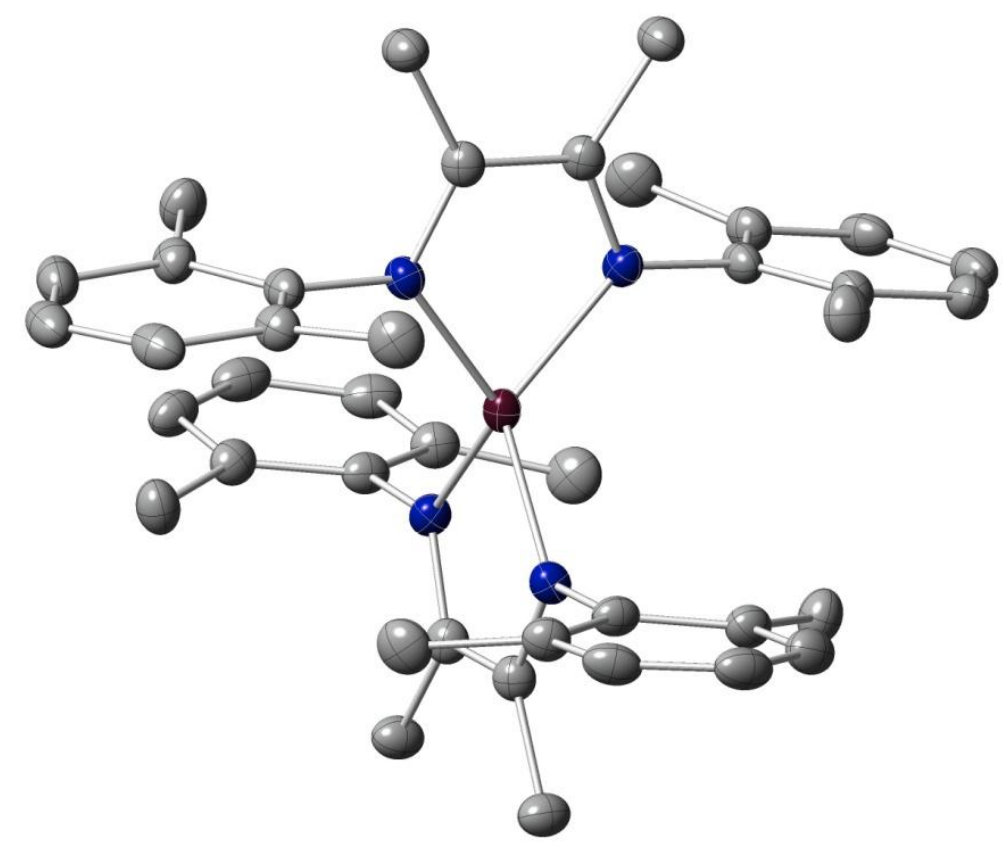

Figure S22. X-ray structure of $\mathbf{5}$. Thermal ellipsoids are drawn at the $50 \%$ probability level, $\mathrm{H}$ atoms are omitted for clarity. 
Table S6. Crystal data and structure refinement for $\mathbf{5}$.

\begin{tabular}{|c|c|}
\hline & Complex_5 \\
\hline \multicolumn{2}{|l|}{ Crystal data } \\
\hline Chemical formula & $\mathrm{C}_{40} \mathrm{H}_{48} \mathrm{FeN}_{4}$ \\
\hline$M_{\mathrm{r}}$ & 640.67 \\
\hline $\begin{array}{l}\text { Crystal system, } \\
\text { space group }\end{array}$ & Orthorhombic, Fddd \\
\hline Temperature $(\mathrm{K})$ & 100 \\
\hline$a, b, c(\AA)$ & 11.364 (6), 24.534 (13), $24.644(13)$ \\
\hline$V\left(\AA^{3}\right)$ & $6871(6)$ \\
\hline$z$ & 8 \\
\hline Radiation type & Mo $K$ \\
\hline$\mu\left(\mathrm{mm}^{-1}\right)$ & 0.47 \\
\hline Crystal size $(\mathrm{mm})$ & $0.4 \times 0.15 \times 0.15$ \\
\hline \multicolumn{2}{|l|}{ Data collection } \\
\hline Diffractometer & $\begin{array}{l}\text { Bruker D8 goniometer with CCD area detector } \\
\text { diffractometer }\end{array}$ \\
\hline Absorption correction & $\begin{array}{l}\text { Multi-scan } \\
\text { SADABS (Sheldrick, 2008) }\end{array}$ \\
\hline$T_{\min }, T_{\max }$ & $0.835,0.933$ \\
\hline $\begin{array}{l}\text { No. of measured, } \\
\text { independent and } \\
\text { observed }[I>2 \sigma(I)] \\
\text { reflections }\end{array}$ & $17818,1652,1462$ \\
\hline$R_{\text {int }}$ & 0.091 \\
\hline$(\sin \theta / \lambda)_{\max }\left(\AA^{-1}\right)$ & 0.611 \\
\hline \multicolumn{2}{|l|}{ Refinement } \\
\hline $\begin{array}{l}R\left[F^{2}>2 \sigma\left(F^{2}\right)\right] \\
w R\left(F^{2}\right), S\end{array}$ & $0.041,0.102,1.05$ \\
\hline No. of reflections & 1652 \\
\hline No. of parameters & 107 \\
\hline $\mathrm{H}$-atom treatment & $\mathrm{H}$-atom parameters constrained \\
\hline$\Delta \rho_{\max }, \Delta \rho_{\min }\left(\mathrm{e} \AA^{-3}\right)$ & $0.24,-0.68$ \\
\hline
\end{tabular}




\section{Computational details}

Density functional theory (DFT) calculations were performed using the ORCA 3.0.3 program package ${ }^{11}$ at the computer cluster at the Max-Planck Institut für Kohlenforschung. Geometry optimizations were carried out at the B3LYP ${ }^{12,13} /$ def2-SVP ${ }^{14,15}$ level using the atomic coordinates of the crystal structures for complexes 2 and 3; for complex C, a staring geometry was generated using GaussView 5. Scalar relativistic corrections have been applied using ZORA. ${ }^{16,17,18}$ Ground state structures were confirmed by frequency calculations at the same level of theory. Single point calculations to determine molecular properties of complex $\mathbf{2}$, complex 2 isomer and $\mathbf{3}$ have been performed at the B3LYP/TZVP ${ }^{4,5}$ level using ZORA ${ }^{6}$. For the isomer of complex $\mathbf{2}$, the 1,5-COD ligand was rotated starting from the optimized structure of 2. The Broken Symmetry Approach (BS) was used in which the experimentally determined open-shell solutions were indicated as initial guess. ${ }^{19}$ Mössbauer Isomer Shifts were calculated from the electron density $\rho_{0}$ at Fe using the linear fit parameters described in the literature by Neese and co-workers. ${ }^{20}$ Time-Dependent DFT (TD-DFT) calculations of 2 were performed from the optimized structure using B3LYP/TZVP and ZORA employing the conductor-like screening model (COSMO) to simulate solvent effects ( $n$-hexane).$^{21}$ The UV/Vis absorption spectrum was generated using ORCA and plotted using Origin 2015G. Images of molecular structures and spin density plots were generated using Chemcraft 1.7 and GaussView 5.

\footnotetext{
${ }^{11}$ F. Neese: The ORCA program system (WIREs Comput Mol Sci 2012, 2, 73).

${ }^{12}$ A. D. Becke, Phys. Rev. A 1988, 38, 3098.

${ }^{13}$ C. T. Lee, W. T. Yang, R. G. Parr, Physical Review B 1988, 37, 785.

${ }^{14}$ A. Schäfer, H. Horn, R. Ahlrichs J. Chem. Phys. 1992, 97, 2571.

${ }^{15}$ A. Schäfer, C. Huber, R. Ahlrichs J. Chem. Phys. 1994, 100, 5829.

${ }^{16}$ D. A. Pantazis, X. Y. Chen, C. R. Landis and F. Neese J. Chem. Theory Comput.2008, 4, 908.

${ }^{17}$ E. van Lenthe; E. J. Baerends, J. B. Snijders J. Chem. Phys. 1993, 99, 4597.

${ }^{18}$ C. J. van Wüllen Chem. Phys. 1998, 109, 392.

${ }^{19}$ L. Noodleman J. Chem. Phys. 1981, 74, 5737.

${ }^{20}$ M. Römelt, S. Ye, F.Neese Inorg. Chem. 2009, 48, 784.

${ }^{21}$ A.Klamt, G. Schüürmann J. Chem. Soc., Perkin. Trans. 2, 1993, 799.
} 
DFT Results for Complex 2

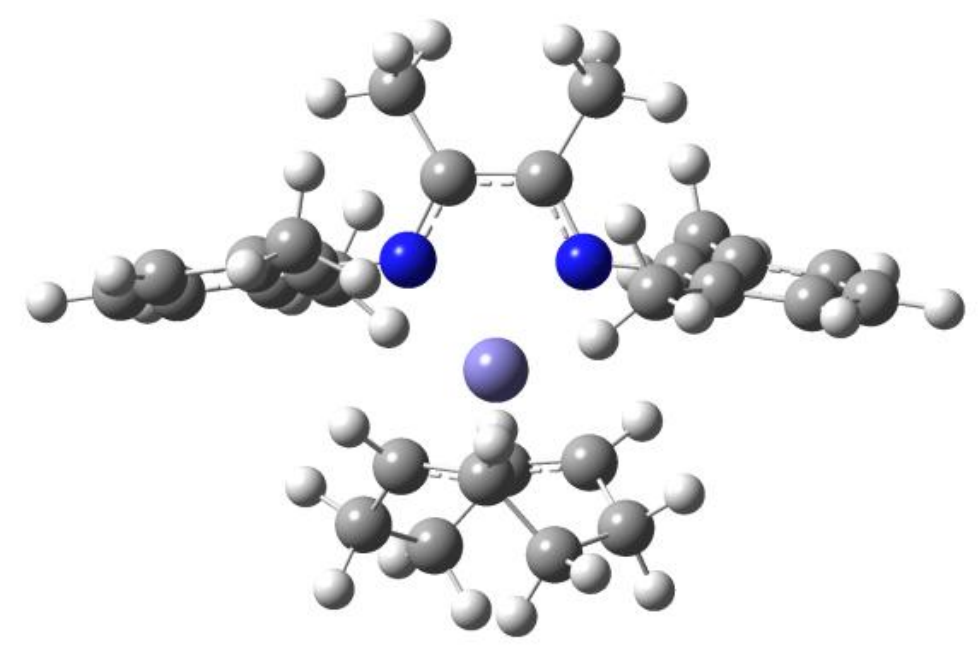

Figure S23. Optimized structure of complex 2 with B3LYP/def2-SVP.

Table S7. Cartesian coordinates $(\AA)$ of the optimized structure of complex 2 with B3LYP/def2-SVP.

\begin{tabular}{|c|c|c|c|}
\hline Atom & $x$ & $Y$ & Z \\
\hline $\mathrm{Fe}$ & 2.081369 & 18.255158 & 4.933513 \\
\hline $\mathrm{N}$ & 1.829173 & 20.141304 & 4.127189 \\
\hline $\mathrm{N}$ & 3.618644 & 19.281209 & 5.856569 \\
\hline C & 4.398008 & 18.473719 & 8.035713 \\
\hline C & 4.626651 & 18.675012 & 6.651506 \\
\hline C & 0.712007 & 20.542301 & 3.347955 \\
\hline C & 5.836034 & 18.233120 & 6.057383 \\
\hline C & 3.711062 & 20.572747 & 5.483117 \\
\hline C & 0.721395 & 20.329471 & 1.946631 \\
\hline C & 2.721214 & 21.046626 & 4.575282 \\
\hline C & 0.026522 & 17.656611 & 5.033116 \\
\hline C & 3.015907 & 16.339830 & 4.719309 \\
\hline C & 6.549905 & 17.341955 & 8.212871 \\
\hline C & 0.686404 & 17.169133 & 6.171421 \\
\hline
\end{tabular}




\begin{tabular}{|c|c|c|c|}
\hline C & 5.367650 & 17.803964 & 8.795290 \\
\hline C & -0.419873 & 20.657154 & 1.200746 \\
\hline C & -1.548683 & 21.419516 & 3.190378 \\
\hline C & 2.255244 & 16.598111 & 3.567893 \\
\hline C & -0.426339 & 21.111248 & 3.974273 \\
\hline C & 6.777309 & 17.563270 & 6.853856 \\
\hline C & 3.144661 & 19.003655 & 8.689187 \\
\hline$C$ & -0.436050 & 21.412496 & 5.455374 \\
\hline C & -1.555229 & 21.192271 & 1.813481 \\
\hline C & 1.955244 & 19.792810 & 1.261541 \\
\hline C & -0.286994 & 16.870690 & 3.771424 \\
\hline C & 6.131681 & 18.496423 & 4.598812 \\
\hline$C$ & 4.791524 & 21.498225 & 5.991489 \\
\hline C & 1.139431 & 15.724717 & 6.363472 \\
\hline C & 2.704121 & 22.497118 & 4.151100 \\
\hline C & 2.595961 & 15.479784 & 5.899640 \\
\hline C & 0.885990 & 15.991044 & 3.274427 \\
\hline $\mathrm{H}$ & -0.569077 & 18.561567 & 5.157719 \\
\hline $\mathrm{H}$ & 4.091213 & 16.509316 & 4.648926 \\
\hline $\mathrm{H}$ & 7.291557 & 16.818340 & 8.815645 \\
\hline $\mathrm{H}$ & 0.561929 & 17.754180 & 7.085939 \\
\hline $\mathrm{H}$ & 5.189564 & 17.647234 & 9.859800 \\
\hline $\mathrm{H}$ & -0.411687 & 20.491113 & 0.122681 \\
\hline $\mathrm{H}$ & -2.428826 & 21.846271 & 3.673324 \\
\hline $\mathrm{H}$ & 2.809889 & 16.961563 & 2.699335 \\
\hline $\mathrm{H}$ & 7.703187 & 17.213381 & 6.395495 \\
\hline $\mathrm{H}$ & 3.114530 & 20.102360 & 8.666388 \\
\hline $\mathrm{H}$ & 3.082624 & 18.686908 & 9.736787 \\
\hline
\end{tabular}




\begin{tabular}{|c|c|c|c|}
\hline $\mathrm{H}$ & 2.245732 & 18.658213 & 8.166835 \\
\hline $\mathrm{H}$ & 0.084090 & 20.640284 & 6.033632 \\
\hline $\mathrm{H}$ & -1.462036 & 21.498635 & 5.832221 \\
\hline $\mathrm{H}$ & 0.071368 & 22.364085 & 5.675158 \\
\hline $\mathrm{H}$ & -2.436676 & 21.435668 & 1.220814 \\
\hline $\mathrm{H}$ & 2.797369 & 20.494239 & 1.348212 \\
\hline $\mathrm{H}$ & 1.769080 & 19.618713 & 0.195333 \\
\hline $\mathrm{H}$ & 2.287434 & 18.853035 & 1.715924 \\
\hline $\mathrm{H}$ & -0.541700 & 17.599200 & 2.990318 \\
\hline $\mathrm{H}$ & -1.191805 & 16.252548 & 3.913117 \\
\hline $\mathrm{H}$ & 5.244480 & 18.357350 & 3.970404 \\
\hline $\mathrm{H}$ & 6.925107 & 17.833988 & 4.233181 \\
\hline $\mathrm{H}$ & 6.469190 & 19.531178 & 4.438533 \\
\hline $\mathrm{H}$ & 5.393541 & 21.015481 & 6.766819 \\
\hline $\mathrm{H}$ & 4.362670 & 22.414538 & 6.419798 \\
\hline $\mathrm{H}$ & 5.473121 & 21.816012 & 5.187635 \\
\hline $\mathrm{H}$ & 0.451400 & 15.052168 & 5.835537 \\
\hline $\mathrm{H}$ & 1.053064 & 15.457987 & 7.425654 \\
\hline $\mathrm{H}$ & 1.967685 & 22.672129 & 3.360946 \\
\hline $\mathrm{H}$ & 3.687052 & 22.810212 & 3.772619 \\
\hline $\mathrm{H}$ & 2.462086 & 23.169620 & 4.988200 \\
\hline $\mathrm{H}$ & 3.277933 & 15.708871 & 6.729634 \\
\hline $\mathrm{H}$ & 2.746650 & 14.408544 & 5.673930 \\
\hline $\mathrm{H}$ & 0.827485 & 14.989056 & 3.717403 \\
\hline $\mathrm{H}$ & 0.784336 & 15.839019 & 2.191269 \\
\hline
\end{tabular}




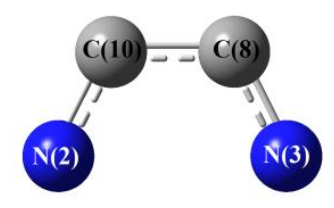

$\mathrm{Fe}(1)$

Figure S24. Fragments of complex 2 that predominately bear spin density. All other atoms are omitted for clarity.

Table S8. Comparison of selected experimentally determined and calculated bond lengths of complex 2 .

\begin{tabular}{l|l|l} 
Bond & Length / Å (Exp) & Length / Å (calcd) \\
\hline $\mathrm{Fe}(1)-\mathrm{N}(2)$ & 1.997 & 2.067 \\
$\mathrm{Fe}(1)-\mathrm{N}(3)$ & 1.988 & 2.066 \\
$\mathrm{~N}(2)-\mathrm{C}(10)$ & 1.348 & 1.348 \\
$\mathrm{C}(10)-\mathrm{C}(8)$ & 1.346 & 1.424 \\
$\mathrm{~N}(3)-\mathrm{C}(8)$ & 1.346 & 1.348
\end{tabular}

Table S9. Mulliken Charges and Spin Densities on Fe and the diimine ligand of complex 2.

\begin{tabular}{l|l|l} 
Fragment & Charge & Spin \\
\hline $\mathrm{Fe}$ & 0.496664 & 3.19835 \\
Diimine & -0.425625 & -0.853613
\end{tabular}

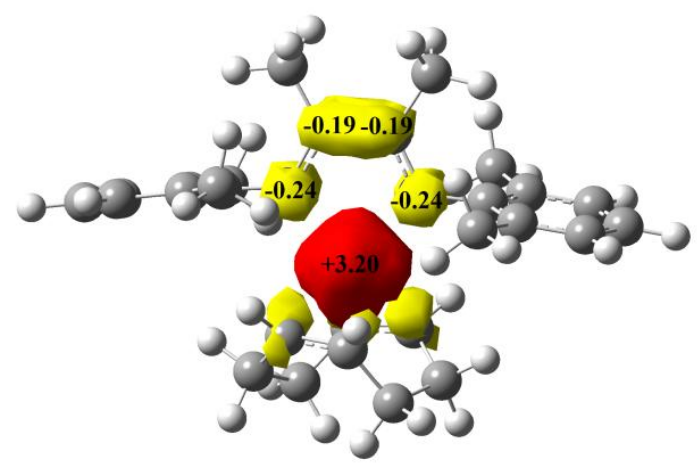

Figure S25. Spin density plot of complex 2 using B3LYP/TZVP. 
Table S10. Comparison of experimental and calculated Mössbauer parameters of complex 2.

\begin{tabular}{l|l|l} 
Parameter & Exp & Calcd. \\
\hline$\delta\left(\mathrm{mm} \cdot \mathrm{s}^{-1}\right)$ & 0.47 & 0.39 \\
$\left|\Delta E_{\mathrm{Q}}\right|\left(\mathrm{mm} \cdot \mathrm{s}^{-1}\right)$ & 1.37 & 1.49 \\
$\eta$ & - & 0.16
\end{tabular}

TD-DFT Results for Complex 2

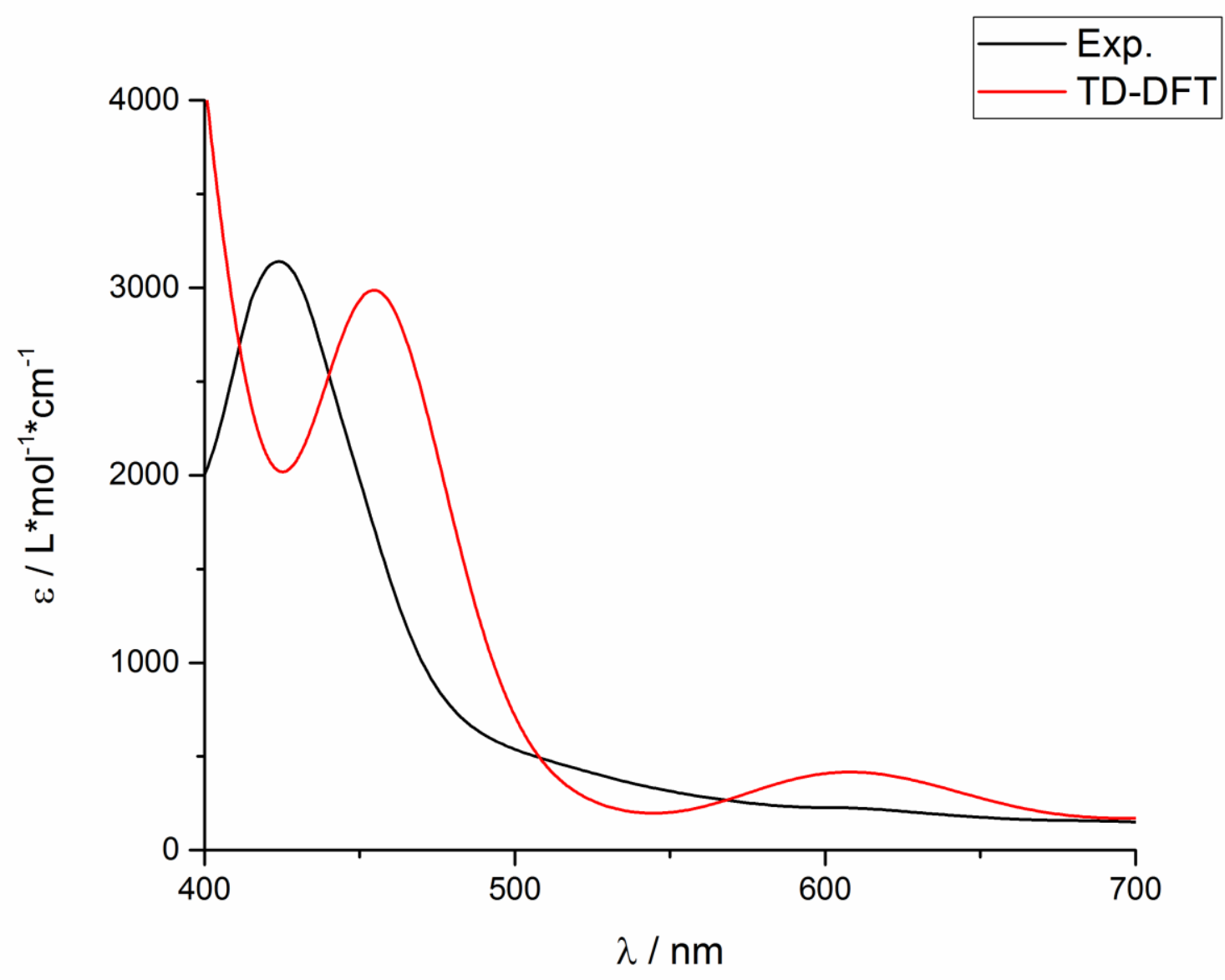

Figure S26. Experimentally determined (black) and calculated (red) UV/Vis spectra of complex 2.

Table S11. TD-DFT data for complex 2. The most intense transitions in the visible region are highlighted.

\begin{tabular}{l|l|l|l} 
Excited State & $\mathbf{E} / \mathbf{e V}$ & $\boldsymbol{\lambda} / \mathbf{n m}$ & $\begin{array}{l}\text { Oscillator } \\
\text { Strength } \mathbf{f}\end{array}$ \\
\hline 1 & 0.9373 & 1322.9 & 0.0005
\end{tabular}




\begin{tabular}{|c|c|c|c|}
\hline 2 & 1.0256 & 1208.9 & 0.0001 \\
\hline 3 & 1.2797 & 968.8 & 0.0000 \\
\hline 4 & 1.5895 & 780 & 0.0026 \\
\hline 5 & 1.8653 & 664.7 & 0.0005 \\
\hline 6 & 2.0435 & 606.7 & 0.0039 \\
\hline 7 & 2.0722 & 598.3 & 0.0007 \\
\hline 8 & 2.4573 & 504.6 & 0.0011 \\
\hline 9 & 2.5191 & 492.2 & 0.0019 \\
\hline 10 & 2.7302 & 454.1 & 0.0309 \\
\hline 11 & 3.0660 & 404.4 & 0.0104 \\
\hline 12 & 3.2066 & 386.7 & 0.0066 \\
\hline 13 & 3.2374 & 383 & 0.0220 \\
\hline 14 & 3.2961 & 376.2 & 0.0019 \\
\hline 15 & 3.3079 & 374.8 & 0.0164 \\
\hline 16 & 3.3286 & 372.5 & 0.0095 \\
\hline 17 & 3.3408 & 371.1 & 0.0424 \\
\hline 18 & 3.4543 & 358.9 & 0.0113 \\
\hline 19 & 3.5117 & 353.1 & 0.0502 \\
\hline 20 & 3.6131 & 343.2 & 0.0094 \\
\hline
\end{tabular}


DFT Results for Complex 3

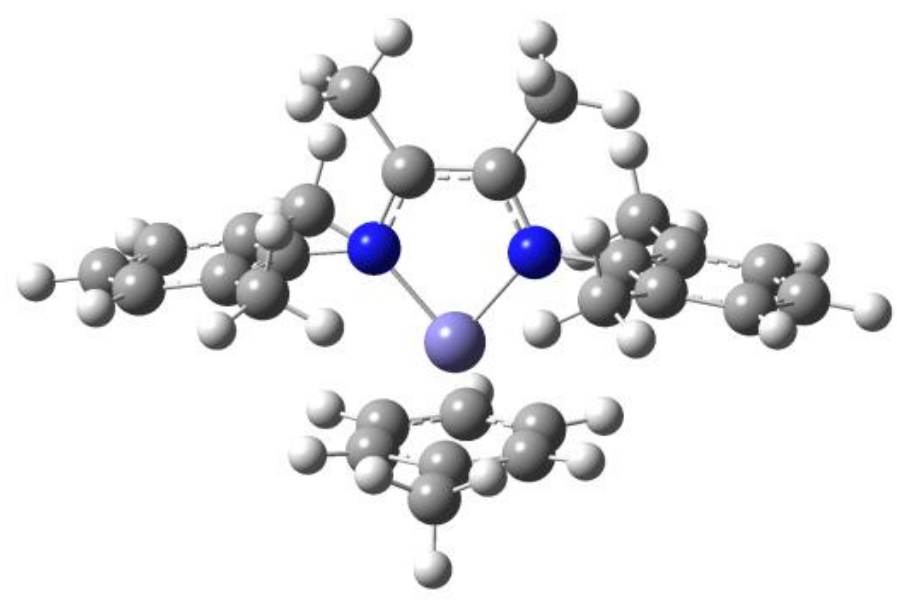

Figure S27. Optimized structure of complex 3 with B3LYP/def2-SVP.

Table S12. Cartesian coordinates $(\AA)$ of the optimized structure of complex 3 with B3LYP/def2-SVP.

$\begin{array}{llll}\text { Atom } & \mathbf{X} & \mathbf{Y} & \mathbf{Z} \\ \text { C } & 1.268260 & 4.886999 & 0.375906 \\ \text { C } & 0.846831 & 4.767213 & 1.817806 \\ \text { C } & 0.368782 & 3.573157 & 2.398911 \\ \text { C } & 0.231470 & 2.278719 & 1.632713 \\ \text { C } & 3.736816 & 6.406435 & 2.797458 \\ \text { C } & 2.728096 & 7.412961 & 2.296931 \\ \text { C } & 3.142349 & 8.689741 & 1.887770 \\ \text { C } & 2.227658 & 9.622301 & 1.396024 \\ \text { C } & 0.877416 & 9.279539 & 1.303288 \\ \text { C } & 0.420819 & 8.014097 & 1.701483 \\ \text { C } & 1.354803 & 7.079243 & 2.211866 \\ \text { C } & -1.039442 & 7.652559 & 1.567635 \\ \text { C } & 1.934722 & 1.885598 & 4.976042 \\ \text { C } & 0.441274 & 1.716648 & 5.117534 \\ \text { C } & -0.085495 & 0.672582 & 5.892868\end{array}$




\begin{tabular}{|c|c|c|c|}
\hline $\mathrm{C}$ & -1.463394 & 0.472374 & 5.992575 \\
\hline $\mathrm{C}$ & -2.333915 & 1.316854 & 5.301099 \\
\hline $\mathrm{C}$ & -1.848846 & 2.373739 & 4.516433 \\
\hline $\mathrm{C}$ & -0.450198 & 2.583045 & 4.440596 \\
\hline$C$ & -2.801621 & 3.249001 & 3.737694 \\
\hline$C$ & 1.209271 & 7.045678 & 5.552505 \\
\hline$C$ & -0.104966 & 7.404530 & 5.156357 \\
\hline C & -1.203688 & 6.562655 & 5.456333 \\
\hline $\mathrm{C}$ & -0.961475 & 5.356898 & 6.159163 \\
\hline$C$ & 0.354473 & 5.003169 & 6.553100 \\
\hline$C$ & 1.466704 & 5.839409 & 6.260296 \\
\hline$C$ & 2.854920 & 5.489265 & 6.733723 \\
\hline$N$ & 0.903631 & 5.811145 & 2.676423 \\
\hline $\mathrm{N}$ & 0.058912 & 3.693156 & 3.711159 \\
\hline $\mathrm{Fe}$ & 0.322644 & 5.446239 & 4.478414 \\
\hline $\mathrm{H}$ & 2.319069 & 5.195444 & 0.285019 \\
\hline $\mathrm{H}$ & 0.676043 & 5.641017 & -0.161237 \\
\hline $\mathrm{H}$ & 1.156943 & 3.936416 & -0.153597 \\
\hline $\mathrm{H}$ & -0.341994 & 2.414692 & 0.706388 \\
\hline $\mathrm{H}$ & -0.281147 & 1.518674 & 2.230189 \\
\hline $\mathrm{H}$ & 1.211395 & 1.868423 & 1.346545 \\
\hline $\mathrm{H}$ & 3.985921 & 5.668510 & 2.021298 \\
\hline $\mathrm{H}$ & 3.342186 & 5.840935 & 3.648270 \\
\hline $\mathrm{H}$ & 4.670583 & 6.897896 & 3.094414 \\
\hline $\mathrm{H}$ & 4.198942 & 8.951061 & 1.958690 \\
\hline $\mathrm{H}$ & 2.565067 & 10.610901 & 1.086699 \\
\hline $\mathrm{H}$ & 0.159281 & 10.003028 & 0.916222 \\
\hline $\mathrm{H}$ & -1.652686 & 8.545926 & 1.402494 \\
\hline
\end{tabular}




$\begin{array}{llll}\mathrm{H} & -1.404164 & 7.129756 & 2.458617 \\ \mathrm{H} & -1.207552 & 6.973017 & 0.719401 \\ \mathrm{H} & 2.471272 & 1.351850 & 5.769348 \\ \mathrm{H} & 2.221724 & 2.942891 & 4.996691 \\ \mathrm{H} & 2.288879 & 1.484709 & 4.014596 \\ \mathrm{H} & 0.598979 & 0.006731 & 6.419867 \\ \mathrm{H} & -1.857269 & -0.341726 & 6.600688 \\ \mathrm{H} & -3.411045 & 1.155903 & 5.365195 \\ \mathrm{H} & -3.831321 & 3.125457 & 4.093756 \\ \mathrm{H} & -2.788669 & 2.995168 & 2.667292 \\ \mathrm{H} & -2.522689 & 4.306520 & 3.808608 \\ \mathrm{H} & 2.041708 & 7.675112 & 5.243022 \\ \mathrm{H} & -0.248744 & 8.294421 & 4.548249 \\ \mathrm{H} & -2.208030 & 6.821241 & 5.127259 \\ \mathrm{H} & -1.772339 & 4.653412 & 6.332444 \\ \mathrm{H} & 0.520723 & 4.034786 & 7.020448 \\ \mathrm{H} & 3.623769 & 5.901335 & 6.069722 \\ \mathrm{H} & 2.998455 & 4.403898 & 6.794121 \\ \mathrm{H} & 3.032068 & 5.901885 & 7.738028\end{array}$

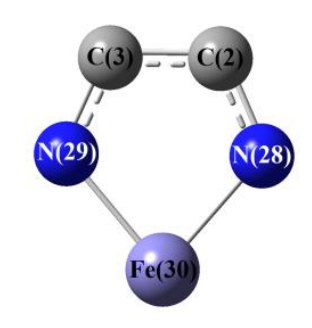

Figure S28. Fragments of complex $\mathbf{3}$ that predominately bear spin density. All other atoms are omitted for clarity. 
Table S13. Comparison of selected experimentally determined and calculated bond lengths of complex 3 .

\begin{tabular}{l|l|l} 
Bond & $\begin{array}{l}\text { Length / ̊ } \\
\text { (Exp) }\end{array}$ & $\begin{array}{l}\text { Length / ̊ } \\
\text { (calcd) }\end{array}$ \\
\hline $\mathrm{Fe}(30)-\mathrm{N}(29)$ & 1.886 & 1.932 \\
$\mathrm{Fe}(30)-\mathrm{N}(28)$ & 1.891 & 1.928 \\
$\mathrm{~N}(29)-\mathrm{C}(3)$ & 1.358 & 1.354 \\
$\mathrm{C}(3)-\mathrm{C}(2)$ & 1.398 & 1.411 \\
$\mathrm{~N}(28)-\mathrm{C}(2)$ & 1.369 & 1.353
\end{tabular}

Table S14. Mulliken Charges and Spin Densities on Fe and the diimine ligand of complex 3.

\begin{tabular}{l|l|l} 
Fragment & Charge & Spin \\
\hline Fe & 0.217115 & 0.972939 \\
Diimine & -0.259971 & -0.788385
\end{tabular}

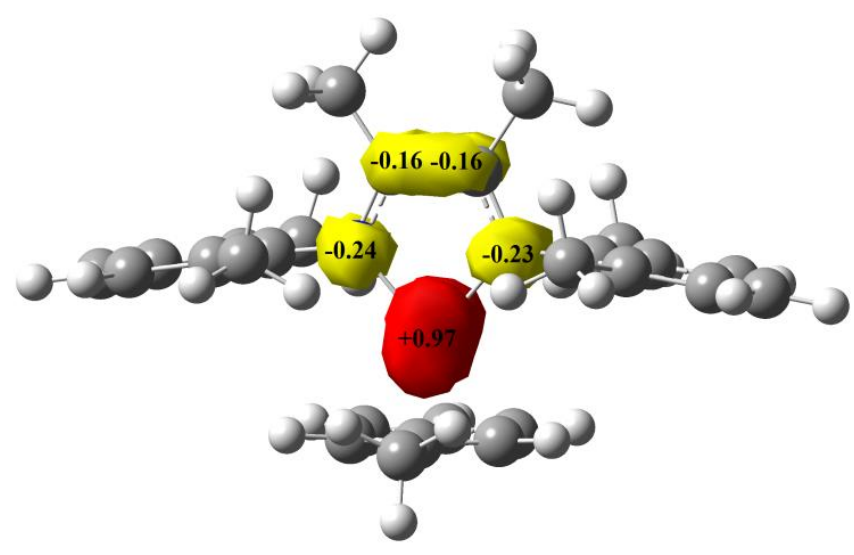

Figure S29. Spin density plot of complex $\mathbf{3}$ using B3LYP/TZVP.

Table S15. Comparison of experimental and calculated Mössbauer parameters of complex 3.

\begin{tabular}{l|l|l} 
Parameter & Exp & Calcd. \\
\hline$\delta\left(\mathrm{mm} \cdot \mathrm{s}^{-1}\right)$ & 0.44 & 0.40 \\
$\left|\Delta E_{\mathrm{Q}}\right|\left(\mathrm{mm} \cdot \mathrm{s}^{-1}\right)$ & 0.27 & 0.97 \\
$\eta$ & - & 0.82
\end{tabular}


DFT Results for Complex C

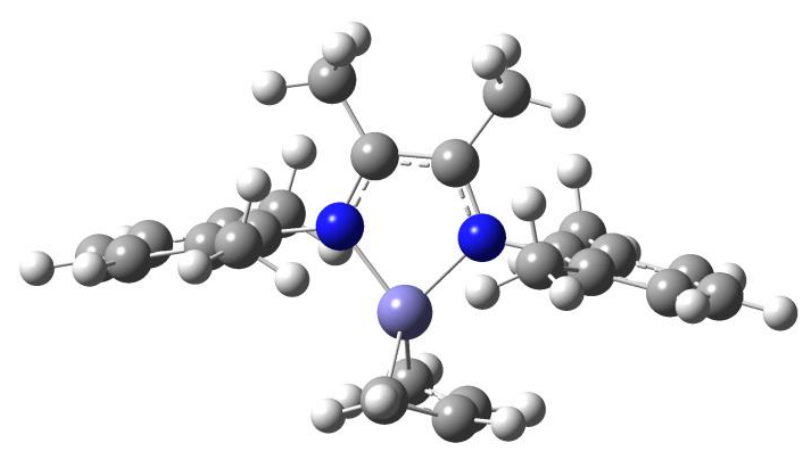

Figure S30. Optimized structure of complex $\mathbf{C}$ with B3LYP/def2-SVP.

Table S16. Cartesian coordinates $(\AA)$ of the optimized structure of complex $\mathbf{C}$ with B3LYP/def2-SVP.

\begin{tabular}{c|ccc} 
Atom & $\mathbf{X}$ & $\mathbf{Y}$ & $\mathbf{Z}$ \\
\hline Fe & -0.095969 & 0.897263 & 0.001634 \\
N & 1.164013 & -0.486051 & -0.001026 \\
N & -1.307410 & -0.498800 & -0.001379 \\
C & -3.399557 & -0.128766 & 1.231279 \\
C & -2.712887 & -0.264625 & -0.000490 \\
C & 2.574057 & -0.287907 & -0.000419 \\
C & -3.400057 & -0.122374 & -1.231272 \\
C & -0.774136 & -1.750961 & -0.004057 \\
C & 3.266939 & -0.177082 & -1.230313 \\
C & 0.626094 & -1.737031 & -0.003811 \\
C & -5.446280 & 0.358998 & 0.001677 \\
C & -4.765279 & 0.189233 & 1.207877 \\
C & 4.645220 & 0.082164 & -1.206147 \\
C & 4.644580 & 0.078805 & 1.207424 \\
C & 3.266272 & -0.180472 & 1.230128 \\
C & -4.765767 & 0.195484 & -1.205669 \\
C & -2.686956 & -0.352365 & 2.541817 \\
C & 2.545648 & -0.377063 & 2.541371 \\
C & 5.332279 & 0.217866 & 0.001016 \\
C & 2.547157 & -0.370575 & -2.542490 \\
C & -2.687950 & -0.339141 & -2.543234 \\
C & -1.591385 & -3.014655 & -0.006354 \\
C & 1.449418 & -2.998198 & -0.006315 \\
H & -6.508708 & 0.616300 & 0.002555 \\
H & -5.298208 & 0.304140 & 2.156125 \\
H & 5.183512 & 0.177101 & -2.153661 \\
& & &
\end{tabular}




\begin{tabular}{l|lll}
$\mathrm{H}$ & 5.182350 & 0.171161 & 2.155493 \\
$\mathrm{H}$ & -5.299081 & 0.315347 & -2.153082 \\
$\mathrm{H}$ & -2.465165 & -1.422802 & 2.696258 \\
$\mathrm{H}$ & -3.300248 & -0.013407 & 3.389900 \\
$\mathrm{H}$ & -1.720993 & 0.172335 & 2.564182 \\
$\mathrm{H}$ & 1.582335 & 0.151625 & 2.554340 \\
$\mathrm{H}$ & 3.157332 & -0.029129 & 3.387192 \\
$\mathrm{H}$ & 2.318765 & -1.444090 & 2.712710 \\
$\mathrm{H}$ & 6.404933 & 0.429092 & 0.001598 \\
$\mathrm{H}$ & 2.319629 & -1.437096 & -2.716026 \\
$\mathrm{H}$ & 3.159746 & -0.021450 & -3.387161 \\
$\mathrm{H}$ & 1.584208 & 0.158786 & -2.555270 \\
$\mathrm{H}$ & -1.722873 & 0.187289 & -2.564118 \\
$\mathrm{H}$ & -3.302406 & 0.002342 & -3.389453 \\
$\mathrm{H}$ & -2.464313 & -1.408501 & -2.702316 \\
$\mathrm{H}$ & -2.668410 & -2.795197 & -0.012523 \\
$\mathrm{H}$ & -1.382614 & -3.639266 & 0.880958 \\
$\mathrm{H}$ & -1.372768 & -3.642146 & -0.889120 \\
$\mathrm{H}$ & 1.233845 & -3.618640 & -0.894482 \\
$\mathrm{H}$ & 1.227193 & -3.626266 & 0.874739 \\
$\mathrm{H}$ & 2.526265 & -2.782308 & -0.001502 \\
$\mathrm{C}$ & -.992003 & 2.573607 & 0.712712 \\
$\mathrm{H}$ & 1.975295 & 2.543185 & 1.193312 \\
$\mathrm{C}$ & 0.991761 & 2.576872 & -0.702151 \\
$\mathrm{H}$ & 1.974894 & 2.548769 & -1.183216 \\
$\mathrm{C}$ & -0.152394 & 2.269059 & -1.487687 \\
$\mathrm{H}$ & -1.149267 & 2.639811 & -1.192599 \\
$\mathrm{H}$ & -0.037268 & 2.169753 & -2.571042 \\
$\mathrm{C}$ & -0.151873 & 2.262164 & 1.497265 \\
$\mathrm{H}$ & -1.148849 & 2.634421 & 1.204477 \\
$\mathrm{H}$ & -0.036206 & 2.157765 & 2.580091 \\
& & & \\
\hline & & & \\
\hline & & & \\
\hline
\end{tabular}

The $\mathrm{BS}(3,1)$ solution is about $15.5 \mathrm{kcal} / \mathrm{mol}$ more stable than the $\mathrm{BS}(1,1)$ solution. 
Qualitative MO analysis of complex 2 and 3
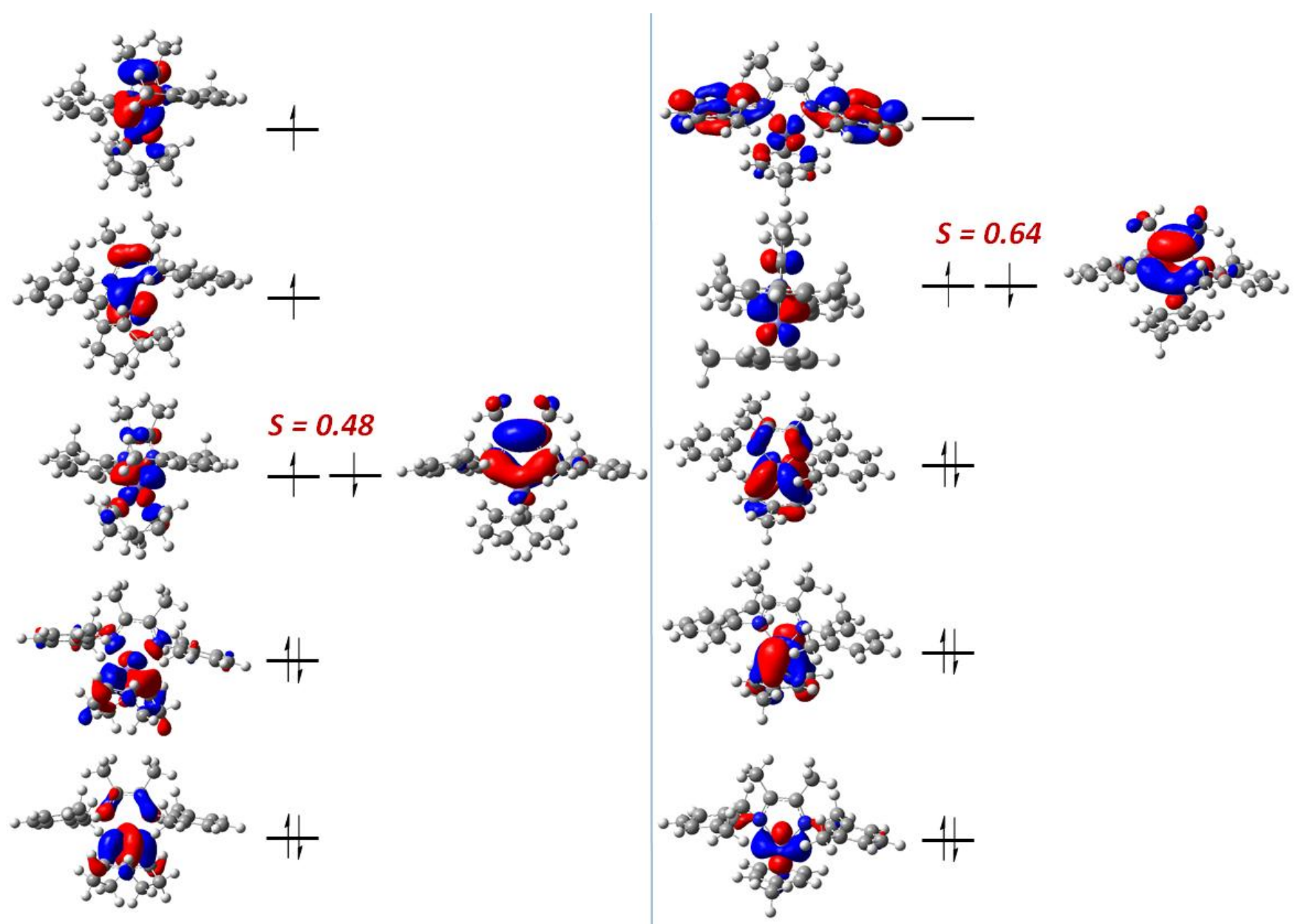

Figure S31. Qualitative MO diagram of (a) complex 2 derived from BS $(3,1)$ B3LYP/TZVP and (b) complex 3 from BS(1,1) B3LYP/TZVP calculations; the singly and doubly occupied orbitals represent quasi-restricted orbitals, the magnetic orbitals represent corresponding orbitals.

To understand the difference in spin states for complexes $\mathbf{2}$ and $\mathbf{3}$, a qualitative $\mathrm{MO}$ analysis was performed. In both complexes, a large spatial overlap of magnetic orbitals is observed, $S=0.48$ for complex 2 and $S=$ 0.64 for complex $\mathbf{3}$, respectively, as shown in Figure S31 which represents antiferomagnetically coupling between $\mathrm{Fe}$ and the diimine radical anion.

In complex 2, the molecular orbital on the iron that is magnetically coupled to the diimine ligand is singly occupied, and shows an antibonding interaction with the $\pi$ orbital of the COD ligand. We speculate that this antibonding interaction is what makes the COD ligand-metal bond weaker (Figure 4a), and responsible for fast dissociation of the COD ligand during catalysis.

In complex 3, a molecular orbital on iron that shows an antibonding interaction with the $\pi^{*}$ orbital of the arene is unoccupied (LUMO, Figure S31b). We speculate that the antibonding interaction between the arene ligand 
and $\mathrm{Fe}$ is responsible for the low spin ground state of complex $\mathbf{3}$. Strong binding of the arene ligand to the metal does not allow for rapid ligand substitution, and therefore complex $\mathbf{3}$ does not show reactivity toward diene dimerization in the absence of an activating reagent such as trialkylaluminum.

The relative orientation of the weakly binding COD ligand and the diimine ligand make a pseudo-tetrahedral geometry, resulting in smaller splitting of the d orbitals and a high-spin ground state for $\mathrm{Fe}(\mathrm{I})$ in complex 2 . 


\section{SPECTROSCOPIC DATA}

\section{Mössbauer Data}

Crystalline samples of iron complex 2 were analyzed by Mössbauer spectroscopy. As shown in the Figure S17 and S18, the COD ligand bound to 2 rotates and produces two subtly distinct isomers. Distinct crystals were found to consistently give two similar spectra as shown in Figure S33. Repeated attempts gave either spectrum (a) or (b) in Figure S33 or mixtures of these two when a solid sample of 2 before recrystallization was used as shown in Figure S34. By collecting multiple times the single-crystal X-ray structure of 2 and collecting Mössbauer data of crystalline batches, it was concluded that the slight change in Mössbauer parameters is due to isomerization (rotation) of the COD ligand. The magnetic data collected on pure isomer (Figure S33a) or mixtures (Figure S34) were equivalent as shown in Figure S42 in the magnetic data section.

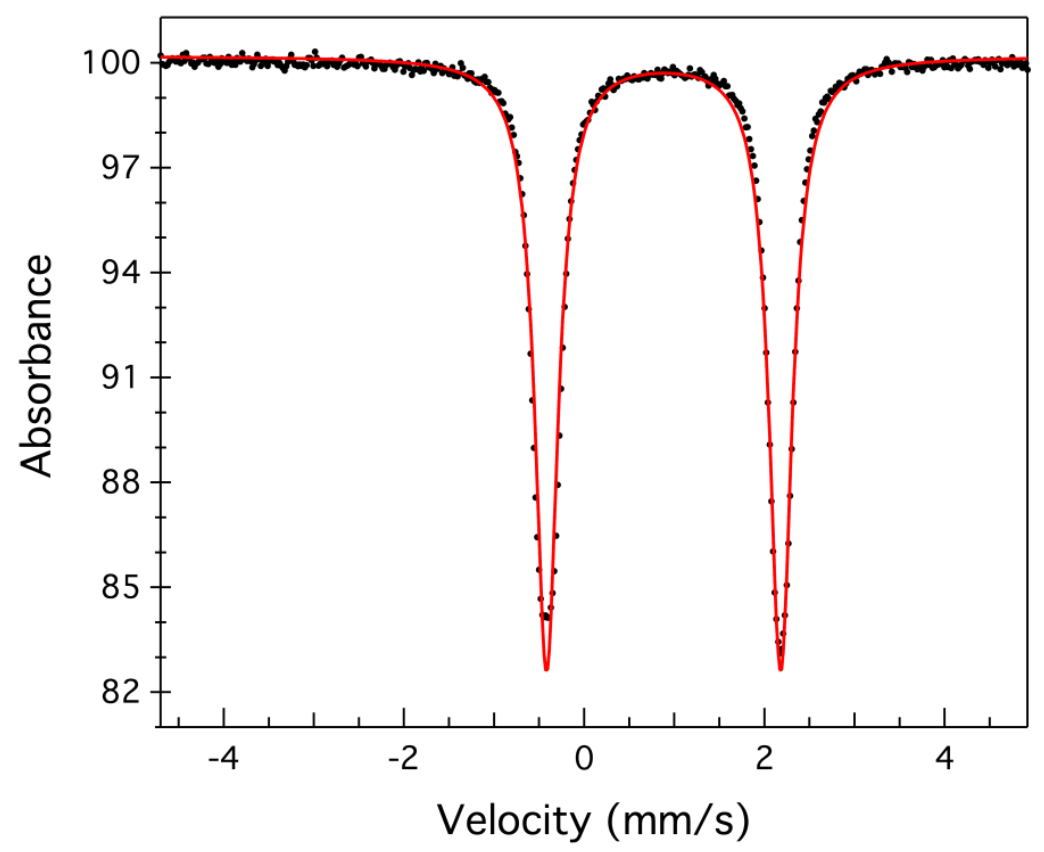

Figure S32. Zero-field ${ }^{57} \mathrm{Fe}$ Mössbauer spectrum of Fe(II) dichloride complex 1 at $90 \mathrm{~K} . \delta,\left|\Delta E_{\mathrm{Q}}\right|(\mathrm{mm} / \mathrm{s}): 0.88$, $2.60(\gamma=0.31 \mathrm{~mm} / \mathrm{s})$. 
(a)

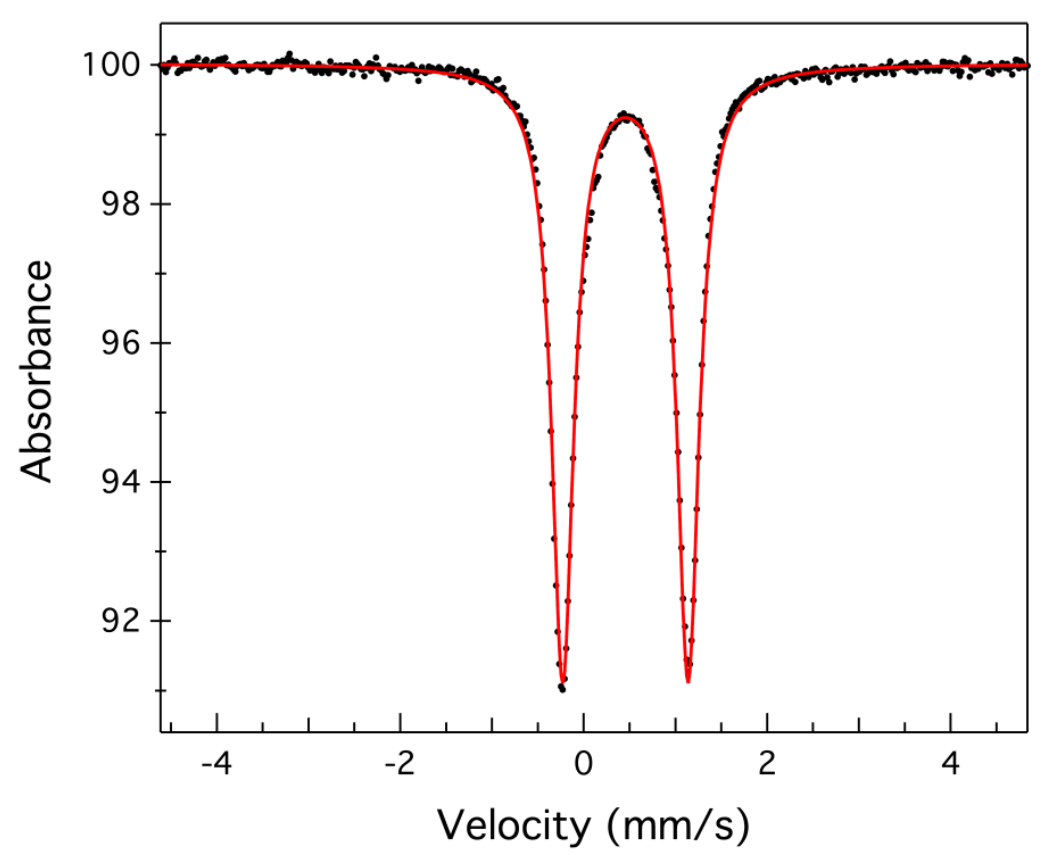

(b)

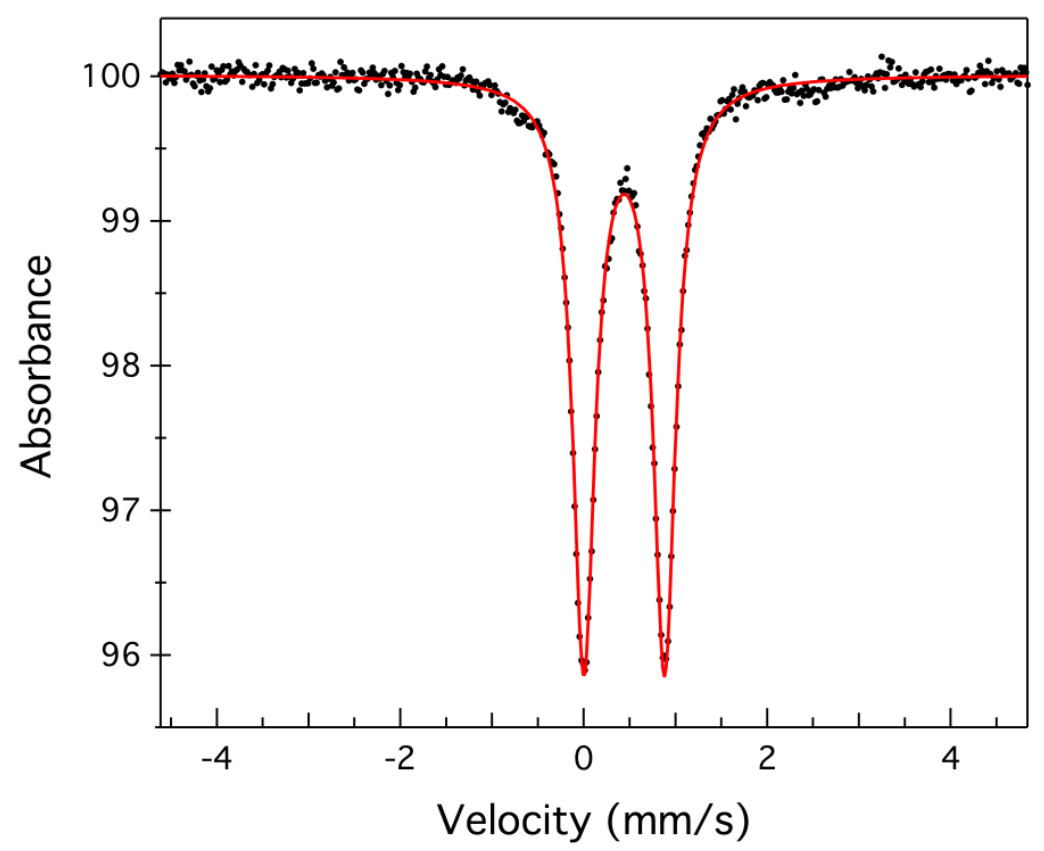

Figure S33. Zero-field ${ }^{57} \mathrm{Fe}$ Mössbauer spectrum of Fe complex 2 at $90 \mathrm{~K} . \delta,\left|\Delta E_{\mathrm{Q}}\right|(\mathrm{mm} / \mathrm{s}):(\mathrm{a}) 0.47,1.37(\gamma=$ $0.29 \mathrm{~mm} / \mathrm{s})$; (b) $0.44,0.88(\gamma=0.30 \mathrm{~mm} / \mathrm{s})$. 


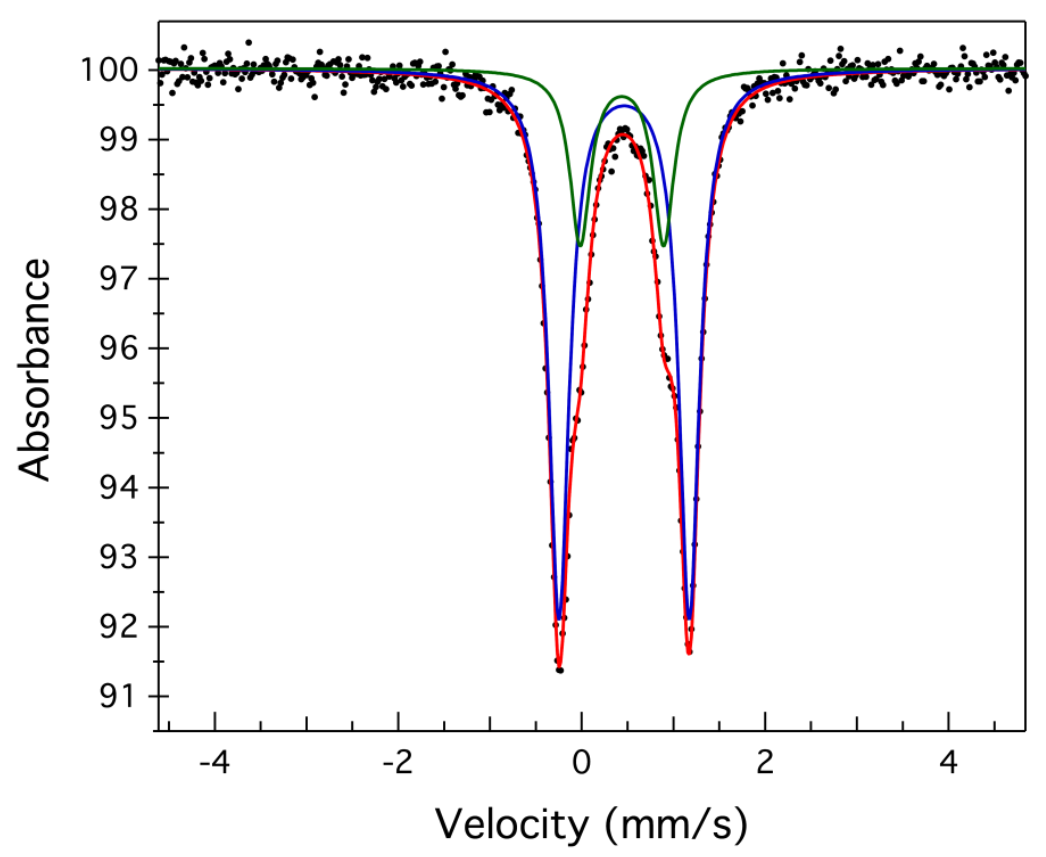

Figure S34. Zero-field ${ }^{57} \mathrm{Fe}$ Mössbauer spectrum of Fe complex 2 at $90 \mathrm{~K} . \delta,\left|\Delta E_{\mathrm{Q}}\right|(\mathrm{mm} / \mathrm{s}): 0.47,1.42(\gamma=$ $0.27 \mathrm{~mm} / \mathrm{s}$, blue trace) and $0.44,0.91(\gamma=0.27 \mathrm{~mm} / \mathrm{s}$, green trace)

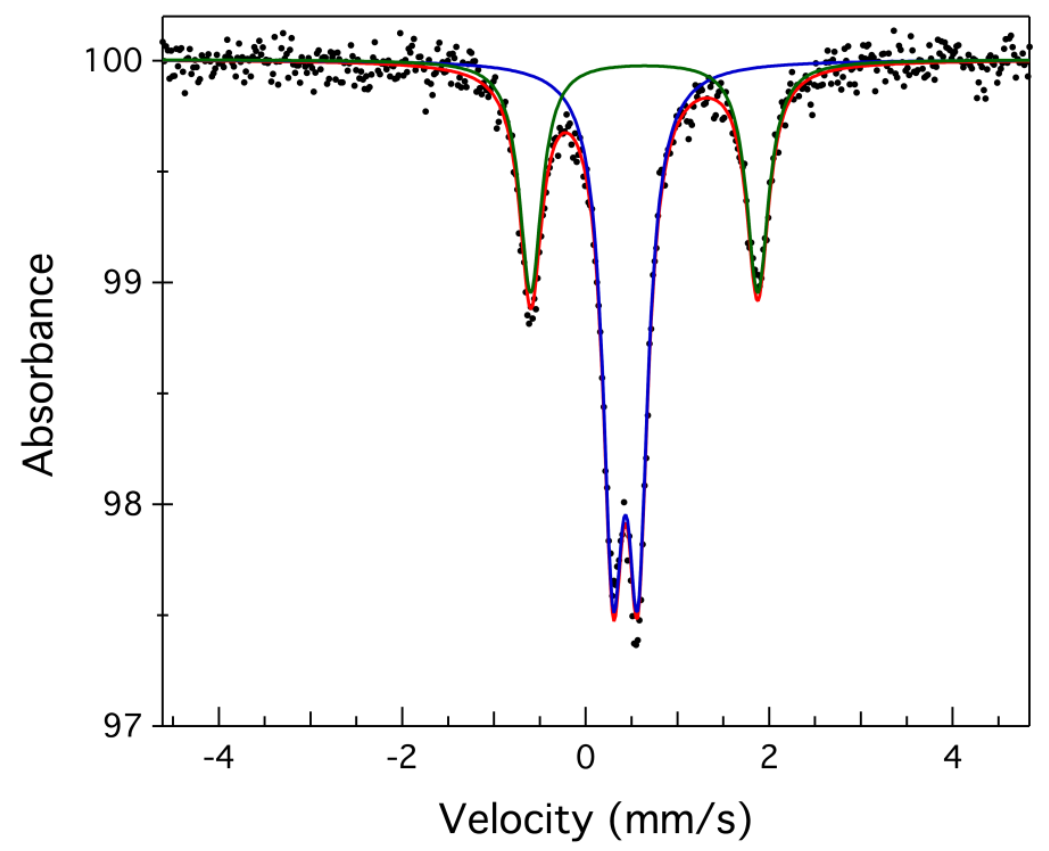

Figure S35. Zero-field ${ }^{57} \mathrm{Fe}$ Mössbauer spectrum of Fe complex 3 at $90 \mathrm{~K} . \delta,\left|\Delta E_{\mathrm{Q}}\right|(\mathrm{mm} / \mathrm{s}): 0.44,0.27(\gamma=$ $0.27 \mathrm{~mm} / \mathrm{s}$, blue trace). The second component with parameters $\delta,\left|\Delta E_{\mathrm{Q}}\right|(\mathrm{mm} / \mathrm{s}): 0.64,2.47(\gamma=0.29 \mathrm{~mm} / \mathrm{s}$, green trace) correspond to $\mathbf{5}$ formed during the synthesis of $\mathbf{3}$. 


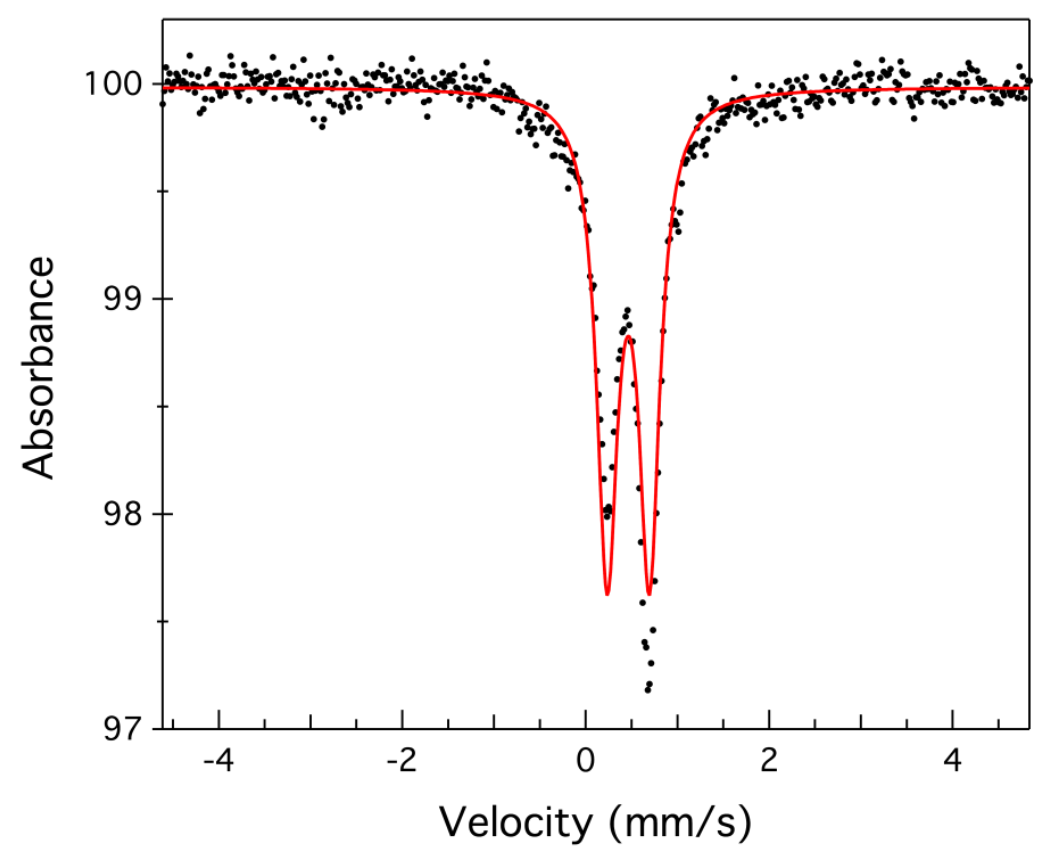

Figure S36. Zero-field ${ }^{57} \mathrm{Fe}$ Mössbauer spectrum of Fe complex 4 at $90 \mathrm{~K} . \delta,\left|\Delta E_{\mathrm{Q}}\right|(\mathrm{mm} / \mathrm{s}): 0.47,0.46(\gamma=$ $0.28 \mathrm{~mm} / \mathrm{s})$.

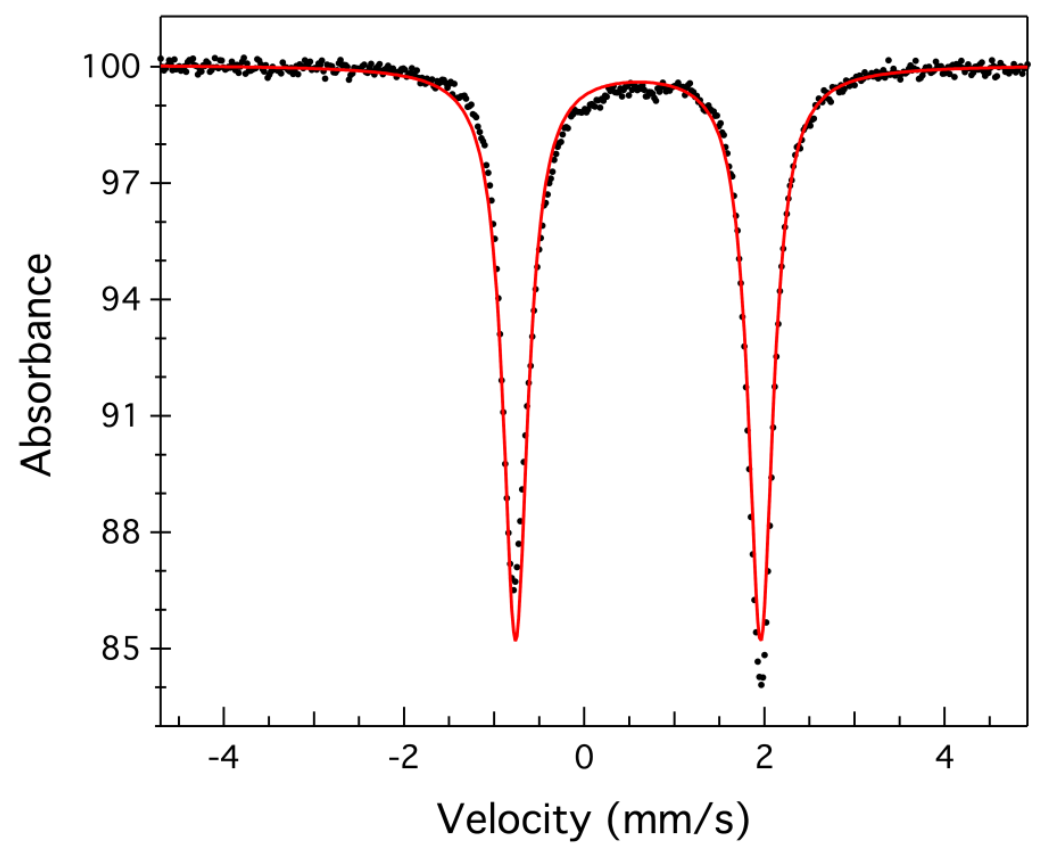

Figure S37. Zero-field ${ }^{57} \mathrm{Fe}$ Mössbauer spectrum of Fe complex 5 at $90 \mathrm{~K} . \delta,\left|\Delta E_{\mathrm{Q}}\right|(\mathrm{mm} / \mathrm{s}): 0.60,2.72(\gamma=$ $0.34 \mathrm{~mm} / \mathrm{s})$. 
Computational Studies on Different Isomer Shifts Observed for Polymorphs of Complex 2

Reduction of (diimine)Fe(II) chloride complex 1 to $\mathrm{Fe}(\mathrm{I}) \mathrm{COD}$ complex 2 produces one of two subtly distinct polymorphs upon crystallization, in which the conformation of the COD ligand binding to iron differs slightly (Figure S17-19). One polymorph shows a shift to Mössbauer parameters of $\delta=0.47 \mathrm{~mm} / \mathrm{s}$ and $\left|\Delta E_{\mathrm{Q}}\right|=1.37$ $\mathrm{mm} / \mathrm{s}$ (Figure 3 top), while the other displays $\delta=0.44 \mathrm{~mm} / \mathrm{s}$ and $\left|\Delta E_{Q}\right|=0.88 \mathrm{~mm} / \mathrm{s}$ (Figure S30). MB parameters were calculated for both polymorphs of 2 and almost identical MB parameters were found for both isomers. Perturbing the rotation angle of the COD ligand afforded IS and QS which differ by $0.02 \mathrm{~mm} / \mathrm{s}$ and $0.03 \mathrm{~mm} / \mathrm{s}$. Thus rotation of COD in 2 is the most plausible reason for the observed MB spectra.

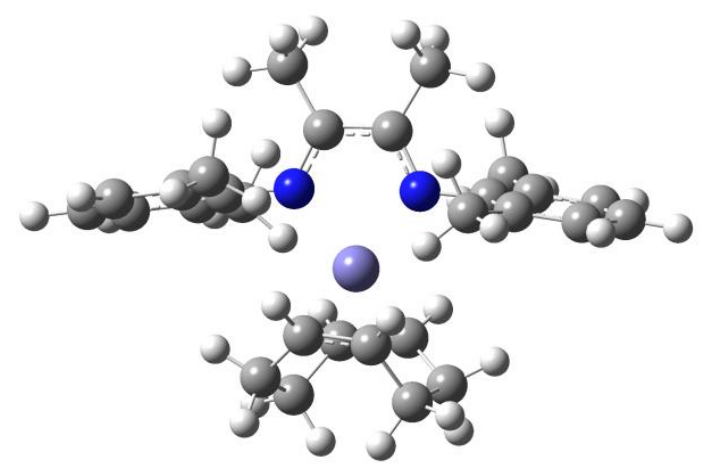

Figure S38. Structure of complex 2 isomer for single point calculation.

Table S17. Cartesian coordinates $(\AA)$ of the structure of complex 2 isomer.

\begin{tabular}{l|lll} 
Atom & $\mathbf{X}$ & $\mathbf{Y}$ & $\mathbf{Z}$ \\
\hline $\mathrm{Fe}$ & 2.081370 & 18.255200 & 4.933510 \\
$\mathrm{~N}$ & 1.829170 & 20.141300 & 4.127190 \\
$\mathrm{~N}$ & 3.618640 & 19.281200 & 5.856570 \\
$\mathrm{C}$ & 4.398010 & 18.473700 & 8.035710 \\
$\mathrm{C}$ & 4.626650 & 18.675000 & 6.651510 \\
$\mathrm{C}$ & 0.712007 & 20.542300 & 3.347950 \\
$\mathrm{C}$ & 5.836030 & 18.233100 & 6.057380 \\
$\mathrm{C}$ & 3.711060 & 20.572700 & 5.483120 \\
$\mathrm{C}$ & 0.721395 & 20.329500 & 1.946630 \\
$\mathrm{C}$ & 2.721210 & 21.046600 & 4.575280 \\
$\mathrm{C}$ & 6.549900 & 17.342000 & 8.212870
\end{tabular}




\begin{tabular}{|c|c|c|c|}
\hline C & 5.367650 & 17.804000 & 8.795290 \\
\hline C & -0.419873 & 20.657200 & 1.200750 \\
\hline C & -1.548680 & 21.419500 & 3.190380 \\
\hline C & -0.426339 & 21.111200 & 3.974270 \\
\hline C & 6.777310 & 17.563300 & 6.853860 \\
\hline C & 3.144660 & 19.003700 & 8.689190 \\
\hline C & -0.436050 & 21.412500 & 5.455370 \\
\hline C & -1.555230 & 21.192300 & 1.813480 \\
\hline C & 1.955240 & 19.792800 & 1.261540 \\
\hline C & 6.131680 & 18.496400 & 4.598810 \\
\hline C & 4.791520 & 21.498200 & 5.991490 \\
\hline C & 2.704120 & 22.497100 & 4.151100 \\
\hline $\mathrm{H}$ & 7.291560 & 16.818300 & 8.815650 \\
\hline $\mathrm{H}$ & 5.189560 & 17.647200 & 9.859800 \\
\hline $\mathrm{H}$ & -0.411687 & 20.491100 & 0.122681 \\
\hline $\mathrm{H}$ & -2.428830 & 21.846300 & 3.673320 \\
\hline $\mathrm{H}$ & 7.703190 & 17.213400 & 6.395490 \\
\hline $\mathrm{H}$ & 3.114530 & 20.102400 & 8.666390 \\
\hline $\mathrm{H}$ & 3.082620 & 18.686900 & 9.736790 \\
\hline $\mathrm{H}$ & 2.245730 & 18.658200 & 8.166840 \\
\hline $\mathrm{H}$ & 0.084090 & 20.640300 & 6.033630 \\
\hline $\mathrm{H}$ & -1.462040 & 21.498600 & 5.832220 \\
\hline $\mathrm{H}$ & 0.071368 & 22.364100 & 5.675160 \\
\hline $\mathrm{H}$ & -2.436680 & 21.435700 & 1.220810 \\
\hline $\mathrm{H}$ & 2.797370 & 20.494200 & 1.348210 \\
\hline $\mathrm{H}$ & 1.769080 & 19.618700 & 0.195333 \\
\hline $\mathrm{H}$ & 2.287430 & 18.853000 & 1.715920 \\
\hline $\mathrm{H}$ & 5.244480 & 18.357400 & 3.970400 \\
\hline
\end{tabular}




\begin{tabular}{|c|c|c|c|}
\hline $\mathrm{H}$ & 6.925110 & 17.834000 & 4.233180 \\
\hline $\mathrm{H}$ & 6.469190 & 19.531200 & 4.438530 \\
\hline $\mathrm{H}$ & 5.393540 & 21.015500 & 6.766820 \\
\hline $\mathrm{H}$ & 4.362670 & 22.414500 & 6.419800 \\
\hline $\mathrm{H}$ & 5.473120 & 21.816000 & 5.187630 \\
\hline $\mathrm{H}$ & 1.967680 & 22.672100 & 3.360950 \\
\hline $\mathrm{H}$ & 3.687050 & 22.810200 & 3.772620 \\
\hline $\mathrm{H}$ & 2.462090 & 23.169600 & 4.988200 \\
\hline C & 0.174946 & 17.618900 & 5.528240 \\
\hline C & 2.907350 & 16.359400 & 4.218140 \\
\hline C & 1.111360 & 16.990100 & 6.362810 \\
\hline C & 1.862650 & 16.762400 & 3.371250 \\
\hline C & -0.508305 & 17.001500 & 4.319990 \\
\hline C & 1.549690 & 15.533800 & 6.237560 \\
\hline C & 2.807220 & 15.353500 & 5.352830 \\
\hline C & 0.445946 & 16.195600 & 3.405390 \\
\hline $\mathrm{H}$ & -0.329653 & 18.499100 & 5.928060 \\
\hline $\mathrm{H}$ & 3.924510 & 16.538600 & 3.867130 \\
\hline $\mathrm{H}$ & 1.269870 & 17.452100 & 7.340310 \\
\hline $\mathrm{H}$ & 2.162500 & 17.235900 & 2.433140 \\
\hline $\mathrm{H}$ & -0.947227 & 17.824200 & 3.740000 \\
\hline $\mathrm{H}$ & -1.357480 & 16.368500 & 4.634730 \\
\hline $\mathrm{H}$ & 0.717906 & 14.933600 & 5.847330 \\
\hline $\mathrm{H}$ & 1.756760 & 15.132200 & 7.238910 \\
\hline $\mathrm{H}$ & 3.702860 & 15.475100 & 5.976930 \\
\hline $\mathrm{H}$ & 2.850940 & 14.320600 & 4.962480 \\
\hline $\mathrm{H}$ & 0.479808 & 15.144700 & 3.718800 \\
\hline $\mathrm{H}$ & 0.038141 & 16.184200 & 2.385470 \\
\hline
\end{tabular}


Table S18. Comparison of experimental and calculated Mössbauer parameters of complex 2 isomer.

\begin{tabular}{l|l|l} 
Parameter & $\begin{array}{l}\text { Calcd. } \\
\text { Complex 2 }\end{array}$ & $\begin{array}{l}\text { Calcd. isomer (COD further } \\
\left.\text { rotated from complex 2 by } 30^{\circ}\right)\end{array}$ \\
\hline$\delta\left(\mathrm{mm} \cdot \mathrm{s}^{-1}\right)$ & 0.39 & 0.41 \\
$\left|\Delta E_{\mathrm{Q}}\right|\left(\mathrm{mm} \cdot \mathrm{s}^{-1}\right)$ & 1.49 & 1.46 \\
$\eta$ & 0.16 & 0.11
\end{tabular}

When Mössbauer parameters of complex 2 that has a structure in Figure S18 was calculated for by single point, almost identical isomer shift was calculated for both conformers. However, when the COD ligand was rotated for 30 degrees from one isomer, we were able to observe isomer shifts different by $0.02 \mathrm{~mm} / \mathrm{s}$. 


\section{Magnetic Data}
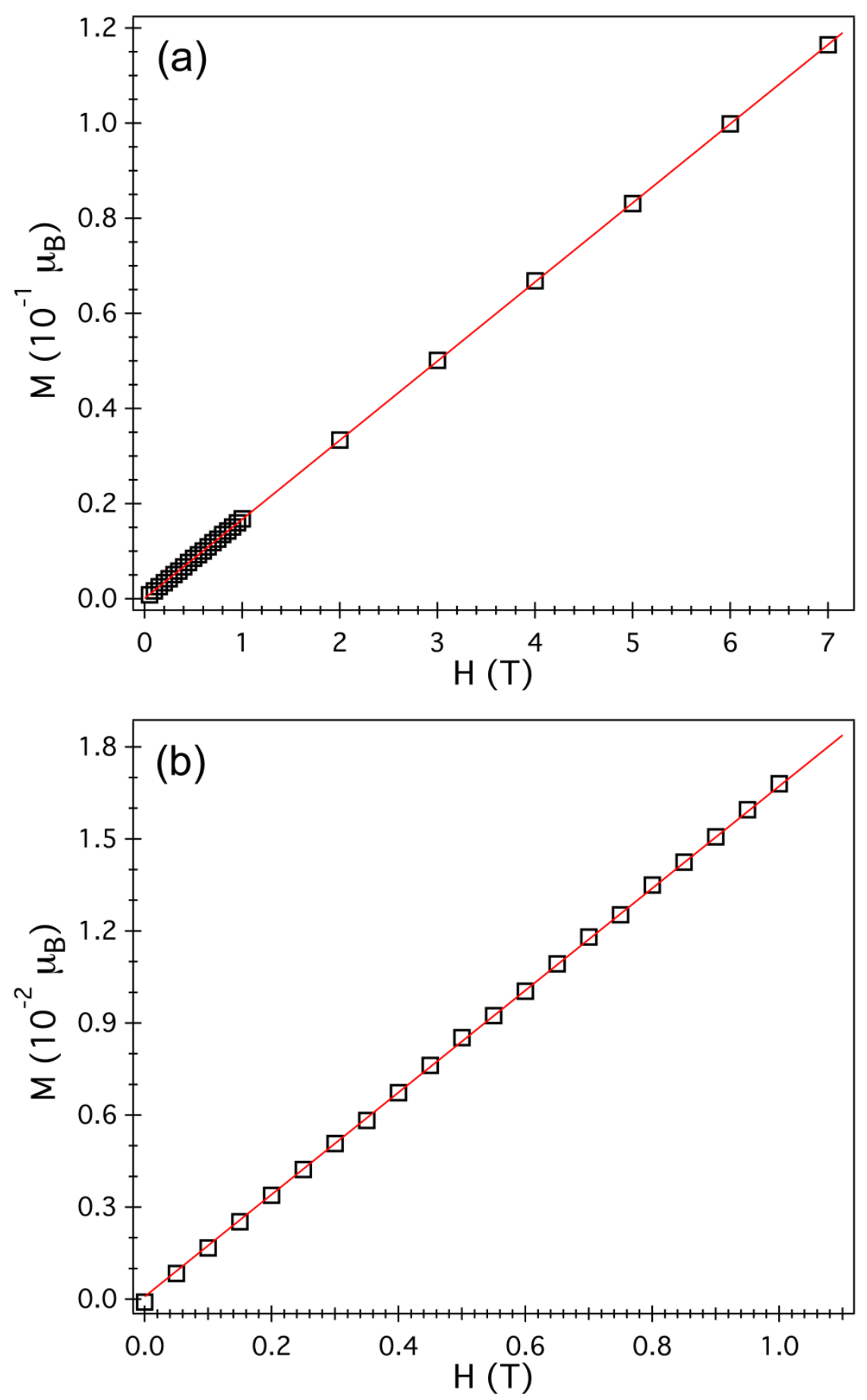

Figure S39. (a) Magnetization data at $100 \mathrm{~K}$ for Fe complex 2. (b) Zoomed in plot from 0 to $1 \mathrm{~T}$ from that in (a). This data confirms that no ferromagnetic impurities are present. 


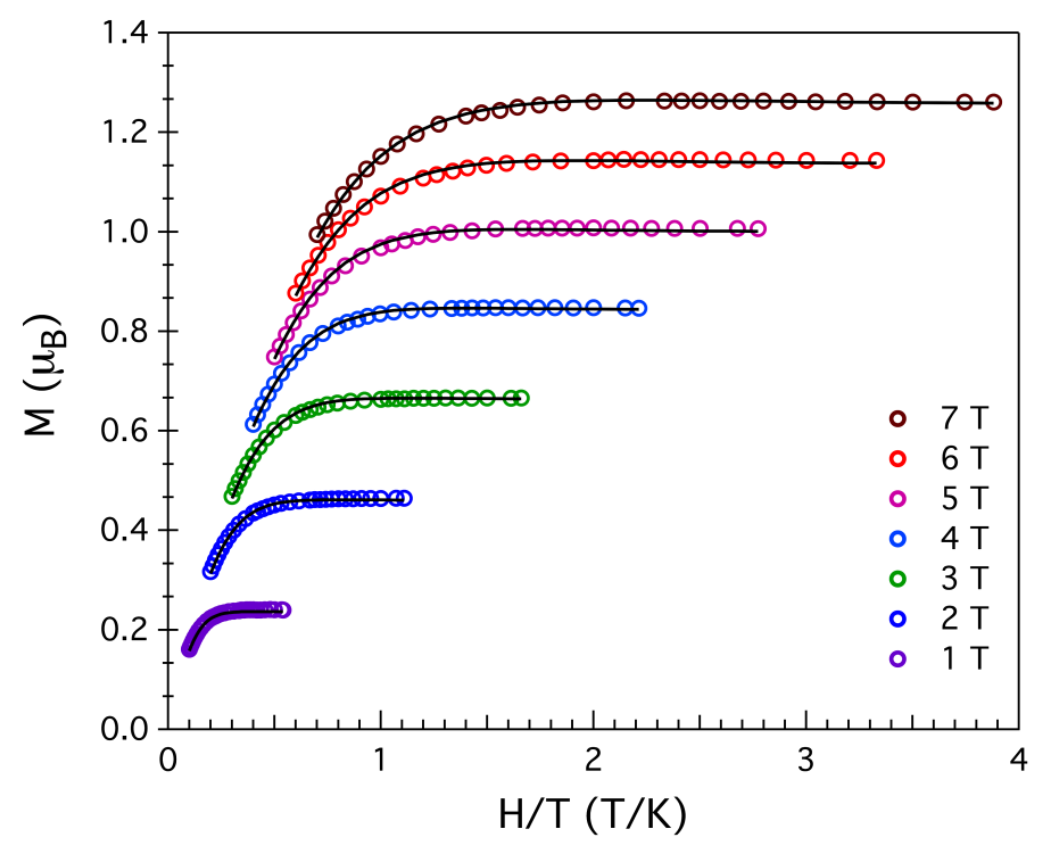

Figure S40. Variable-temperature, variable-field reduced magnetization data for Fe complex 2 . The fit is shown as continuous black lines and the corresponding fit parameters are: $S=1$ (set), $g=2.02$ and $D=+3.5$ $\mathrm{cm}^{-1}$.

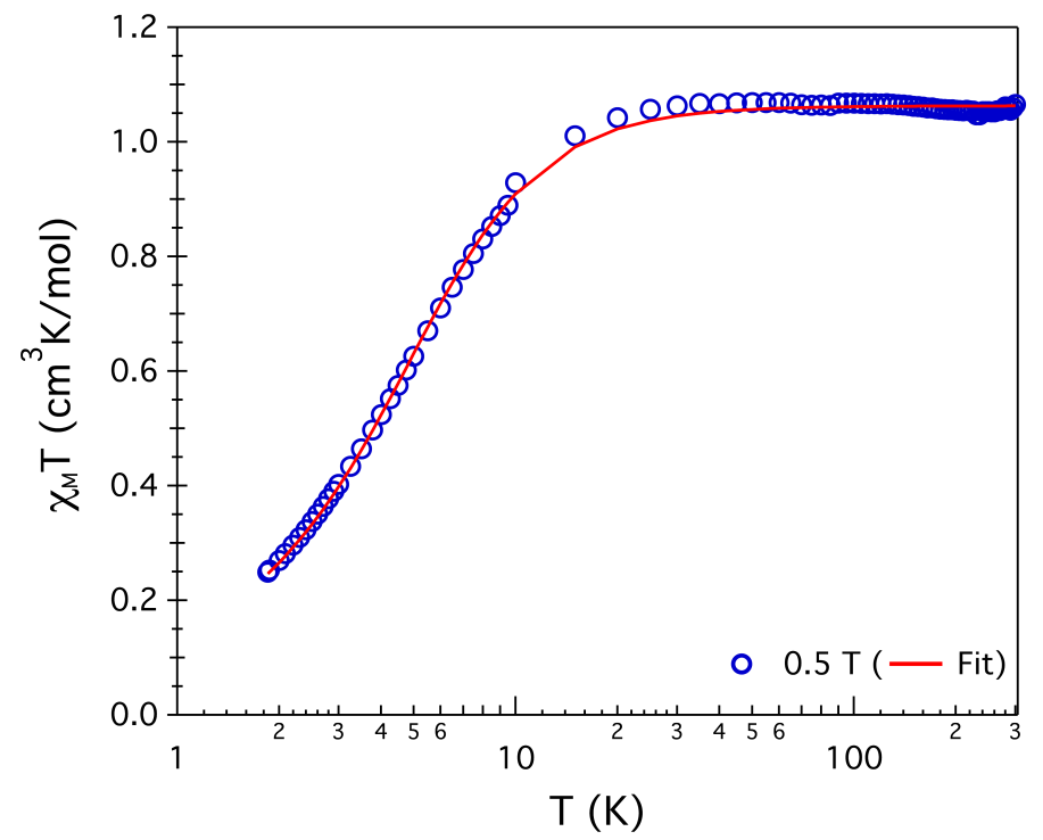

Figure S41. Variable-temperature magnetic susceptibility data for Fe complex 2. The temperature is plotted in a logarithmic way to visualize the quality of the fit. Same data as in Figure 3a bottom. 


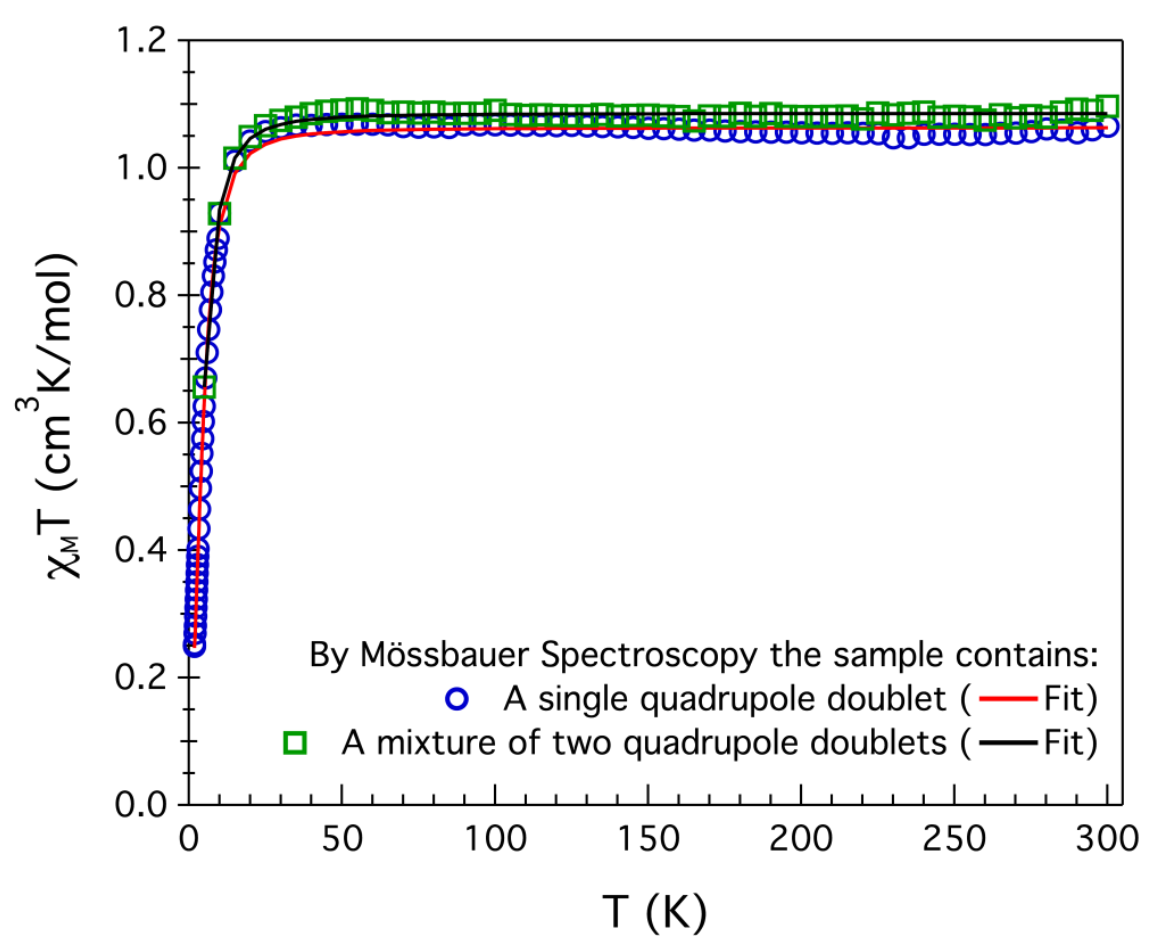

Figure S42. Variable-temperature magnetic susceptibility data for Fe complex 2. Data for a pure isomer of 2 (blue circles, with ${ }^{57} \mathrm{Fe}$ Mössbauer spectrum as in Figure S22a) and for the mixture of isomers (green squares, with ${ }^{57} \mathrm{Fe}$ Mössbauer spectrum as in Figure S23) is plotted together. Fit parameters: data in blue circles (same as in Figure 3a bottom): $g=2.06,|D|=3.7 \mathrm{~cm}^{-1}$; data in green squares: $g=2.08,|D|=3.6 \mathrm{~cm}^{-1}$.

Note: Eicosane was used to immobilize the sample and to provide a layer against oxidation in air during the few seconds it takes to mount into the magnetometer. It was melted right above the melting point $(\mathrm{mp}=38$ ${ }^{\circ} \mathrm{C}$ ) and added to the sample at room temperature. During this process the crystals did not dissolve because eicosane freezes immediately. 


\section{Discussion of magnetic data for Fe complex 2:}

The magnetic susceptibility data was analyzed by employing the spin-Hamiltonian operator in Eq. S6, as described in the main text. Analytical expression for magnetic susceptibility can be found in the review by Boca et. al. ${ }^{22}$ and elsewhere. In addition the variable-temperature, variable-field (VTVH) reduced magnetization data was fit by employing the zero-field spin Hamiltonian in Eq. S7. All data were fit by employing $\mathrm{PHI}^{23}$

$$
\begin{gathered}
\widehat{H}=D \hat{S}_{z}^{2}+g_{i s o} \mu_{B} \mathbf{S} \cdot \mathbf{H} \\
\widehat{H}=D \hat{S}_{z}^{2}+E\left(\hat{S}_{x}^{2}-\hat{S}_{y}^{2}\right)+g_{i s o} \mu_{B} \mathbf{S} \cdot \mathbf{H}
\end{gathered}
$$

In the case of the $\mathrm{VTVH}$ reduced magnetization data the inclusion of the transverse $(E)$ zero-field splitting parameter did not improve significantly the overall fit of the data; in addition, including $E$ provided a value of $|E / D|=\sim 0$. Thus, to avoid over-parameterization of the overall fit $E$ was fixed to zero.

\section{Gas Chromatography (GC) Data}

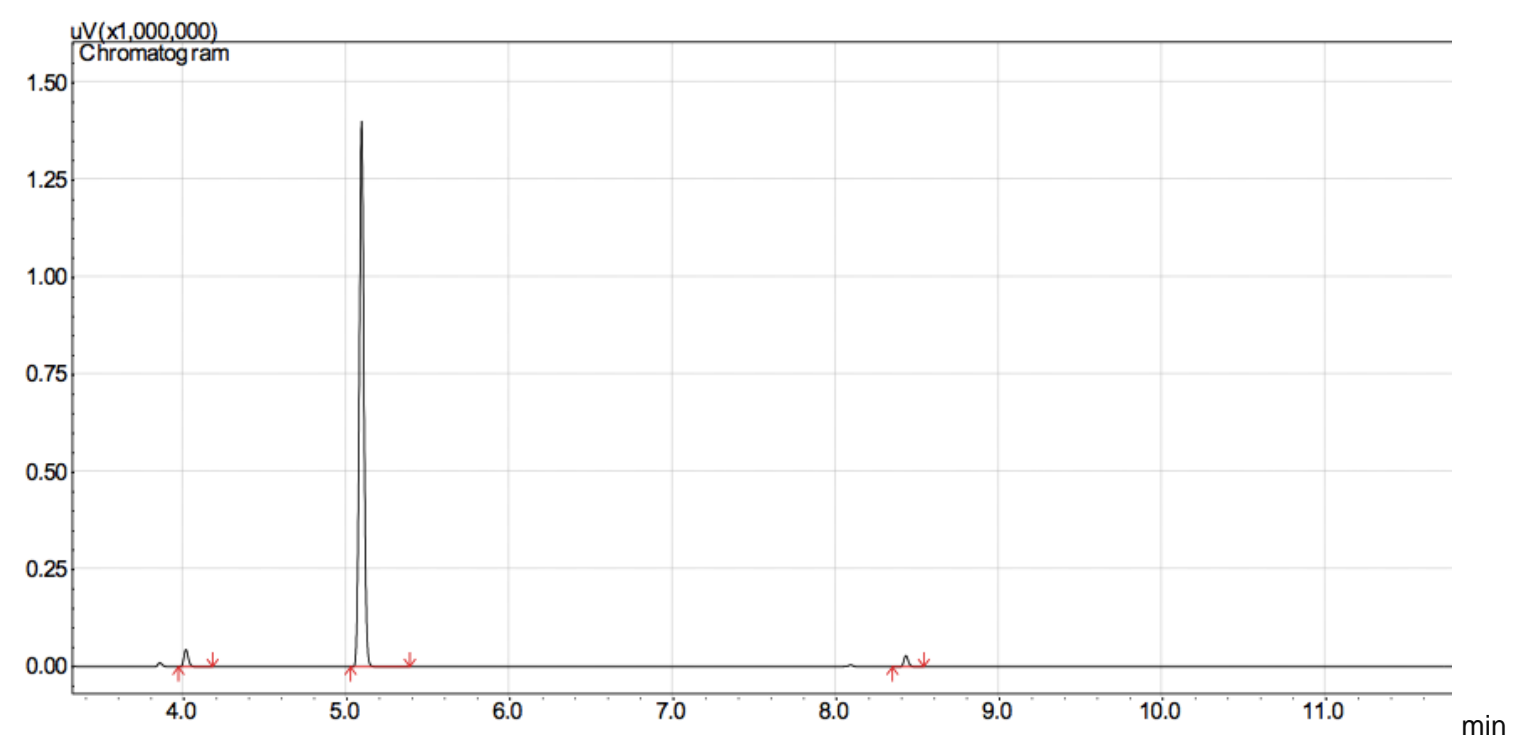

Figure S43. Gas chromatogram of example 2 (160 g scale with $41 \mathrm{ppm}$ catalyst 2 loading): Selectivity for COD $96.0 \%(2.96 \% \mathrm{VCH}, 0.99 \%$ trimer $)$.

${ }^{22}$ Boca, R. Coord. Chem. Rev. 2004, 248, 757.

${ }^{23}$ Chilton, N. F.; Anderson, R. P.; Turner, L. D.; Soncini, A.; Murray, K. S. J. Comput. Chem. 2013, 34, 1164. 


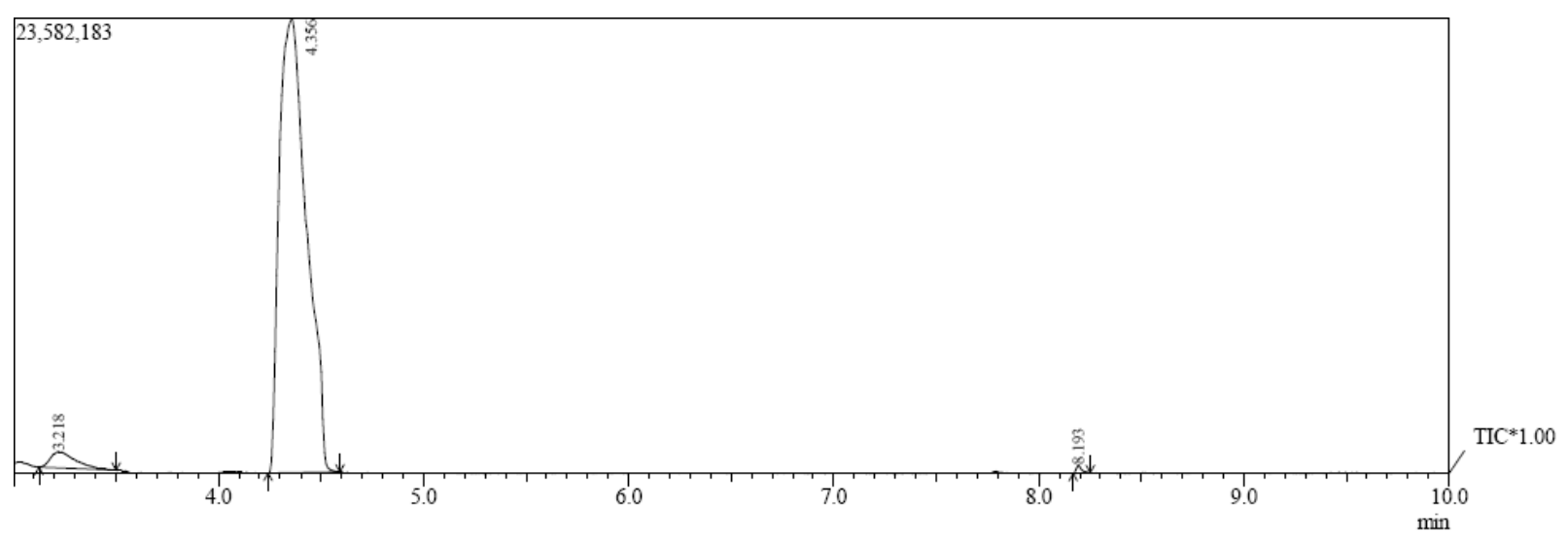

Figure S44. Gas chromatogram of example 3 (100 g scale with 94.7 ppm pre-catalyst 1 loading): Selectivity for COD $96.5 \%$ (3\% VCH, $0.5 \%$ trimer).

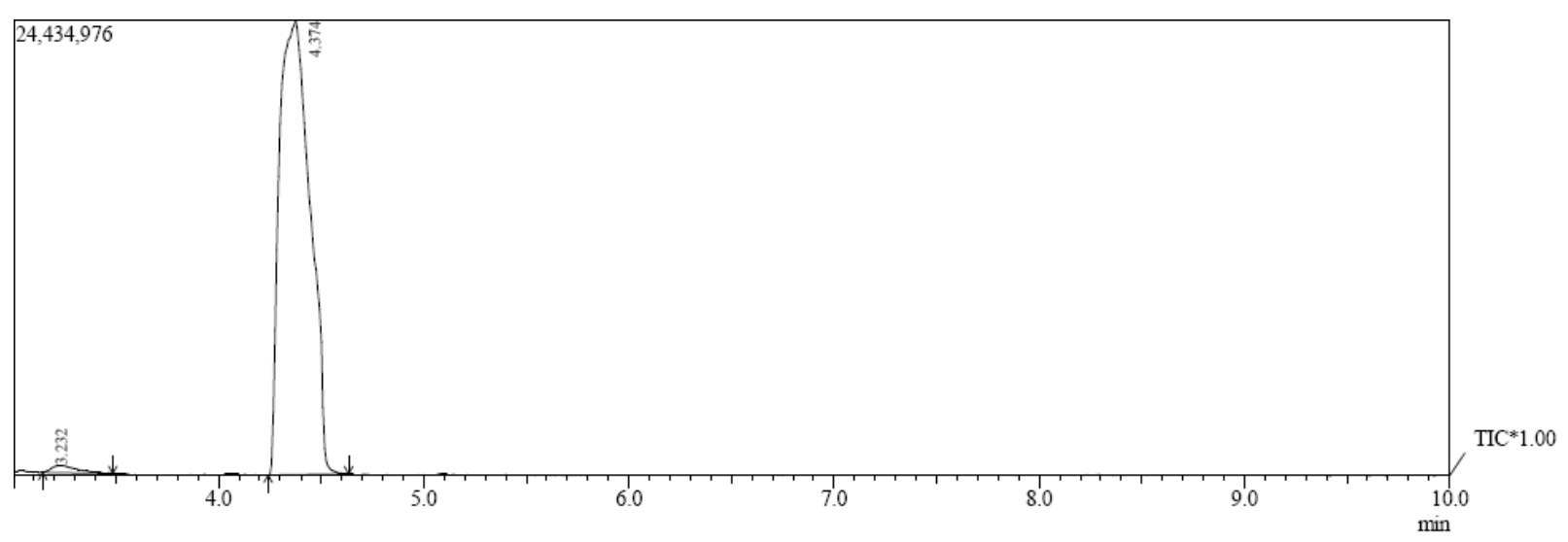

Figure S45. Gas chromatogram of example 4 (100 g scale with $44.2 \mathrm{ppm}$ pre-catalyst 1 loading): Selectivity for $\operatorname{COD} 97.5 \%(2.5 \% \mathrm{VCH})$. 


\section{NMR Data}

- ${ }^{1} \mathrm{H}$ NMR of Bis(2,6-dimethylaniline)-butane-2,3-diimine (S1)

$500 \mathrm{MHz}, \mathrm{CDCl}_{3}, 23 \stackrel{\circ}{\mathrm{C}}$
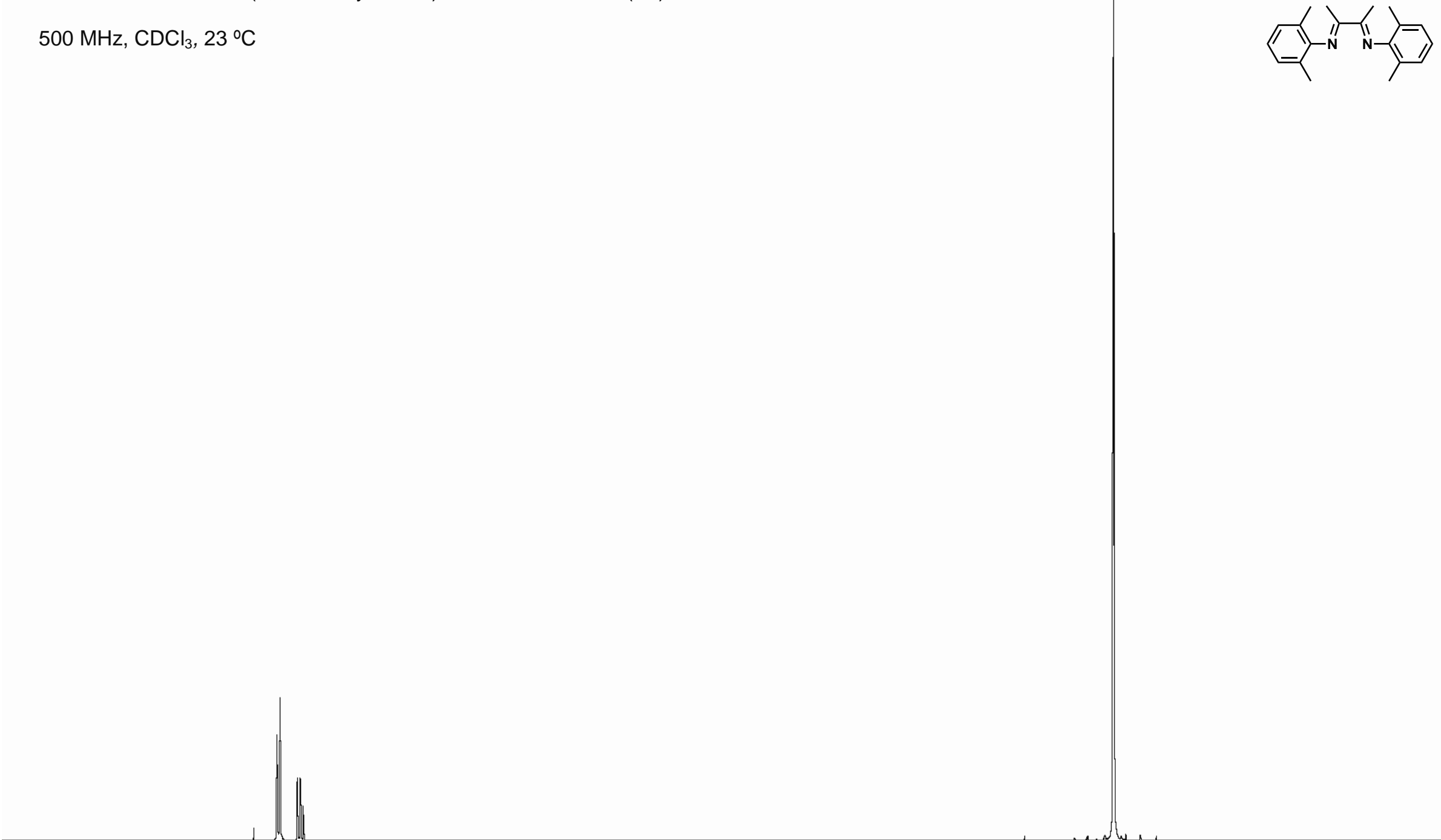

6

5

4 
- ${ }^{13} \mathrm{C}$ NMR of Bis(2,6-dimethylaniline)-butane-2,3-diimine (S1)

$125 \mathrm{MHz}, \mathrm{CDCl}_{3}, 23 \stackrel{\circ}{\circ} \mathrm{C}$

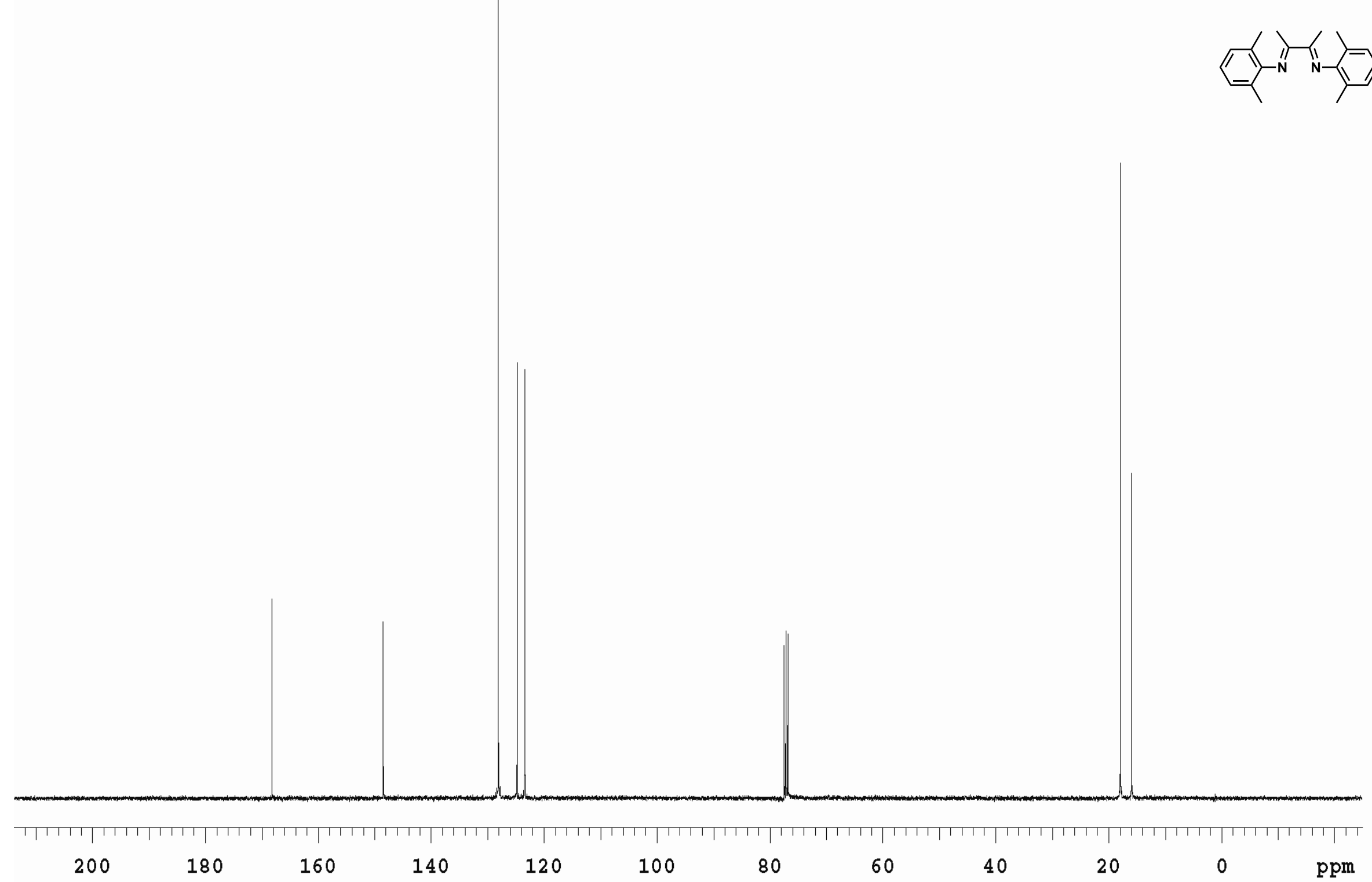


- $\quad{ }^{1} \mathrm{H}$ NMR of Bis(2,6-dimethylaniline)-butane-2,3-diimine iron(II) chloride (1)

$500 \mathrm{MHz}, \mathrm{CD}_{2} \mathrm{Cl}_{2}, 23 \stackrel{\circ}{\circ} \mathrm{C}$
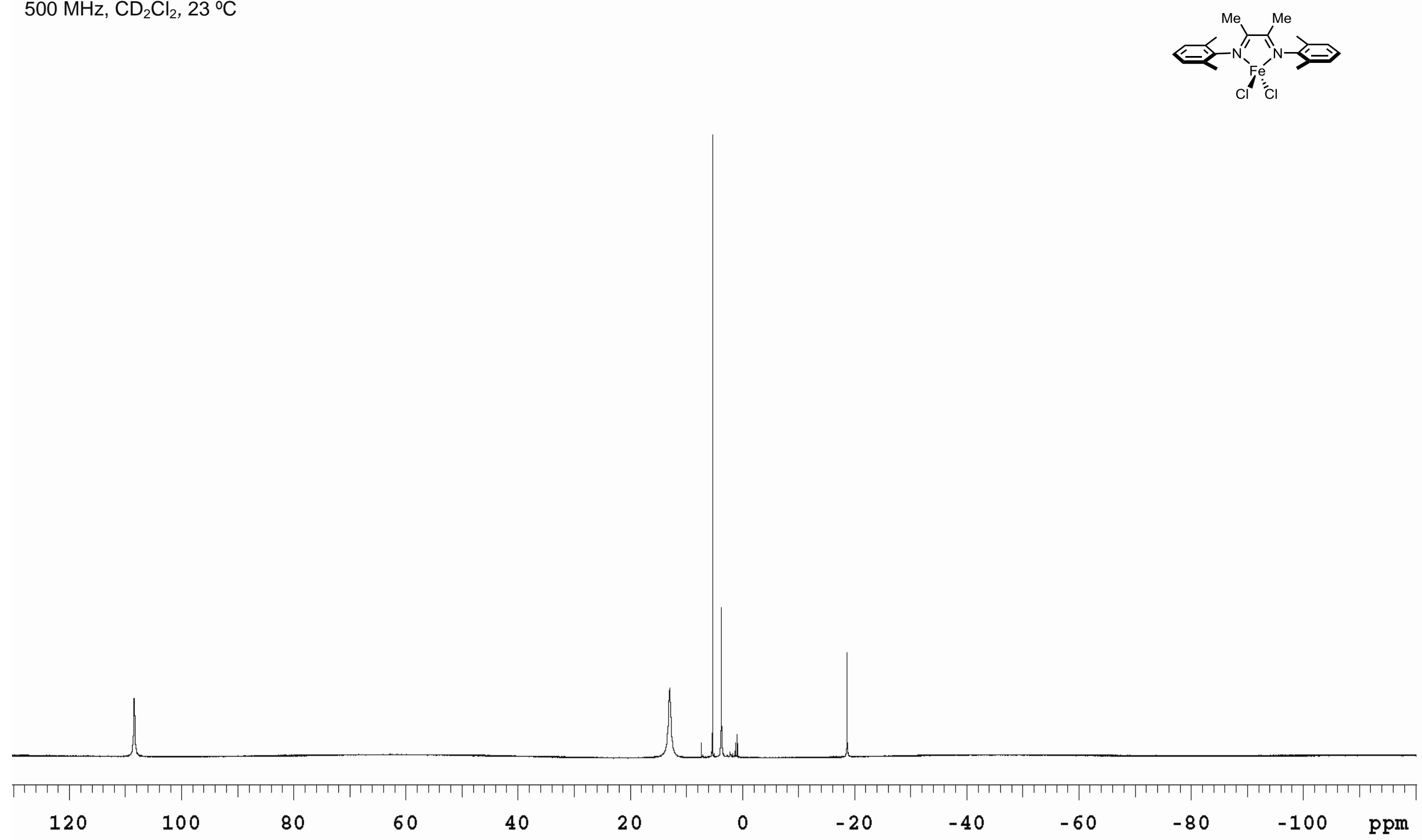
- $\quad{ }^{13} \mathrm{C}$ NMR of Bis(2,6-dimethylaniline)-butane-2,3-diimine iron(II) chloride (1)

$125 \mathrm{MHz}, \mathrm{CD}_{2} \mathrm{Cl}_{2}, 23 \stackrel{\circ}{\circ} \mathrm{C}$

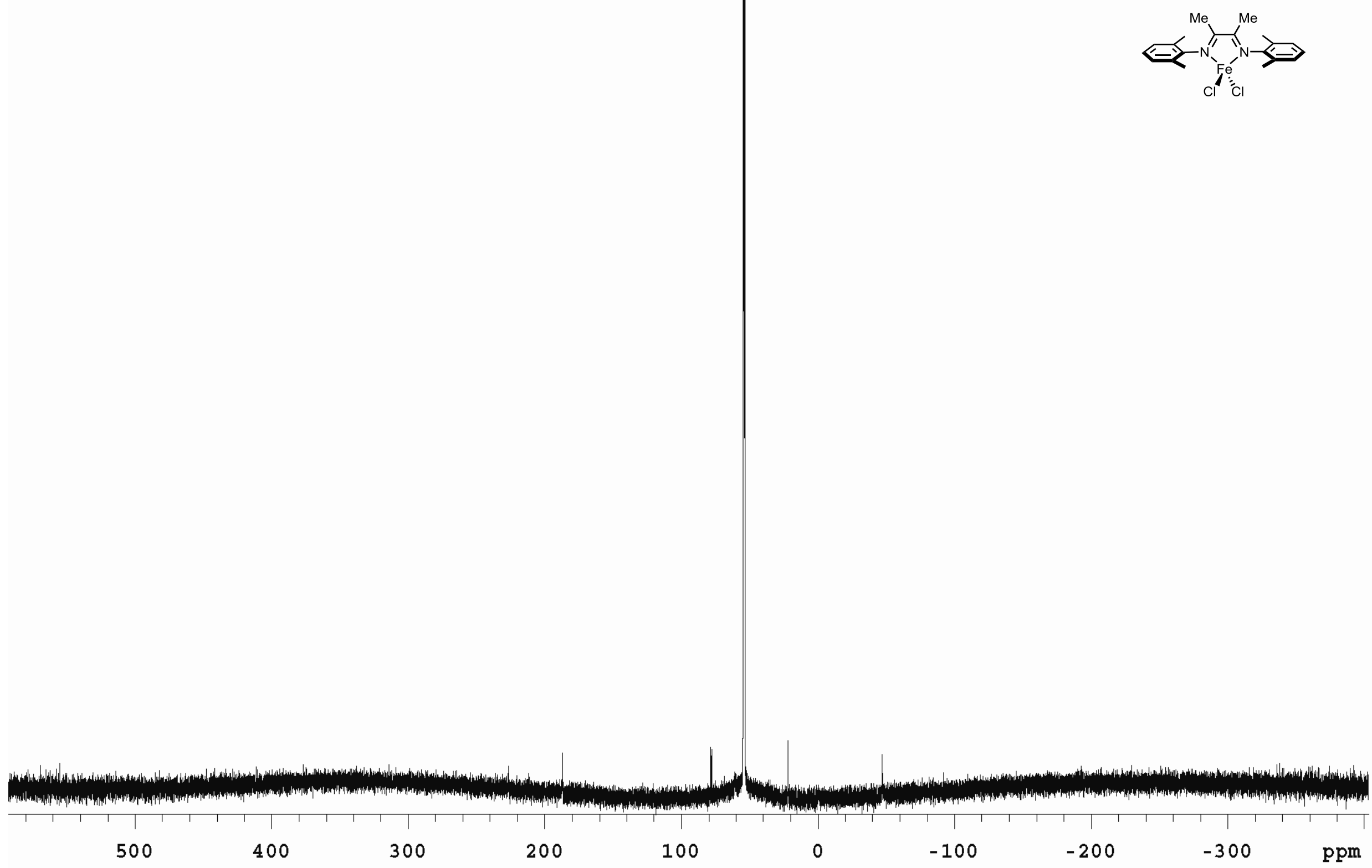


- ${ }^{1} \mathrm{H}$ NMR of Bis(2,6-dimethylaniline)-butane-2,3-diimine iron(I) $\left(\eta^{2}: \eta^{2}-1,5-\mathrm{COD}\right)(2)$

$500 \mathrm{MHz}, \mathrm{C}_{6} \mathrm{D}_{6}, 23 \stackrel{\circ}{\mathrm{C}}$

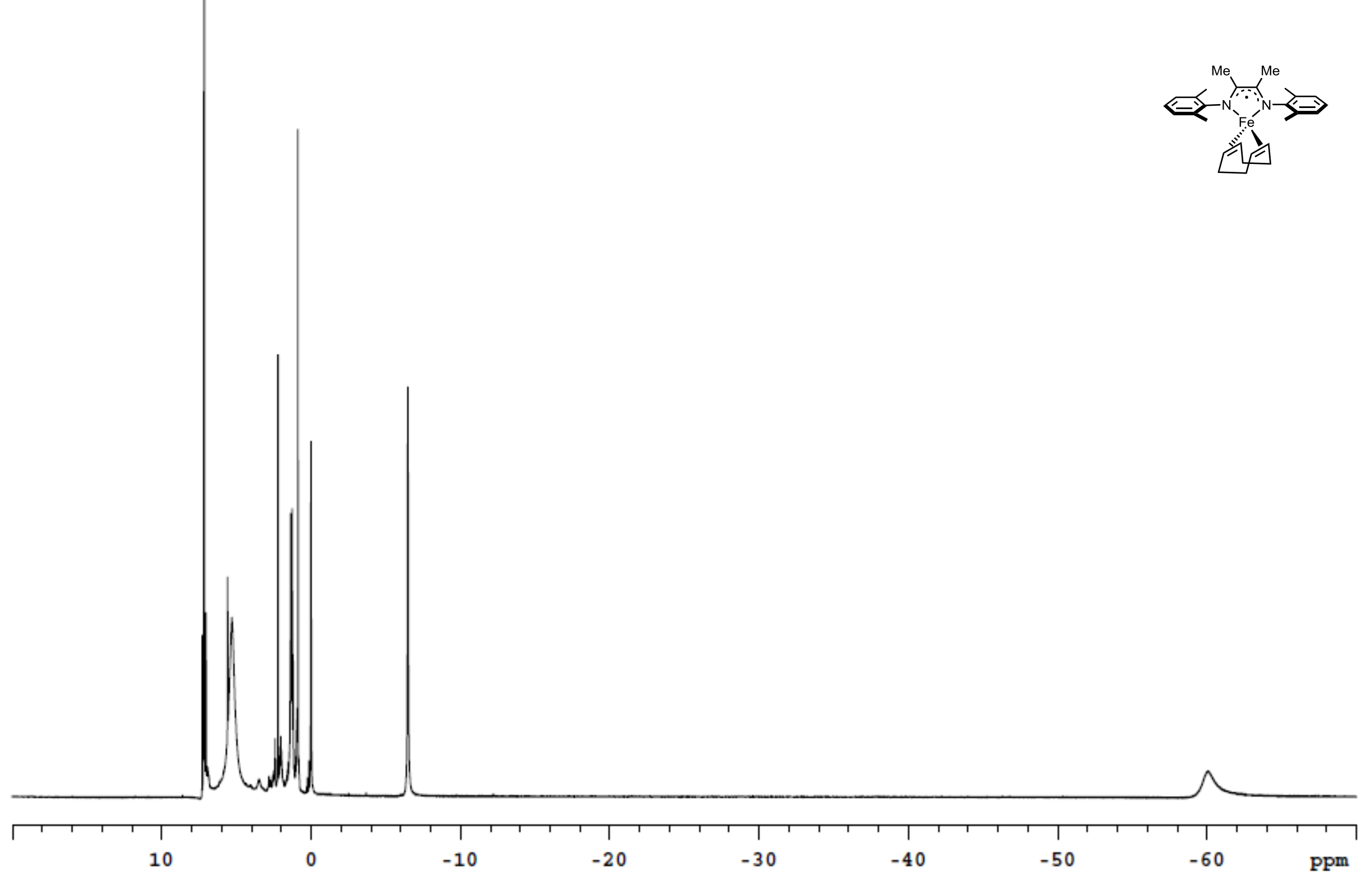


- ${ }^{13} \mathrm{C}$ NMR of Bis(2,6-dimethylaniline)-butane-2,3-diimine iron(I) $\left(\eta^{2}: n^{2}-1,5-C O D\right)(2)$

$125 \mathrm{MHz}, \mathrm{C}_{6} \mathrm{D}_{6}, 23 \stackrel{\circ}{\mathrm{C}}$

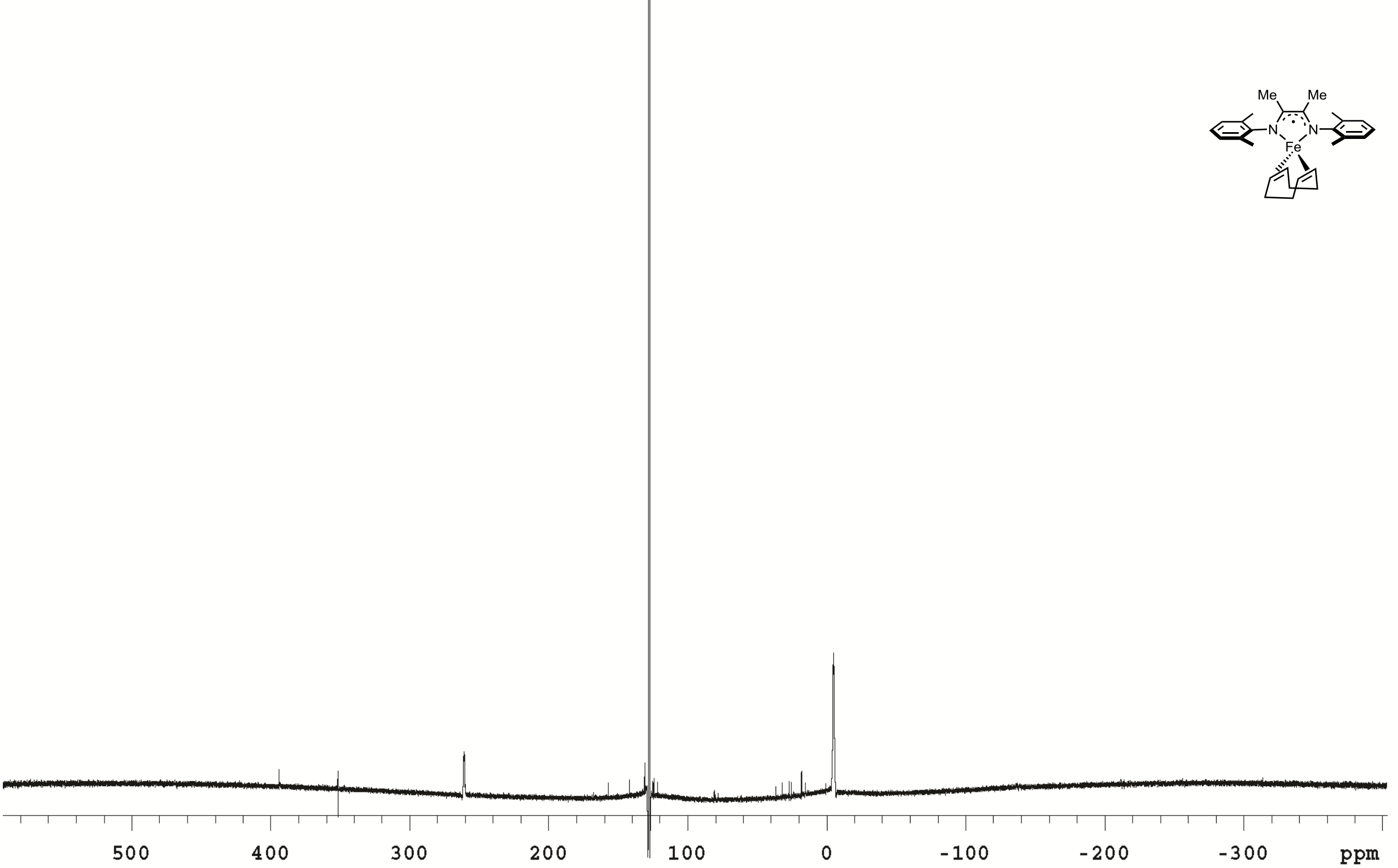


- $\quad{ }^{1} \mathrm{H}$ NMR of $\left[(\operatorname{Bis}(2,6\right.$-dimethylaniline $)-$ butane-2,3-diimine $)\left(\eta^{6}\right.$-toluene $\left.)\right]$ iron (3)

$600 \mathrm{MHz}, \mathrm{C}_{6} \mathrm{D}_{12}, 23 \stackrel{\circ}{\circ} \mathrm{C}$

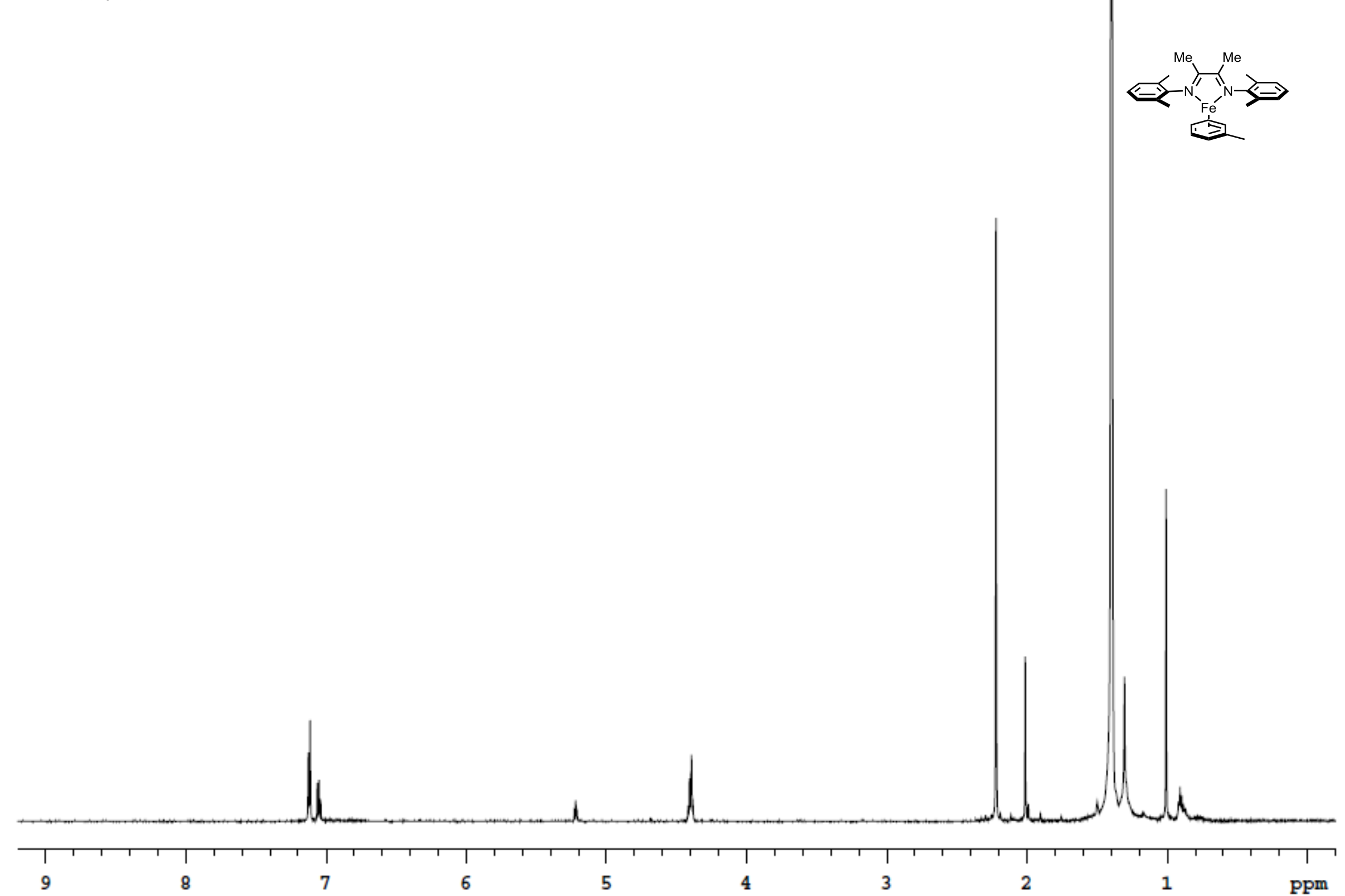


SUPPORTING INFORMATION

S73

- ${ }^{13} \mathrm{C}$ NMR of $\left[\left(\operatorname{Bis}(2,6\right.\right.$-dimethylaniline)-butane-2,3-diimine $)\left(\eta^{6}\right.$-toluene $\left.)\right]$ iron (3)

$125 \mathrm{MHz}, \mathrm{C}_{6} \mathrm{D}_{6}, 23 \stackrel{\circ}{\circ}$

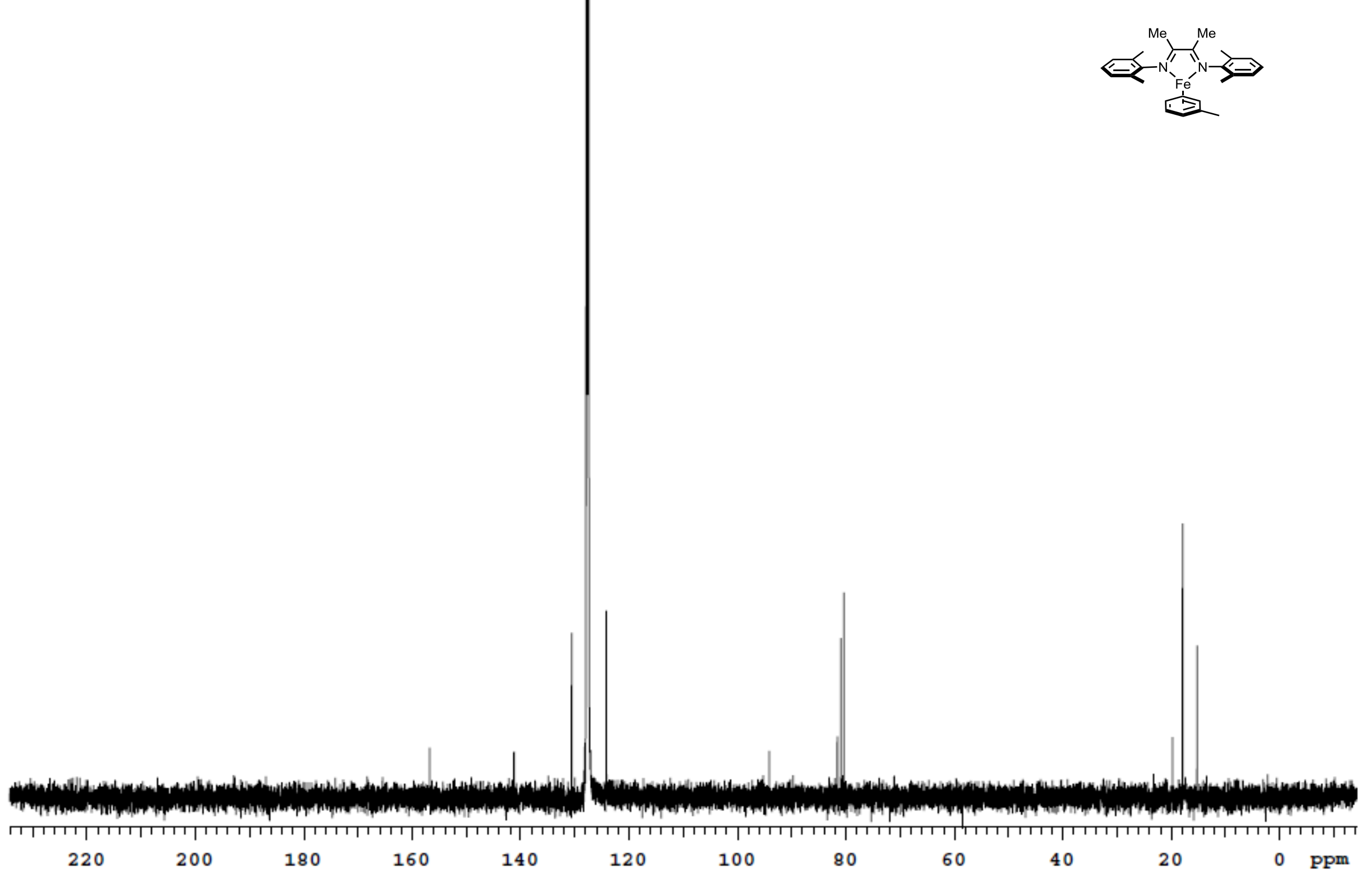


- $\quad{ }^{1} \mathrm{H}$ NMR of Di[bis(2,6-dimethylaniline)-butane-2,3-diimine iron(I)] (4)

$600 \mathrm{MHz}, \mathrm{C}_{6} \mathrm{D}_{6}, 23 \stackrel{\circ}{\mathrm{C}}$

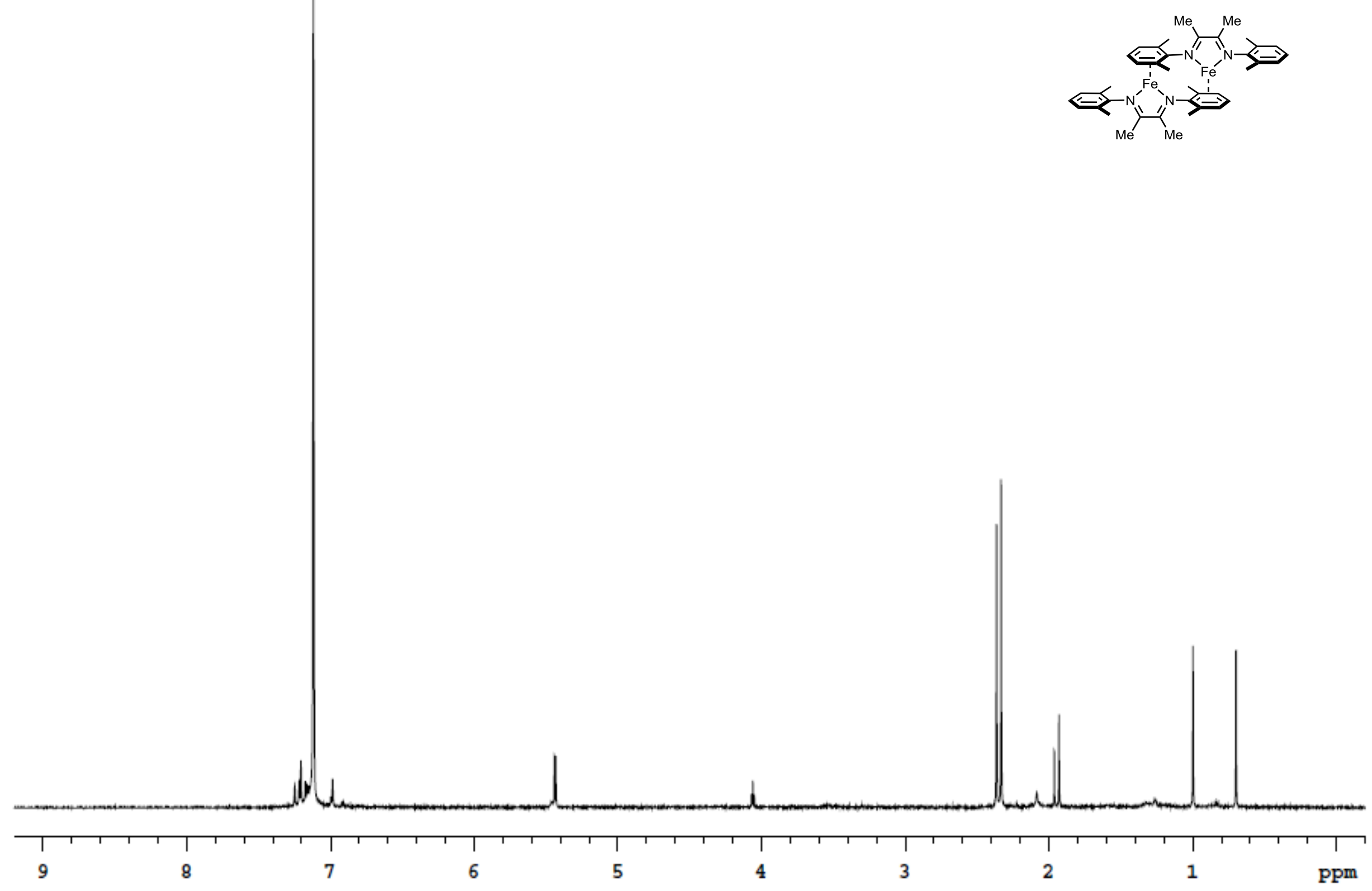


- ${ }^{13} \mathrm{C}$ NMR of Di[bis(2,6-dimethylaniline)-butane-2,3-diimine iron(I)] (4)

$125 \mathrm{MHz}, \mathrm{C}_{6} \mathrm{D}_{6}, 23 \stackrel{\circ}{\mathrm{C}} \mathrm{C}$

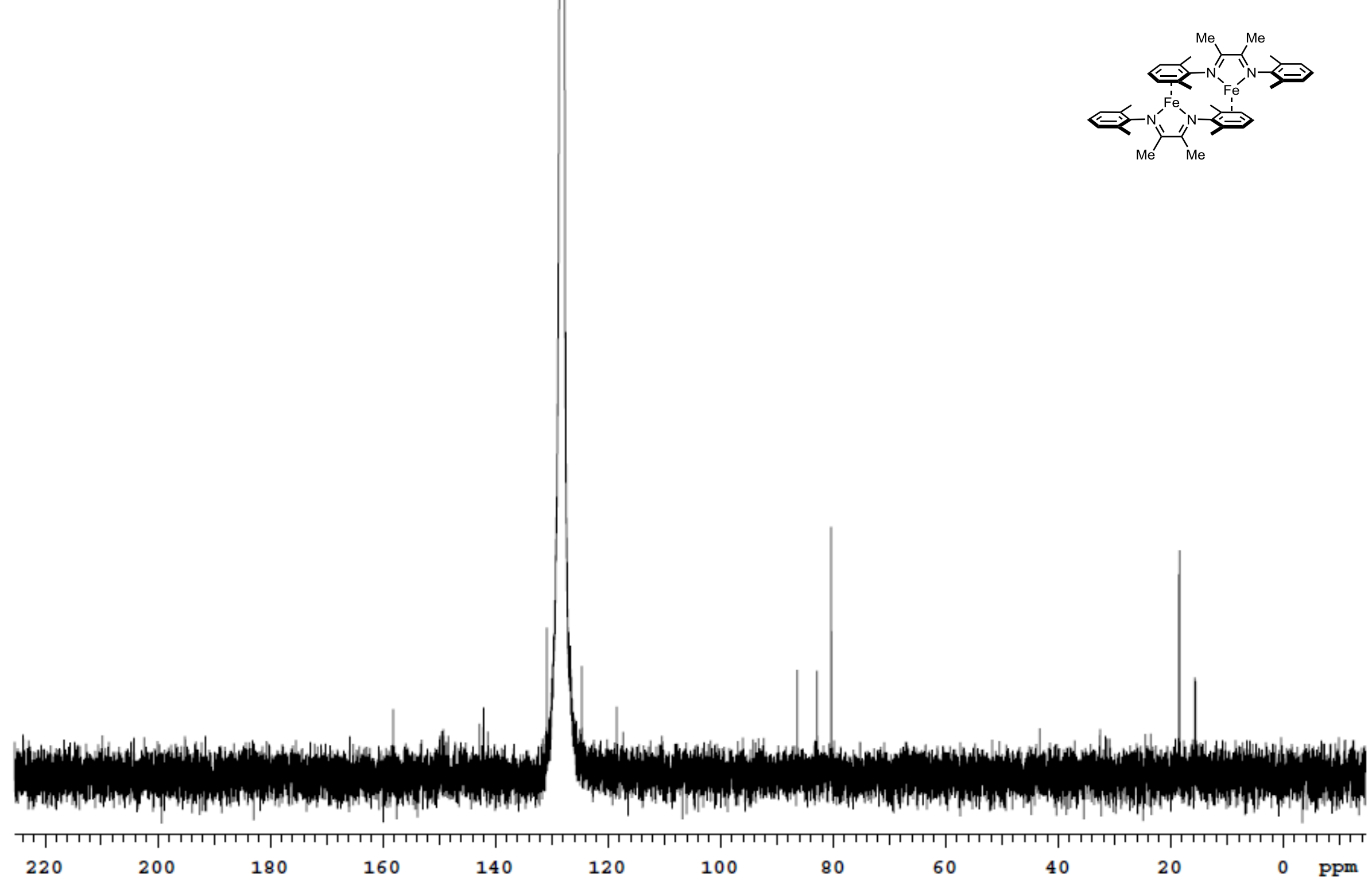


- $\quad{ }^{1} \mathrm{H}$ NMR of Di[bis(2,6-dimethylaniline)-butane-2,3-diimine] iron (5)

$500 \mathrm{MHz}, \mathrm{C}_{6} \mathrm{D}_{6}, 23 \stackrel{\circ}{\circ} \mathrm{C}$

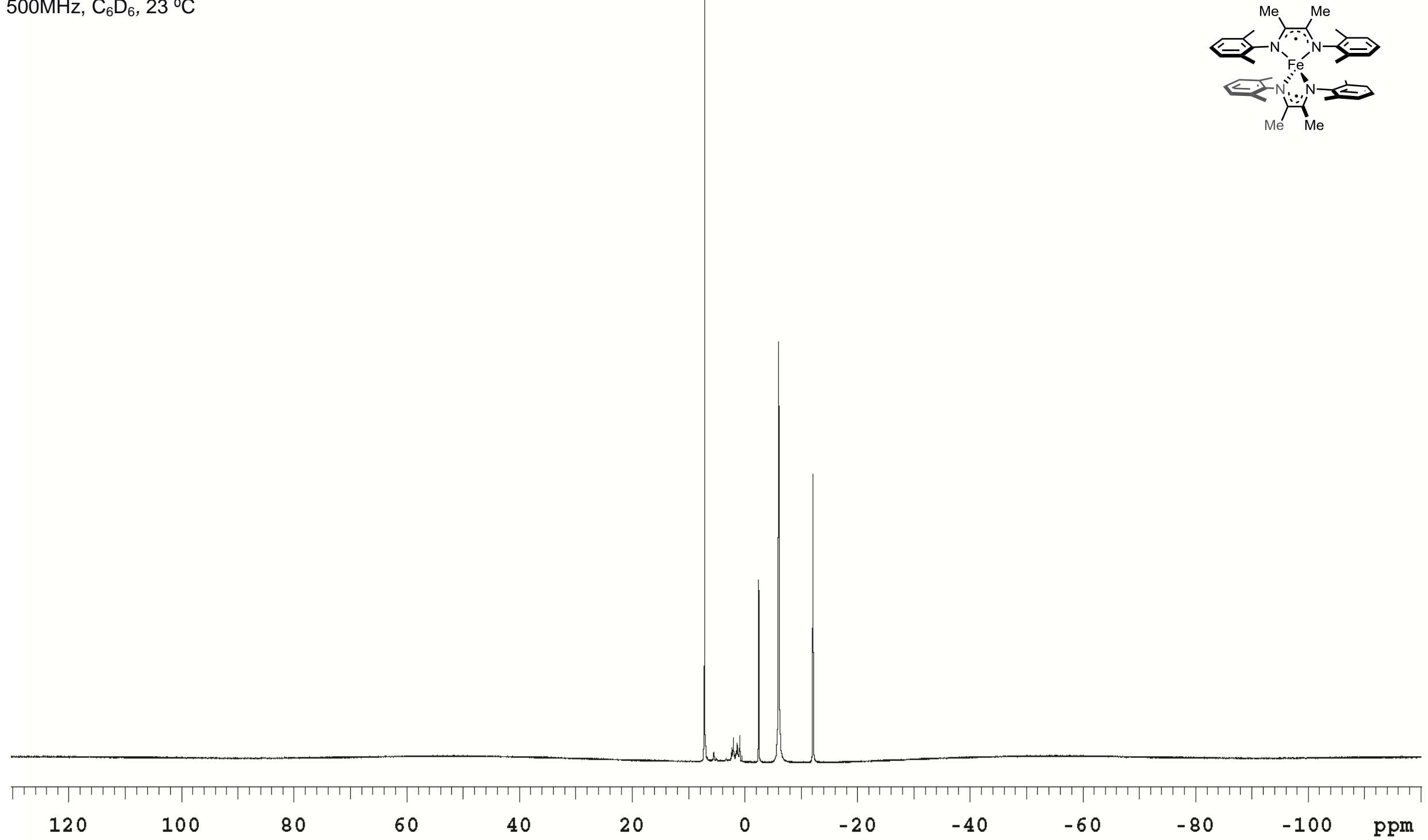


- ${ }^{13} \mathrm{C}$ NMR of Di[bis(2,6-dimethylaniline)-butane-2,3-diimine] iron (5)

$125 \mathrm{MHz}, \mathrm{C}_{6} \mathrm{D}_{6}, 23 \stackrel{\circ}{\mathrm{C}}$

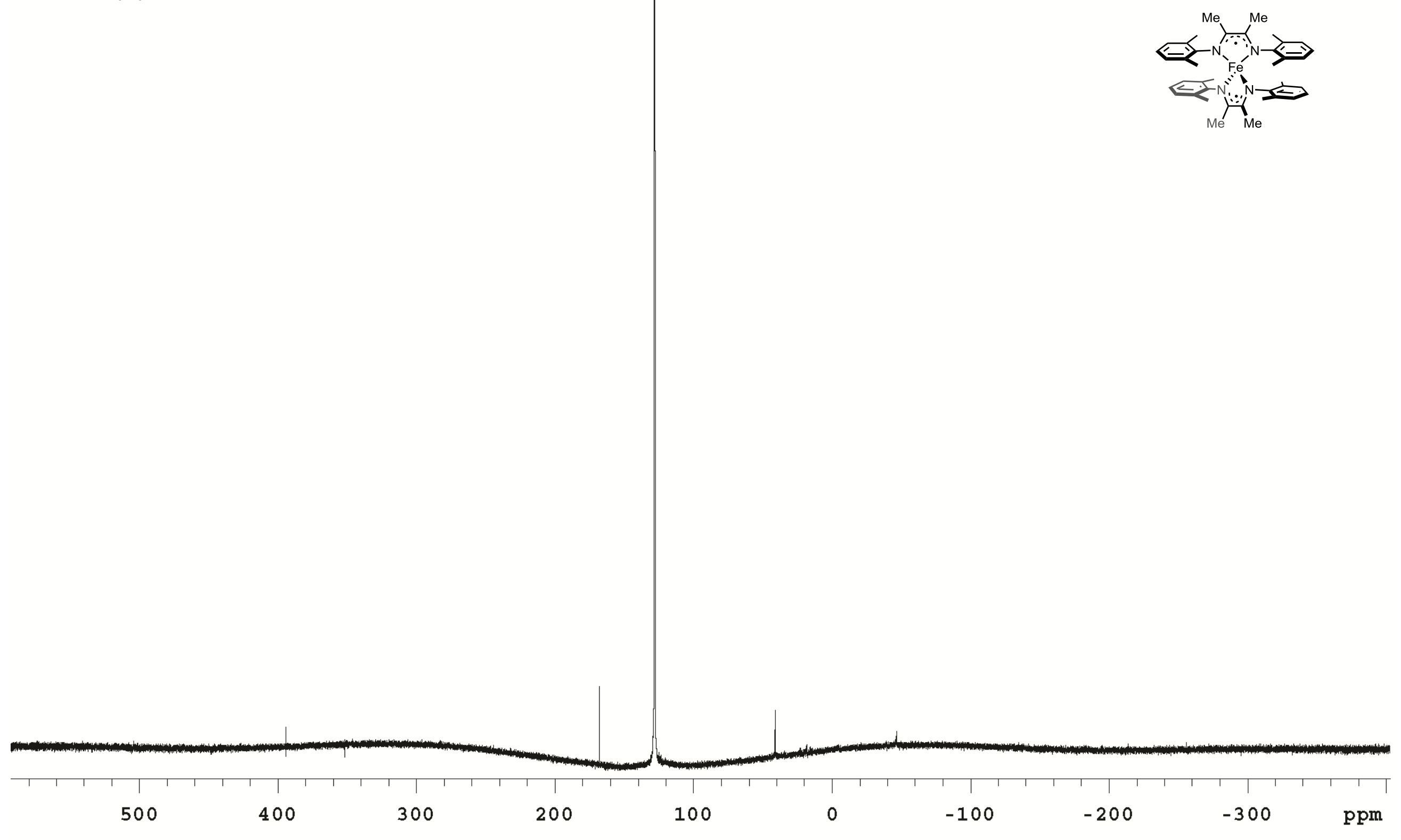


- ${ }^{1} \mathrm{H}$ NMR of COD, Synthesized using pre-catalyst 1; after distillation

$500 \mathrm{MHz}, \mathrm{CDCl}_{3}, 23 \stackrel{\circ}{\mathrm{C}}$

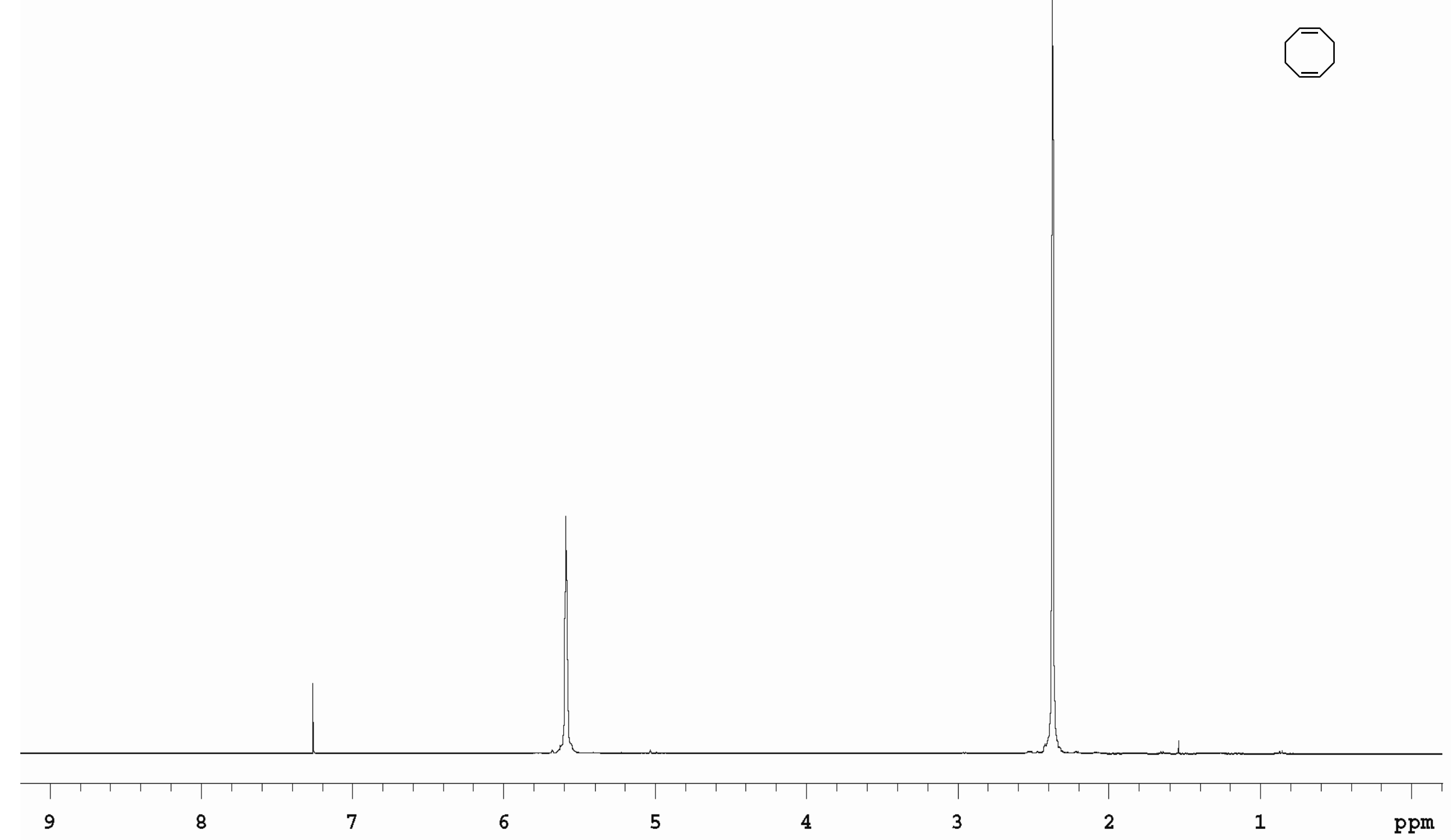


- ${ }^{13} \mathrm{C}$ NMR of COD, Synthesized using pre-catalyst 1; after distillation

$125 \mathrm{MHz}, \mathrm{CDCl}_{3}, 23 \stackrel{\circ}{\mathrm{C}}$

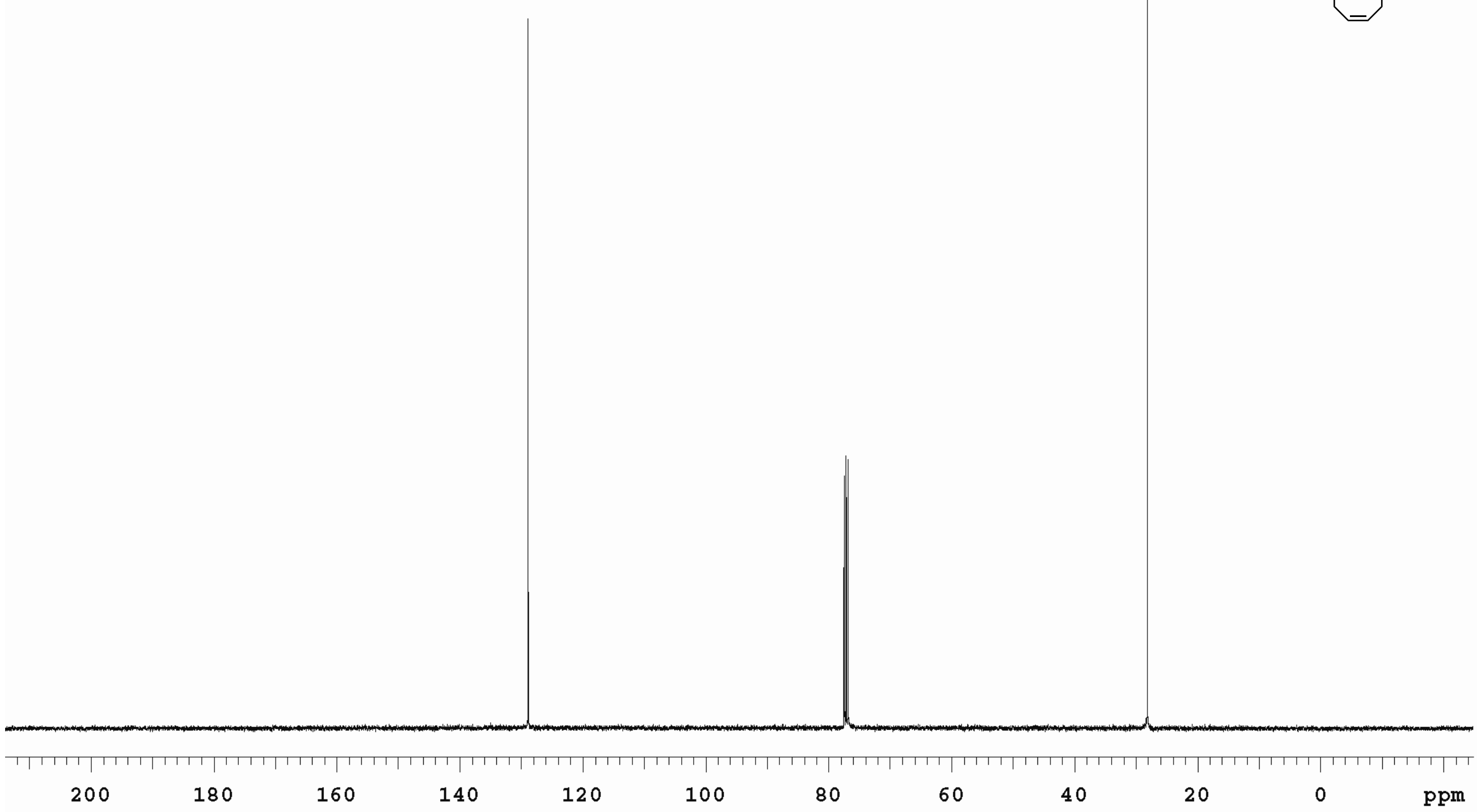


- $\quad{ }^{1} \mathrm{H}$ NMR of COD, Aliquot from Example 1, using $\mathrm{Fe}(\mathrm{I})$ complex 2, without purification

$500 \mathrm{MHz}, \mathrm{CDCl}_{3}, 23 \stackrel{\circ}{\mathrm{C}}$

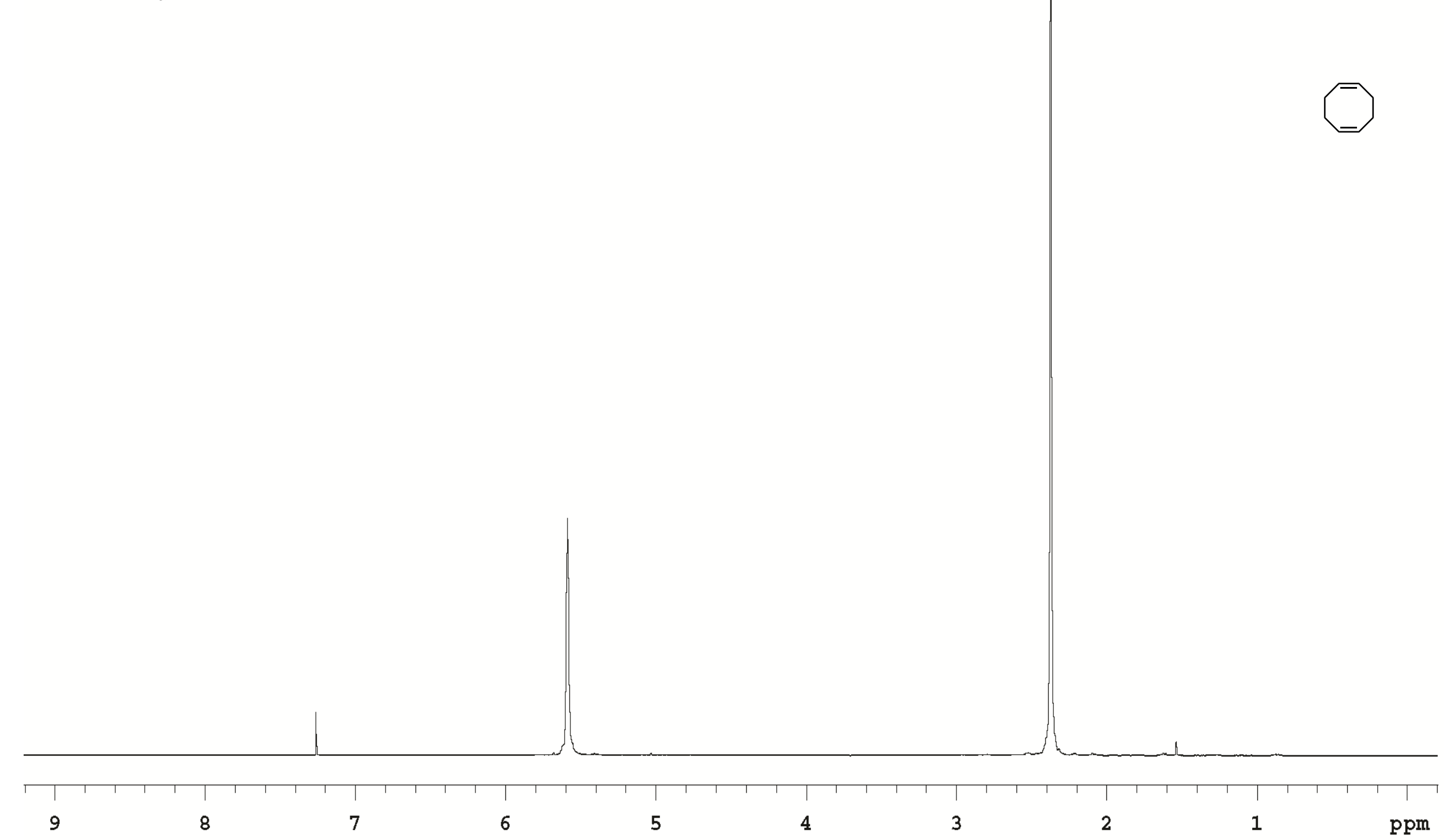


- ${ }^{13} \mathrm{C}$ NMR of $\mathrm{COD}$, Aliquot from Example 1, using $\mathrm{Fe}(\mathrm{I})$ complex 2, without purification

$125 \mathrm{MHz}, \mathrm{CDCl}_{3}, 23 \stackrel{\circ}{\circ} \mathrm{C}$

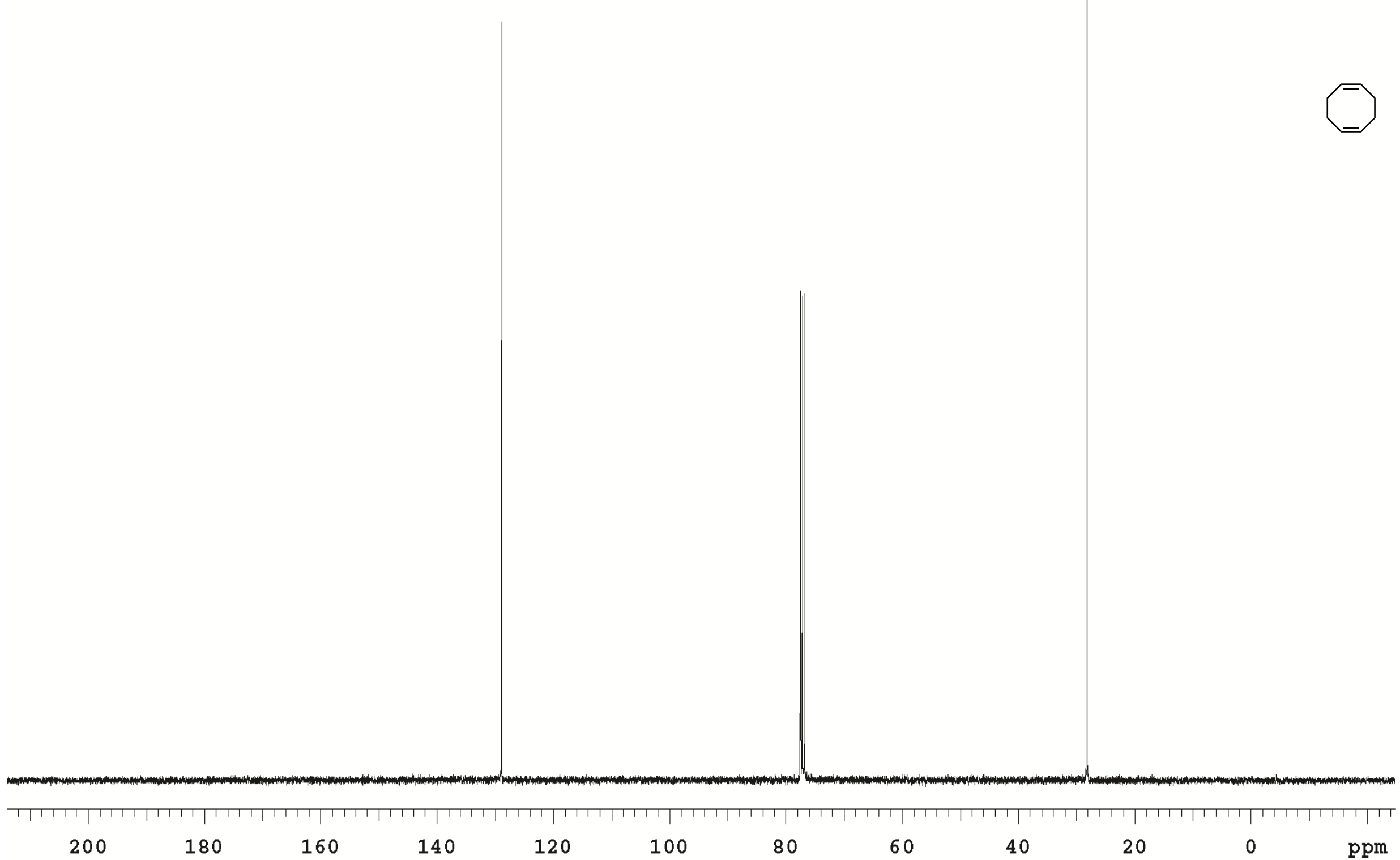

